GENOTYPIC AND ENVIRONMENTAL EFFECTS ON FATTY ACID COMPOSITION, IODINE VALUE AND OIL

CONTENT OF PEANUT (Arachis hypogaea L.)

BY

MARILENE L. A. BOVI

A DISSERTATION PRESENTED TO THE GRADUATE COUNCIL OF THE UNIVERSITY OF FLORIDA IN PARTIAL FULFILLMENT OF THE REQUIREMENTS FOR THE DEGREE OF DOCTOR OF PHILOSOPHY

UNIVERSITY OF FLORIDA

1982 
ACKNOWLEDGEMENTS

The author expresses her sincere gratitude to her major advisor, Dr. A.J. Norden, for his constructive guidance in the research and preparation of this manuscript. Sincere appreciation is likewise extended to Dr. E.S. Horner, Dr. D.W. Gorbet, and Dr. P.M. Lyrene, members of her supervisory committee, for their helpful suggestions in this dissertation.

Special thanks are extended to Dr. F.G. Martin, member of the supervisory committee, for his invaluable help in the analysis of the data, as well as for his suggestions to improve the manuscript.

The author also expresses appreciation to the Brazilian Agency for Agricultural Research (EMBRAPA) for the financial support given during the graduate program.

Sincere thanks are expressed to the members of the author's family for their patience, understanding and encouragement. 
TABLE OF CONTENTS

Page

ACKNOWLEDGEMENTS . . . . . . . . . . . . . . . . $i i$

LIST OF TABLES . . . . . . . . . . . . . . . $i i i$

ABSTRACT . . . . . . . . . . . . . . . . . v vi

INTRODUCTION . . . . . . . . . . . . . . . . . . . . 1

LITERATURE REVIEW . . . . . . . . . . . . . . . . . 5

MATERIALS AND METHODS . . . . . . . . . . . . . 31

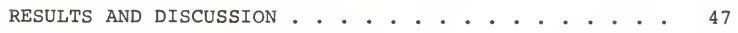

SUMMARY AND CONCLUSIONS . . . . . . . . . . . 107

BIBLIOGRAPHY • . • • • . . . . • . . . . . . 111

BIOGRAPHICAL SKETCH . . . . . . . . . . . . . 119 


\section{LIST OF TABLES}

Table

$\underline{\text { Page }}$

1 Genotypes Involved in the Oil Composition

Analysis... . . . . . . . . . 32

2 Planting and Harvest Dates During the

Ten-Year Period (1966-1974 and 1978) . . . . 38

3 Climatic Parameters from Pegging Initiation to Harvest in a Ten-Year Period (1966-1974 and 1978). . . . . . . . . . . . .

4 Fatty Acids, Iodine Value and Oil Content of 100 Peanut Genotypes. Mean Over Ten Years (1966-1974 and 1978)........... 48

5 Mean Squares from the Analysis of Variance, Coefficients of Variation (C.V.) and Means of Fatty Acids, Iodine Value and oil Percentage of 40 Peanut Genotypes . . . . . . . . . 53

6 Least Square Means, Standard Errors and Genotype Grouping of Oil Components of 40 Peanut Genotypes. . . . . . . . . . . 56

7 Mean Squares from the Analysis of Variance and Coefficients of Variation (C.V.) of Fatty Acids, Iodine Value and Oil Percentage for the Different Maturity Groups . . . . . . .

8 Mean Squares from the Analysis of Variance and Coefficients of Variation (C.V.) of Fatty Acids, Iodine Value and Oil Percentage for the Different Commercial Types . . . . . . 70

9 Mean Oil Composition of Peanut Genotypes for the Different Maturity Groups and Commercial Types............... . . 75

10 Least Square Means (LSM), Standard Errors (Std Error), and Genotype Grouping for the Different Maturity Types . . . . . . . . 
11 Least Square Means (LSM), Standard Errors (Std Error), and Genotype Grouping for the Different Commercial Types . . . . . . 65

12 Correlation Coefficients Among Climatic Parameters and Oil Components of 40 Peanut Genotypes. . . . . . . . . . . . 94

13 Correlation Coefficients Among Climatic

Parameters and Oil Components of Different Maturity Groups. . . . . . . . . . . 95

14 Correlation Coefficients Among Climatic Parameters and Oil Components of Different Commercial Types... . . . . . . . 9 98

15 Correlation Coefficients Among Oil Components of 40 Peanut Genotypes . . . . . . . . 105 
Abstract of Dissertation Presented to the Graduate Council of the University of Florida in Partial Fulfillment of the Requirements for the Degree of Doctor of Philosophy

\title{
GENOTYPIC AND ENVIRONMENTAL EFFECTS ON FATTY ACID COMPOSITION, IODINE VALUE AND OIL CONTENT OF PEANUT (Árachis hypogaea L.)
}

By

\author{
MARILENE L. A. BOVI
}

December 1982

Chairman: A.J. Norden

Major Department: Agronomy

A hundred genotypes from the Peanut Breeding Project of the University of Florida were chemically analyzed for oil content, fatty acid composition and iodine value, during a ten-year period, in an attempt to determine, quantify and utilize chemical data as criteria for genetic selection of superior peanut material in plant breeding work.

The results showed that peanut oil is comprised primarily of oleic, linoleic and palmitic acids, with the first two accounting for about $80 \%$ of the total.

A large variation in fatty acid composition and iodine value (IV 75 to IV 105) was found among the genotypes. The magnitude of this variation should permit the development of new varieties with improved oil quality. Oil percentage varied from 46.2 to $53.4 \%$. 
A subdivision of the genotypes into maturity and market types indicated that there are relatively high levels of genetic variability for oil components within each group. It should be possible to select varieties that best suit industrial and/or nutritional purposes in each group.

The findings indicate that classification of peanut genotypes into specific maturity groups or market types based on characteristics of the oil would be hazardous.

Year effects were highly significant for the combined genotypes, market types and maturity groups. Eicosenoic, a minor fatty acid, seems to be particularly affected by climatic variations.

Correlation coefficients calculated among climatic parameters and oil components showed negative correlations for iodine value $(r=-0.35 * *)$ and oil percentage $(r=-0.42 * *)$, especially with soil temperatures. The significant iodine value association with temperature found in this study might help explain the higher levels of the polyunsaturated fatty acids, such as linoleic, reported in oils from crops grown in cooler locations. Based on this association it should be possible to alter the chemical composition of peanut genotypes by varying the planting date within a given location to coincide with cooler or warmer temperatures during the seed filling period.

Oleic acid was shown to be negatively correlated with linoleic acid $(r=-0.30 * *)$, suggesting that selection of genotypes with improved industrial or nutritional qualities should be possible. 


\section{INTRODUCTION}

Worldwide, peanuts (Arachis hypogaea L.) are mainly an oilseed crop grown primarily for crushing into oil and meal. About two-thirds of the world's peanut crop is used for oil. Peanut supplies about a fifth of the world's edible oil production and comprises a third of the world's trade in edible oils and oil-bearing materials (Woodroof, 1973).

Since 1960 there has been a sharp increase in peanut production with the leading countries being India, Mainland China, Nigeria, the United States and Senegal. Crops in Sudan, Argentina, Burma and Brazil have increased steadily, which was reflected largely in oil production. About $70 \%$ of the oil seed crops of India consist of peanuts. China is another country where peanuts are produced mainly for oil.

Brazil has been showing a strong increase in peanut production since 1977. In that year Brazil produced 323,600 tons of raw peanuts. Subsequently, the figures were 342,100 tons in $1978,461,000$ in $1979,480,900$ in 1980, and 331,100 to August of 1981 (Informacoes Agricolas, 1981). Among the factors responsible for this large increase in production are increased area of planting, better varieties, development of farming machinery and equipment specifically for peanut planting, cultivating and harvesting, two crops 
per year, and the establishment of minimum prices for foreign markets.

About $80 \%$ of the peanut production in Brazil is exported to Spain, Italy, France, the United Kingdom, Hungary, Singapore, the Netherlands, West Germany, Portugal and Japan. Peanuts are exported shelled and unshelled and a large percentage as peanut oil. France is the largest purchaser of Brazilian peanut oil. Of the $20 \%$ of the peanut crop remaining in Brazil, $80 \%$ goes into oil, with the remaining $20 \%$ used in confectioners products, peanut butter, roasted peanuts and as seed.

The United States is one of the few countries in the world where peanuts are used mainly for domestic food consumption. A 1979 report (USDA Agricultural Statistics) shows that over $70 \%$ of the peanut crop in the United States goes for human consumption. The rest is used for seed, animal feed and oil.

Due to competition from other vegetable oils and increased demand for edible nuts, relatively smaller quantities of peanuts are crushed for oil, generally the lower quality kernels. Since 1950, the quantity of peanuts crushed for oil in the United States has decreased to about half. This is due to a higher price for edible peanuts, decreases in demand for vegetable oils, upgrading the quality of peanuts, and better handling and storing practices for peanuts (Woodroof, 1973). 
With over 708 of the crop directed to human consumption, it is no surprise that there are several ways of consuming peanuts in the United States. Peanuts can be consumed as a vegetable, canned, frozen, toasted, etc; but it is the roasted peanut that is most acceptable due to its pleasant and unique flavor. There is a large variety of roasted peanut products, especially peanut butter, that accounts for over $60 \%$ of the total edible peanut production in this country (Woodroof, 1973).

Many factors contribute to the final quality of peanuts and its products, including storage, processing and curing. But the principal factor is the chemical composition of the seeds of different varieties. Lipids, amino acids, and carbohydrates play primary roles in the overall quality of peanut cultivars.

The major implications of lipids in the final quality of peanuts and derived products are in relation to industrial quality and human health, especially as related to essential fatty acids and physiological effects of certain fatty acids in the development of human diseases. Since fatty acid composition is important, both from the standpoint of product quality, and possible physiological aspects of some of the fatty acids, this factor should be considered in the development of new varieties of peanuts. Although there are reports on the fatty acid composition of peanuts grown in other areas of the United States, especially Georgia and North Carolina, 
there is no complete report on breeding lines, introductions and commercial varieties grown in Florida.

The present study was undertaken to screen peanut genotypes from the breeding program of the University of Florida in an attempt to determine, quantify and utilize chemical data as criteria for genetic selection of superior peanut material in plant breeding work. As there are reports of large yearly variation in the chemical composition of peanut oil (Holley and Hammons, 1968; Worthington et al., 1972), breeding lines, introductions and commercial varieties were examined from one to ten growing seasons to determine possible relationships involving yearly variation and fatty acid composition of peanut genotypes. 


\section{LITERATURE REVIEW}

Peanut oil is composed of mixed glycerides of approximately $80 \%$ unsaturated and $20 \%$ saturated fatty acids (Cobb and Johnson, 1973). The oil obtained from peanuts is more saturated than the oils obtained from corn, cottonseed, or linseed, but considerably less saturated than coconut, palm or butter oils (Robinson, 1980).

The main problem of lipids in the industrial quality of peanuts and its products is related to oil stability. Although peanut oil is relatively stable in comparison with many other vegetable oils, it is susceptible to the development of oxidative or hydrolitic rancidity. Oxidative rancidity is the more serious problem in most lipids. The rancidity appears when the unsaturated fatty acids are oxidized and undergo a series of reactions at the double bonds. The initial step in oxidation is the addition of oxygen to form peroxides at or near the points of unsaturation (double bonds). Since peroxides are highly reactive compounds, they readily decompose into various acids, alcohols, aldehydes, ketones, and other hydrocarbons, which are the substances responsible for the off-flavors and rancid odors (St. Angelo and Ory, 1973). The higher the 
degree of total unsaturation in the oil, the lower is the oil stability.

Several parameters, including peroxide and iodine numbers, free fatty acid content, oven keeping time loven stability) of expressed oils, and the oleate/linoleate (0/L) ratio of the oils, have been used to predict the stability of peanut oils (Holley and Hammons, 1968; Worthington et al. , 1972). The iodine number method was first proposed by Huebl in 1884, and in 1898 Wijs introduced a faster method to determine this parameter (Hilditch, 1956). Since then this method has been used extensively for measuring unsaturation of fats.

The iodine number, or value, reflects the melting point of a fat, as well as the resistance of oil to oxidation and consequent oil stability. The higher the iodine number, the greater is the unsaturation of a fat and, generally speaking, the susceptibility to oxidation. The iodine number is defined as the number of grams of iodine absorbed by 100 grams of the substance (Kirschenbauer, 1960). Of the many methods developed for the estimation of unsaturation, the Wijs method has found the widest use. This method employs an excess of iodine monochloride. The unreacted portion of the iodine solution is titrated back with sodium thiosulfate solution, and the absorption is computed taking a blank test into consideration.

Worthington et al. (1972) studied four independent variables as indicators of oil stability. They concluded 
that, although the iodine number does not take into account the much greater susceptibility of polyenes to autoxidation, it still is a good indicator of oil stability. A high statistical correlation was noted between iodine value and such parameters as oil content, refractive index, keeping time, oil stability, shelf-life and oleic/linoleic ratio (Holley and Hammons, 1968). With the advent of the gas chromatograph, iodine number, in research studies, has been calculated directly, assuming purity and complete esterification of the oil. Although in practice (quality control in industry) the iodine value is determined from the refractive index of the expressed oil (French, 1962) or Wijs method (A.O.A.C., 1970), a good agreement between the iodine values calculated from the gas-liquid chromatograph and those obtained by the Wijs method has been found (Worthington et al., 1972).

Oil composition is also important from the standpoint of nutritional properties and physiological effects of fatty acids and certain other oil components. For example, ingestion of linoleic, linolenic and arachidonic acids has been found essential for health, as the animal and human bodies apparently are unable to synthesize these fatty acids. The value of polyunsaturated fatty esters has long been recognized to be like that of vitamins (Burr and Burr, 1929; Holman, 1968). Recently a new dimension has been added since it was established that linoleic acid and its esters were precursors for a group of chemically similar 
hormones called prostaglandins. These compounds help regulate vital functions of the body. Other reports indicate that polyunsaturated fatty esters, such as linolenate, have an important function in the protection of the central nervous system and might be helpful in multiple sclerosis (Bernsohn and Stephanides, 1967).

- Considerable attention has also been directed in recent years to the effect of saturated fatty acids on heart disease and related disorders of the circulatory system. Arachidic (C20:0) and behenic (C22:0) acids have been implicated circumstantially with abnormal cardiovascular conditions in laboratory animals (Kristchevsky et al.. $1970)$.

Accumulation of cholesterol in the lining of the arteries has been shown to be the cause of atherosclerosis, also known as hardening of the arteries. Indications are that in the absence of the essential fatty acids, the higher melting, less unsaturated fatty acids are absorbed in the cholesterol complexes, a fact which may be important regarding cholesterol deposits. Repeated short-term experiments showed that a reduction of saturated fatty acids, such as palmitic and stearic, and an increase in polyunsaturated acids, such as linolenic, in the diet, lower the cholesterol content of the blood (National Diet Heart Study, 1967; Grande et al., 1970).

Atherosclerotic plaques from heart attach sufferers contain cholesterol and cholesterol fatty esters. The exact 
"relation between diet and the circulatory problems has not yet been established, but reports show that linoleic, in addition to being an essential fatty acid, is also hypocholesterimic (Grande et al., 1970). Vergroesen (1977) pointed out that there is accumulating evidence that linoleic acid diets can provide effects such as decreased thrombotic tendency of platelets, preventive and curative effects in sodium-induced hypertension, improvement of physiological function of the heart, and normalization of the biochemical abnormalities in obesity and maturity onset diabetes.

The component acids of a number of peanut oils from different regions have been reported since 1921 (Jamieson et al., 1921). Varied and sometimes conflicting results can be found in most of the papers and extreme differences were reported involving varieties, locations, storage, laboratories, seed maturity, etc. Cobb and Johnson (1973) pointed out that at least six major factors could affect the results in the compositional make up of peanuts. Variety, individual seeds within an aliquot, yearly climatic variations, the portion of the seed tissue analyzed, seed abnormalities, and lack of accuracy and precision in testing methods were recognized by these authors as the major factors responsible for composition variation of peanut oil. As early as 1921 Jamieson and coworkers reported variations in gross composition among Spanish and Virginia market type peanuts. The authors reported that oil in 
Spanish peanuts contained slightly less oleic and more linoleic glycerides than Virginia oil. They found a linoleic content of $25 \%$ for the Spanish type and $22 \%$ in the Virginia market type.

Higgins et al. (1941) reported a wide variation in the linoleic and oleic content of some selected strains of Spanish and Runner type peanuts. Examination of their data shows that, as a group, Runner type peanuts are lower in percentage of linoleic acid than the Spanish type peanuts.

Crawford and Hilditch in 1950 summarized the information reported on composition of peanut oils by various workers between 1920-1950. They called attention to the extreme differences from about $65 \%$ to $40 \%$ in oleic acid content and from about $18 \%$ to nearly $40 \%$ in linoleic acid content of peanut oils, and concluded that those differences might be expected to influence the relative susceptibility of a peanut oil to oxidative rancidity. In their study of the component glycerides of African peanut oil, the authors confirmed on the whole the results obtained by previous workers. They again emphasized the rather wide range of oleic and linoleic acid contents which may be encountered in peanut oils from different sources, but were unable to relate these differences to genetic or environmental factors.

Pickett and Holley (1951), upon examining raw and processed peanut oils for several years, reported that somewhat higher peroxide values were found in the Spanish 
than in the Runner or Virginia types. The greater susceptibility of the oil from spanish type peanuts toward peroxide formation was evident whether the expressed oils were directly aerated and heated or the peanuts were aerated and heated prior to expression. The authors explained the greater susceptibility to rancidity oxidation by Spanish oil in comparison with Runner and Virginia type peanut oil based on physical differences of the seeds. They commented that the Spanish nut seems to have a much softer texture, and the oil appears to flow more readily upon pressing than in either the Runner or Virginia types. This apparent physical difference may allow oxygen to contact the oil in the Spanish more readily and thereby influence rancidity development.

Fore et al. (1953) investigated the oils of 16 varieties of raw shelled peanuts, including both the Bunch and Runner types, in relation to oil composition and stability. They found that there appears to be a correlation between the Iinoleic acid contents and stabilities of the oils studied. Oils from Runner peanuts contained less linoleic acid and had higher stabilities than oils of either Spanish or Virginia peanuts. In general, oils of Virginia peanuts contained less linoleic acid and were more stable than oils of Spanish peanuts. In addition, the authors reported a discernible trend toward increasing stability with decreasing linoleic acid content among the individual oils. Fisher and coworkers (1947) had previously observed 
a similar phenomenon with regard to the relationship between linoleic acid contents and stabilities of various refined vegetable oils. The stability values obtained by Fore et al. (1953) were approximately twice those reported by Fisher and coworkers (1947) for a freshly refined, bleached, deodorized oil of similar linoleic acid and tocopherol content. As a result of these and other observations, Fore et al. suggested that the rate of autoxidation of crude peanut oil is influenced by antioxidants and/or synergists other than tocopherols, and that these components are removed in refining. Years later, French (1962) and Worthington and Holley (1967) also reported considerable variation among peanut genotypes for both major and minor fatty acids.

Holley and Hammons (1968) in a study of 66 different varieties or strains, grown during one season and analyzed for linoleic acid content, reported a correlation coefficient of -0.92 between Iinoleic acid content and oil stability. The authors demonstrated definite genotype differences in such characteristics as protein, oil content, and oil stability.

Worthington and coworkers (1972) investigated 82 peanut genotypes in order to determine the variability in fatty acid composition as well as oil stability among genotypes of diverse genetic origin. They found large differences in fatty acid composition among the genotypes studied. Genotypic differences in length of oil autoxidation 
induction period were also large and ranged from 11.6 to 18.5 days. In general, the authors found that Virginia types, particularly the late maturing, large-seeded varieties, were higher in oleic and lower in linoleic acid than the earlier maturing Spanish types.

Worthington and Hammons (1977) presented fatty acid and oil stability data obtained over several years from genotypes of Arachis hypogaea, together with fatty acid data from other species of the genus Arachis. They reported that some genotypes showed consistent differences in oil stability patterns that were not related to oil linoleic acid content. Analysis of entries from 16 wild Arachis species collections revealed levels of oil linoleic acid higher than those found in Arachis hypogaea.

Pancholy et al. (1978) examined 27 peanut cultivars and found an oil content of 46 to 52 percent. Subsequent study of 77 peanut lines (Pancholy et al., 1980) showed an oil content varying from $42.0 \%$ to $55.2 \%$.

An extensive study done by Cherry (1977) on a group of 37 peanut collections comprising various wild types, together with a sampling of 21 known cultivars in relation to protein and oil composition, revealed that percentages of oil in seed meals of wild species ranged between 46.5 and 63.18, while those of cultivars were 43.6 to 55.58 .

Although most earlier and some recent papers reported differences in oleic and linoleic acid content of Spanish, Virginia and Runner types, due to the large number of 
genetic crosses made in recent years, the classification of types via chemical properties is a hazardous proposition. Crosses between market types do not necessarily conform in chemical composition to the parental types (Norden and Block, 1968). Cherry (1977) pointed out that it is difficult to determine specific taxonomic relationships of species collections and cultivars, within and among samples from sections of Arachis, based only on percentage of meal protein and oil. Quantities of protein and oil were randomly distributed among wild species and cultivars and could not be used to develop a chemotaxonomic relationship in Arachis.

The individual seed within an aliquot is another important factor responsible for variations in the analytical results. The peanut plant is highly indeterminate in growth, and under favorable environmental conditions continues to produce fruits over an extended period of time. Consequently, seeds found on a plant at harvest time will span a broad range of developmental stages. As a result, maturity of the individual seed and its specific environment in the soil, as well as post-harvest treatments, could affect markedly the fatty acid analysis. Carotenoids, sugars, amino acids contents, and roasted flavor development have been reported to be especially affected by those factors (Pattee and Purcell, 1967; Newell et al., 1967; and Mason et al., 1969). 
Worthington (1968) studied developmental changes in the fatty acid of various tissues of the Virginia Bunch 67 variety until maturation. He reported that cotyledon and germ composition roughly paralleled one another during maturation, as did testa and shells. During maturation of the cotyledons, palmitic, linoleic, linolenic, eicosenoic, behenic, and lignoceric acids declined in concentration while oleic acid increased. The other acids present did not change appreciably.

Hartzook (1969) observed a reciprocal relationship between oleic and linoleic acid content in mature and immature seeds. The linoleic acid level dropped from $43.9 \%$ in the immature to $38.2 \%$ in the mature seeds, while the oleic increased from $45.6 \%$ to $48.8 \%$. During maturation, stearic, oleic, arachidic, eicosenoic, behenic, and lignoceric acids increased in concentration, while palmitic, linoleic and linolenic decreased.

Young et al. (1972b) also reported that amounts of stearic and oleic acids are greater in mature than immature seeds, and the amounts of linoleic and other fatty acids are less.

Pattee et al. (1969) reported that the oil content of the kernel increases in a nearly linear manner up to the time the kernels are considered mature at 12 weeks after pegging. Taking this subject a step further, Pattee et al. (1974) in a study on peanut fruit part compositional changes at selected physiological stages during maturation, 
concluded that the lipid content in the seed was low initially and the rate of accumulation became maximum between Stages 7 and 11. The highest level was observed in the seed at full maturity (Stage 13), then declined at over-maturity (Stage 15), suggesting that beyond Stage 13 lipid catabolism predominates over lipid synthesis.

Worthington and Smith (1974) noted significant changes in fatty acid composition of peanut oil from seeds produced on plants which had been treated with growth regulator and/or various fungicides. They reported a decrease in the level of linoleic acid in samples treated with Kylar. Sources of differences were unknown, but it was theorized that they might be associated with an extended period of plant vigor and a change in the proportions of mature and immature seeds in the treated samples. Control of Cercospora leafspot with some foliar fungicides was reported earlier to affect peanut maturity (Young et al., 1972a). Beuchat and coworkers (1974) also reported significant differences in the protein percentage and oil content of peanut kernels, depending upon the fungicide treatment. Delayed maturity was caused by specific fungicide treatments.

Sanders (1980a) demonstrated that the oils from three major commercial varieties of mature peanuts did not differ substantially in relative weight distributions of lipid classes, but that distribution of lipid classes was affected by peanut maturity. His study indicates that the percentage 
of various oil fractions, some thought to influence oxidative stability, vary considerably with peanut maturity. Sanders $(1980 \mathrm{~b})$ reported that oleic acid increased while other fatty acids decreased with maturity.

Post-harvest conditions like curing and storage could also affect the results of total lipid and fatty acid composition of peanut seeds. Brown et al. (1974) studied the effects of storage period prior to oil extraction upon oven stabilities of oil samples using different solvents. They concluded that cold storage prior to extraction can influence oven stabilities and correlations with solvent-extracted and bag-pressed oils. Results indicated that prolonged storage of the peanuts shortened oven keeping times. Correlations with oleate/linoleate ratios decreased with extended storage. Oils extracted from peanuts with seedcoat with chloroform-methanol were less affected.

Young and Holley (1965) held inshell peanuts for more than five years at $4-6^{\circ} \mathrm{C}$ without significant effects on the oil keeping time or roasting properties of freshly shelled sound mature kernels.

Worthington and Holley (1967) noted that, although the proportion of methyl linolenate in synthetic standards has been observed to decrease with time during storage at $-20^{\circ} \mathrm{C}$, little change occurred in the linolenic acid content of peanut oil stored under similar conditions. They attributed the stability of linolenic acid in peanut oil to the presence of naturally occurring antioxidants. 
Khan and coworkers (1979) studied the effects of storage at ambient room temperatures on raw and refined peanut oils. They reported that the free fatty acid content of the raw peanut oil increased from 1.2 to 2.7 percent and the peroxide value increased from 5 to 10 during 660 days of storage. However, no significant change was noted either in iodine value or in visible color of the oil. While raw peanut oils of good initial quality keep well in storage, the peroxide value and color of refined oils are influenced by conditions of storage and handling of oils during storage.

Cecil (1975) studied storage stability of peanut butter from ten peanut genotypes. He stored peanut butter from ten genotypes in glass jars for periods up to 14 months at 0,70 and $100 \mathrm{~F}$. Color and free fatty acid content of the samples apparently varied only with genotypes, but aroma and flavor scores after storage were positively correlated with stability ratings for $100 \mathrm{~F}$, and negatively with peroxide values for 0 and $100 \mathrm{~F}$. Negative correlations of peroxide with stability ratings were significant at all combinations before and after storage.

Yearly climatic variations and location effects were considered important causes of variation in fatty acid composition of peanut samples, since Crawford and Hilditch (1950) stated that same varieties give oils differing in composition when grown in different localities. 
Holley and Hammons (1968) reported some extreme year-to-year effects in the stability of oil from 26 different strains or varieties during an eight year period. Eheart and coworkers (1955) also noted seasonal variations in composition of virginia type peanuts.

A study conducted by Worthington and coworkers (1972), involving 82 peanut genotypes, indicated great seasonal or yearly effect on oil stability. But, as reported earlier by Holley and Hammons (1968), the oil stability yearly variations were completely unrelated to levels of linoleic acid. The source of this variation was unknown, but appeared to be related to seasonal factors such as yearly variations in environmental conditions prevailing during seed formation.

Tai (1972) showed that the cultivar by year interactions were statistically significant when he examined the oleic/linoleic ratios of peanut cultivars grown two years at two locations within a state.

Young et al. (1974) studied the influence of location, soil moisture, and seasonal variation on the fatty acid composition of nine Spanish type peanut varieties. Although no consistent pattern was found, variation in fatty acid composition due to variety was much less in Oklahoma than in Georgia for both the irrigated and nonirrigated peanuts. Location effect and soil moisture conditions gave higher percentages of palmitic and oleic, with a lower percentage of linoleic in the Georgia samples and in the nonirrigated 
samples from both locations. Although significant differences were found in fatty acid composition from the Southeast and Southwest, the unrelated pattern of variation found in the stability of peanut oil led the authors to suggest that there appear to be factors other than fatty acid composition that influence stability of peanut oils. Environmental conditions during seed formation affect fatty acid composition of many seed oils. Researchers reported that some plants produce a more highly unsaturated seed fat when grown at lower temperatures (Hilditch and Williams, 1964; Barker and Hilditch, 1950; Stumpf and Bradbeer, 1959). Harris and James (1969) pointed out that this effect is related to oxygen concentration within the cell system.

Evidence for temperature effects during the growing season on the fatty acid composition of peanut oil, although sought by several authors, was always inconclusive. This may be related to the development of peanut seeds underground. Most of the attempts in determining degrees of association among oil components and climatic parameters were based on the whole growing season (Holley and Hammons, 1968). Short but critical periods of high or low temperatures were disregarded by considering only average season parameters.

Holaday and Pearson (1974) subdivided the days after pegging until maturity into four-week periods. They reported that lower temperatures after pegging significantly 
increased the contents of linoleic acid and decreased the oleic acid of the oil. This lower temperature effect was much more pronounced 0 to 4 weeks before harvest. No study reporting associations among peanut oil composition and soil temperature was found in the literature.

Another factor that can be misleading in the results of fatty acid analysis is the portion of the seed tissue analyzed. Different fruit tissues differ quantitatively and qualitatively in lipid composition.

The fatty acid composition of morphological distinct tissues was studied in detail by Worthington (1968). Using the Virginia Bunch 67 variety during different stages of maturation, the author reported that triglycerides predominated the lipid make up of the cotyledons and embryo, while complex lipids comprised a large percentage of testa and shell lipids. At maturity, shells contained 0.68 crude lipids, testa 2.9\%, embryos $51.3 \%$ and cotyledons 52.2\%. At maturity the triglyceride fraction of the embryo contained $70 \%$ more palmitate, approximately $23 \%$ more linoleate, and 15 times the linolenate of the cotyledons. The cotyledons contained higher levels of oleic and stearic acids.

Fore et al. (1953) demonstrated that the presence of testa in the seeds during solvent extraction of the oils increased the oven keeping time of the ensuing oils. The effects of testa appear to be more significant as the period of storage increases. 
Fedeli and coworkers (1968) examined the fatty acid composition of peanut tissues but did not state the genetic origin of the samples. The oil composition of mature shells more nearly resembled the cotyledons in their study. The authors reported that embryos are richer in linoleic acid, while cotyledons have more oleic acid than embryos.

Ahuja and coworkers (1971) cut seeds of two varieties in three parts and analyzed them for fatty acid composition. They concluded that the oil content was maximum in the middle portion and decreased both in the upward and downward directions. Palmitic and higher fatty acids tended to be distributed evenly in the three parts of the seed. The amount of stearic acid was low in the lower part of the seed and that of palmitoleic was low in the middle part. The embryo (upper part) contains more linoleic and less oleic acid as compared with the other seed parts, which have almost the same amounts of the two fatty acids. These results are in agreement with Fedeli and coworkers (1968), although the last authors separated the seed into its components instead of cutting it in three sections.

Diseases, insect infestation, growth regulators, damage from harvest and other abnormalities of the seeds have also been reported to affect the final analysis of fatty acids. Development of fungi on the surface of peanut seeds has been shown to affect sugars, as well as the total quantity and unsaturation of free fatty acids (Ward and Diener, 1961; Pattee and Sessoms, 1967). Chopra and Kanwar (1966) 
reported that sulphur fertilization on deficient soils lowered protein and raised oil content of peanut seeds. Worthington and Smith (1973) studied the effects of foliar fungicides, applied to peanuts for the control of Cercospora leafspot, on oil stability and fatty acid composition of the oil. They found that Benlate and Bravo gave the most pronounced effects on oil fatty acid composition. In both years studied those fungicides decreased levels of stearic (C18:0) and increased levels of linoleic (C18:2) acid over the control in the Argentine and Florunner varieties, which increased the iodine number of those oils.

Taking this investigation a step further, Worthington and Smith (1974) examined, in a three-year study, the effects of the growth regulator Kylar with and without Benlate on fatty acid composition of peanut oil. Kylar reduced levels of linoleic acid when applied either alone or with fungicide. Fungicide alone significantly increased levels of linoleic acid, and the greatest difference in levels of this fatty acid occurred between samples from plots treated with fungicide alone and those treated with Kylar alone. Alterations in the levels of other fatty acids were less consistent. A visual inspection of the samples suggested that plants treated with Kylar reached maturity earlier than the others. The decrease in level of linoleic acid, together with the greater degree of interior pigmentation of the pods, suggests that Kylar accelerates 
maturation in peanuts. Hartzook (1969) reported that with increased maturity of the seed linoleic acid content in peanut oils was reduced, while oleic acid was increased. Laurence and coworkers (1976) also reported that fungicidal spray increased the length of time to maturity. High oil content accompanied the extended season of sprayed plants, and protein levels usually were proportionally lower. In addition to yield improvement, total protein content of peanut kernels was raised and the oil/protein ratio generally lowered by application of sulphur to sulphur-deficient soils. On soils where sulphur is sufficient, foliar application of sulphur dust may lead to improved yields, but kernel protein production is little affected. In such cases, the authors commented, the oil content of kernels may be increased in comparison with those from untreated plots, probably through delays induced in plant maturity.

Ratner et al. (1979) studied the effects of symbiotic nitrogen fixation on protein and oil accumulation in irrigated peanuts. Oil content of the kernels was found to be in inverse relation to the crude protein content. The kernels of the control sample had the highest oil content and the lowest protein content; on the other hand, kernels from inoculated plots had the highest protein content and the lowest oil content, although on a per-unit area basis yield of oil and protein was higher in inoculated treatments. 
Hovis et al. (1979) studied the effect of two strains of peanut mottle virus on fatty acid, amino acid and protein of six peanut lines. They reported that the greatest effect occurred on fatty acids and the least on the total amino acids. In general, peanuts infected with a necrosis strain had lower percentages of stearic and oleic acids, but higher linoleic, arachidic, behenic, and lignoceric acid contents. Peanuts infected with a mild strain generally showed a slight increase in linoleic acid. There were almost twice as many significant changes in the fatty acids of the susceptible lines (Florunner and Starr) than in the tolerant or moderately tolerant lines.

Hovis and coworkers pointed out that since virus infection changes the chemical composition of peanut seed, there is need for caution when chemical analysis is used to evaluate various seed factors such as oil quality and genetic characteristics. Peanut mottle virus is worldwide in distribution, and its incidence in some fields is very high; therefore, the virus effect could be significant in a variety of standard tests.

Although several factors were shown to be responsible for variations in the results of the analysis of fatty acid components of peanuts, the last factor to be mentioned is, without doubt, of greatest importance. Lack of accuracy and precision in testing methods was always considered a major factor causing variations in fatty acid composition of oils. 
Numerous procedures exist for determining the physicochemical properties of peanuts. Variations in results between different laboratories using the same method are not uncommon. The problem was illustrated in the 1965 report of the Instrumental Methods Committee of the American Oil Chemist's Society, as pointed out by Cobb and Johnson (1973), wherein it was noted that the same peanut oil sample analyzed in fourteen different laboratories produced such ranges as 0.9 to $5.7 \%$ for stearate, 34.2 to $49.3 \%$ for oleate, anà 21.6 to $41.1 \%$ for linoleate.

Several studies of peanut oil fatty acid composition have been reported. In some of the reports there are considerable differences in the fatty acid composition of the same varieties or genetic lines. In those studies, the oils were either pressed or extracted from peanuts with a variety of organic solvents; but it has to be taken into consideration that few systems extract oilseed lipids with equal efficiency.

Although oleate/linoleate ratios and oven keeping time have been used for predicting shelf-life of peanut butter (Worthington and Hammons, 1971), peanut oil (Young et al., 1974; Fore et al., 1953) and other roasted peanut products (Tai, 1972), Brown et al. (1974) reported that those parameters can give misleading values with different types of oil extraction, solvents and period of storage. Using five different varieties, the authors determined the oven stability of oils extracted with five common solvents and 
hydraulically pressed oils. Relationships between oven stabilities, storage period and $\mathrm{O} / \mathrm{L}$ ratios were also determined. Brown et al. concluded that the length of the oven keeping time can be affected by the method of solvent extraction. If the peanuts are relatively fresh, good correlations between $\mathrm{O} / \mathrm{L}$ ratios and keeping times can be obtained using ether of low peroxide content, cyclohexane, or chroroform-methanol, but the values for one set of solvent extracted oils are not directly comparable to those from oils extracted with a different solvent system. These workers postulated that the increased stability of solventextracted oil may have been due either to traces of solvent or solvent contaminants remaining in the oils or to a more efficient extraction of seed antioxidants by the more polar solvents.

Young et al. (1974) studying fatty acid composition of Spanish peanut oil as influenced by planting location, moisture conditions, variety and season, also found differences in oil stability related to differences in the method of oil extraction. The authors reported that solvent-extracted oils from the Georgia peanuts had better than a $50 \%$ longer shelf-life than those grown in Oklahoma. Whereas, oils from these same peanuts prepared by hydraulic pressing did not show differences in stability.

Hokes (1977) found that removal of phosphatides from the oil by precipitation reduced oven stability. Thus, differences in the relative amounts of polar lipias 
extracted by different solvents might explain the findings of Brown and coworkers (1974).

Prior to the advent of the gas-chromatograph the analysis of fatty acids has been based, in most of the papers, on the preliminary resolution of the mixed peanut fatty acids into insoluble and soluble lead salts, together with fractional distillation of the esters of the acids from the insoluble and, in some papers, from soluble lead salts. In other cases the mixed fatty acids have been determined as total saturated and oleic and linoleic acids from their iodine and thiocyanogen values. Data on the fatty acid composition of oils were obtained with considerable difficulty and results were sometimes conflicting. For example, until gas chromatography was applied to fatty acid analysis, the presence of linolenic acid in peanut seeds was subject to conflicting results.

Craig and Murty (1959) found eicosenoic (C20:1) acid but not linolenic acid in peanut oil. These workers, however, observed that methyl linolenate has an emergence time coincidental with methyl eicosenoate on diethylene glycol succinate columns, and that this liquid phase is therefore unsuitable for the analysis of oils containing both these acids.

Iverson and coworkers (1963) fractioned peanut oil methyl ester with urea and confirmed the presence of eicosenoic acid by gas-liquid chromatography and chemical techniques, but did not detect linolenic acid. On the other 
hand, French (1962) reported linolenate concentrations of 1.1 to 1.68 , which would appear to be rather high. Worthington and Holley (1967) examined oils from seven genetically diverse peanut cultivars and reported levels varying from 0.02 to $0.04 \%$ of linolenic acid in peanut seeds.

The polarity of the liquid phases must be taken into consideration, in order to unambiguously demonstrate and quantify linolenic acid in oils that also contain arachidic and eicosenoic acid. In this case it is necessary to choose a gas-liquid chromatograph liquid phase with polarity characteristics that permit elution of the C18 series of fatty acid methyl esters prior to elution of the $c 20$ series (Craig and Murty, 1959). Diethylene glycol succinate and other polyester phases of similar polarity are frequently used in the analysis of fatty acid methyl esters, but these phases do not adequately separate linolenic from arachidic and eicosenoic acid esters. Thus, eicosenoic acid, and less frequently arachidic acid, are sometimes misidentified and reported as linolenic acid in the analysis of peanut oil. For example, Koman and Kotuc (1976) reported values for eicosenoic and linolenic acid in peanut oil but not arachidic acid, although arachidic acid was first isolated from Arachis oil by Gossman in 1854 (Cobb and Johnson, 1973). Another example can be cited as in the paper by Fristom and coworkers (1975). In this paper the authors misidentified eicosenoic acid as linolenic acid. Correction 
of the mistake was reported later by Exler and coworkers (1977) .

Worthington (1977) reported that authentic peanut oils contain less than approximately $0.15 \%$ linolenic acid, and that this value is not greatly influenced by geographic area of production.

The genetic material in most of the papers reported here was comprised of peanut seeds grown in Georgia or North Carolina locations. In some of them a mixture of seeds of more than one location was utilized.

Variations in results of oil composition due to location, years, diseases, fertilizers, age, maturity, methodology of chemical analyses, etc., have been reported and were stressed and evidenced in this literature review.

To minimize these variations and properly select peanut genotypes with improved chemical characteristics of the seeds, it is imperative to study diverse genotypes growing in the same location, during several years with a standard procedure. 
MATERIALS AND METHODS

The material for this study involved 100 genotypes including peanut varieties, breeding lines and introductions obtained from stocks of the Peanut Breeding Project of the University of Florida and are designated by the numbers and names in use in this project. Genotype selection was based either upon prior knowledge of chemical composition in other locations (Holley and Hammons, 1968; Worthington and Hammons, 1971; Worthington, 1977; and Sanders, 1980a), or upon possible use in the development of new commercial varieties, and included subspecies hypogaea as well as subspecies fastigiata.

Table 1 shows genotypes and their pedigrees, years in which fatty acid analyses of samples were made, and total number of observations.

The genotypes involved in this study comprise a large portion of the currently available peanut gene pool. Most of them have been in experimental observation for over two decades and have served as a genetic source for several new varieties and crosses at the University of Florida.

All peanuts were grown according to the recommended cultivation practices during the years of 1966 to 1974 and 


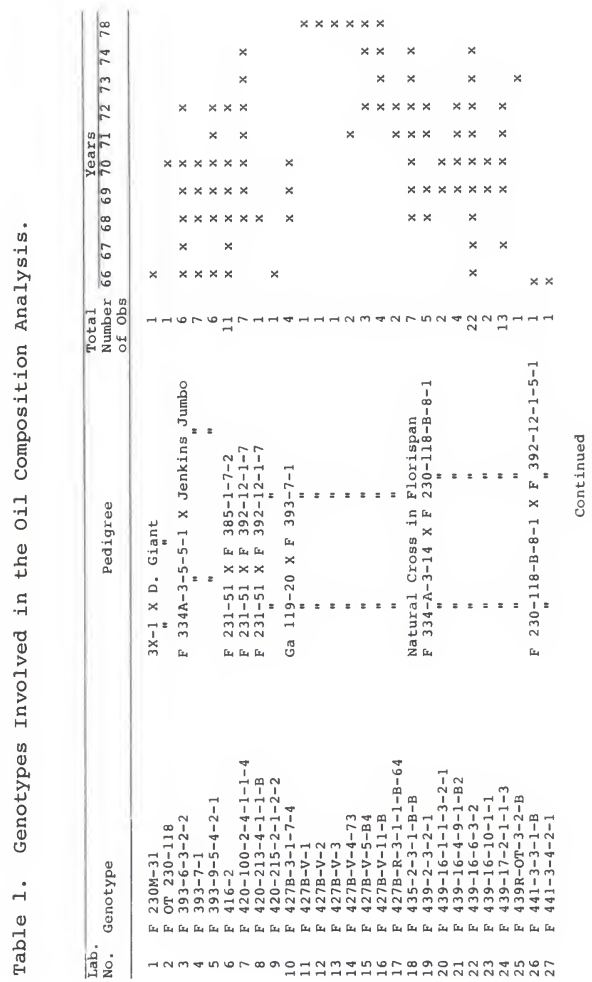




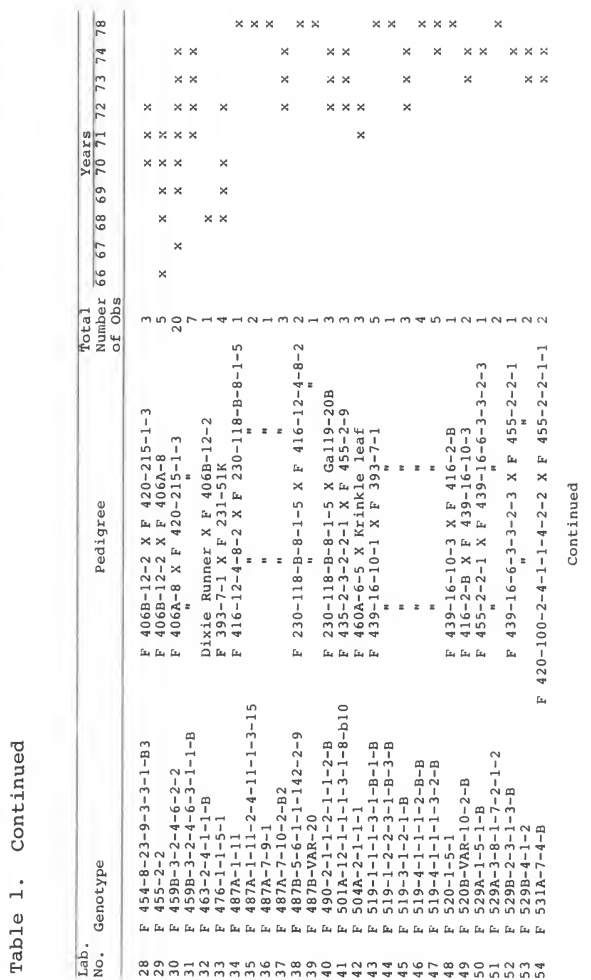




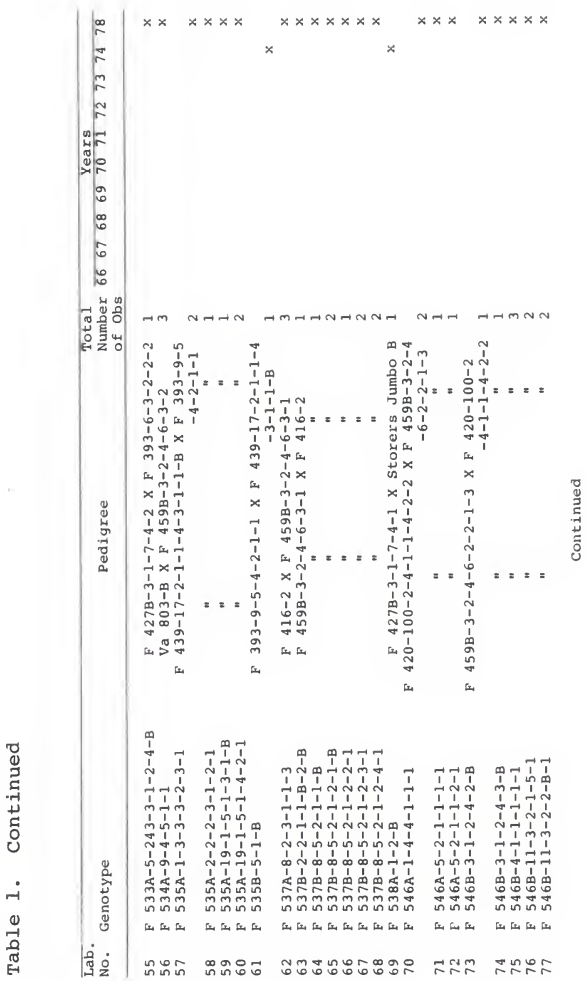




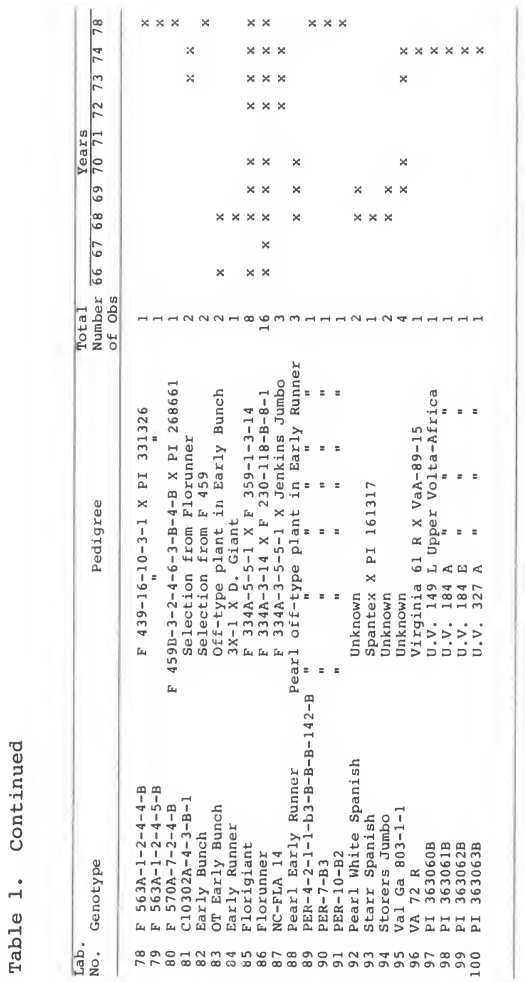


in 1978 at the University of Florida Green Acres Agronomy Farm.

The peanut seeds were fungicide-treated and hand planted in the field. They were sown $20 \mathrm{~cm}$ apart, in rows $60 \mathrm{~m}$ long, with $91 \mathrm{~cm}$ between rows to avoid competition. Overhead irrigation was applied at planting and during dry periods to obtain uniform emergence and adequate water for normal growth.

Fertilizers were applied before planting at a rate of 560 to $785 \mathrm{~kg} / \mathrm{ha}$ of $4-12-12$ plus $22 \mathrm{~kg} / \mathrm{ha}$ of No. 503 Frited Trace Elements (F.T.E.). The applications were on a broadcast basis followed by double discing.

A split application of gypsum at a rate of approximately $780 \mathrm{~kg} / \mathrm{ha}$ was broadcast over the rows, from six to eight weeks after planting, to insure uniform and sufficient Ca for normal seed development.

Herbicides, fungicides and insecticides were applied as needed, and varied from year to year in accordance to phytosanitary problems and product availability.

The harvest date was determined by the physiological aspect of the plants such as loss of older leaves, general yellowing of foliage, decreased peg strength (Bailey and Bear, 1973) and by the hardness and pronounced roughness of the pod surface (Sturkie and Buchanan, 1973). In general, Spanish type peanuts and other small seeded types were harvested 7 to 12 days prior to the large seeded peanuts. 
Planting and harvest dates for all years are included in Table 2 .

At harvest the plants were stack cured for 6 to 8 weeks prior to picking with a carding-type machine. After that the pod samples were promptly forwarded to the laboratory, where they were kept in cold storage until the samples were prepared for the analytical work. Samples were hand shelled and carefully selected for sound, mature kernels as indicated by seed size, absence of wrinkles and by the pigmentation of the seedcoat and interior of the pericarp. This procedure was followed to minimize the influence of maturity on the results of chemical analysis (Young et al.', 1972b; Sanders, 1980a) and also to remove moldy and defective kernels. Analytical work was usually completed within six months after harvest.

The procedure for analysis of fatty acids in peanuts involved oil extraction, esterification and chromatography. For oil extraction a 10-gram sample of shelled peanuts was homogenized in a waring Blender with $75 \mathrm{ml}$ of hexane for five minutes. The homogeneate was transferred to a $200 \mathrm{ml}$ volumetric flask, brought to room temperature, and diluted with hexane. The suspension was mixed and allowed to settle. A $25 \mathrm{ml}$ aliquot of the supernatant solution was evaporated to dryness in a vacuum oven at $70^{\circ} \mathrm{C}$. The oil percentage was calculated using the weight of this oil in relation to the initial weight of the sample. 
Table 2. Planting and Harvest Dates During the Ten-Year Period (1966-1974 and 1978).

\begin{tabular}{lll}
\hline Year & Date of Planting & Date of Harvest \\
\hline 1966 & May 3 & August 25/Sept. 10 \\
1967 & May 16 & September $14-21$ \\
1968 & May 9 & September $5-12$ \\
1969 & April 18 & August $18-26$ \\
1970 & May 20 & September $18-23$ \\
1971 & May 27 & September 22-30 \\
1972 & June 7 & October 2-12 \\
1973 & April 26 & August 20-27 \\
1974 & May 10 & September $5-12$ \\
1978 & May 3 & August 23/Sept. 11 \\
\hline
\end{tabular}


The glyceride esters of the extracted oils were converted into methyl esters by interesterification, using sodium methoxide as a catalyst (Craig and Murty, 1959). The interesterification procedure is simple and requires less time to prepare the samples for gas-chromatograph analysis than the common esterification procedure.

Methyl ester derivatives of fatty acids were prepared using a mixture of $100 \mathrm{mg}$ of oil, $21 \mathrm{ml}$ of methanol, and $0.5 \mathrm{mg}$ of sodium refluxed for 30 minutes with constant stirring. The cooled mixture was acidified with $1 \mathrm{ml}$ of acetic acid to inactivate the catalyst, diluted with $20 \mathrm{ml}$ of deionized water, and extracted with $5 \mathrm{ml}$ of hexane three times. The combined hexane fractions were evaporated to $1 / 2 \mathrm{ml}$ under dry nitrogen, and a one microliter aliquot was chromatographed.

Fatty acid methyl esters were analyzed on a Packard, Model 7831, gas chromatograph, using a $183 \mathrm{~mm}$ versus $4 \mathrm{~mm}$ glass column packed with a $20 \%$ coating of diethylene glycol succinate on 80-100 mesh fire-brick (Applied Science Laboratories, Inc., State College, Pennsylvania). The column temperature was $185^{\circ} \mathrm{C}$ and the flame ionization detector temperature was $195^{\circ} \mathrm{C}$. Gas flow rates were as follows: air flow rate was $350 \mathrm{ml} / \mathrm{min}$, hydrogen flow rate varied between 25 and $35 \mathrm{ml} / \mathrm{min}$, and helium carrier gas was used at a flow rate of about $30 \mathrm{ml} / \mathrm{min}$.

Craig and Murty (1959) found that the succinatediethylene glycol polyester used for the column 
completely separated stearic and oleic esters, but a log plot showed that the methyl linolenate had an emergence time coincident with methyl eicosenoate, which would complicate the analysis of oils containing both of these fatty acids, as do peanut oils. Besides that, the analytical procedure using polyester columns in the fatty acid determination is rapid and ideally suited when a large number of samples are to be analyzed, and also when small quantities of fats and oils are utilized in the analysis. The inaccuracy due to inadequate separation of linolenic acid from eicosenoic acid provided only a small bias in the results, because linolenic acid in peanuts has been reported to be present in small amounts, ranging from 0.03 to 0.13 weight percentage of total fatty acids (Worthington, 1977). Thus, results on eicosenoic acid included also small percentages of linolenic acid.

Peak areas were integrated manually by triangulation at $1 / 2$ height and percentages of fatty acids were computed in relation to total peak areas.

Periodically, percentage of total area under peaks was calculated on chromatograms obtained by the injection of actual standard quantitative mixtures of fatty acid methyl esters into the column and detector of the chromatograph in order to determine the quantitative efficiency of the instrument. Analysis of the standards showed errors of less than $5 \%$ of the total mixture in relation to the stated standard composition. Using the same column, fatty acid 
methyl esters in the samples were identified by comparing their relative retention volumes and logarithm of relative retention volumes with those of known standards obtained from Applied Science Laboratories, Inc., and by plots of the logarithm of relative retention volumes versus carbon numbers (Packard Operation Manual, 1967). Relative retention times were calculated by converting distance from initiation of solvent peak to intersection of tangents to sides of respective peaks into units of time.

It was possible to separate and quantify eight fatty acids which account for approximately 988 of the total fatty acids in peanut oil. The remaining percentages are composed of the glycerol portion of triglycerides and other constituents. Iodine values were calculated directly from the amounts of unsaturated acids determined by the gas chromatograph, assuming purity and complete esterification of the oil and are, therefore, approximately $6 \%$ higher than would have been obtained by direct measurement (Worthington et al. , 1972).

Cumulative rainfall, mean maximum and minimum air temperature, mean maximum and minimum soil temperature, and the average of the four last parameters for each year were recorded in relation to the period of fruit formation and seed development (from 8 weeks after planting until harvest). The climatological data were obtained from the Agronomy Department records (1966-1978), and the values are reported in Table 3. Correlation coefficients were 


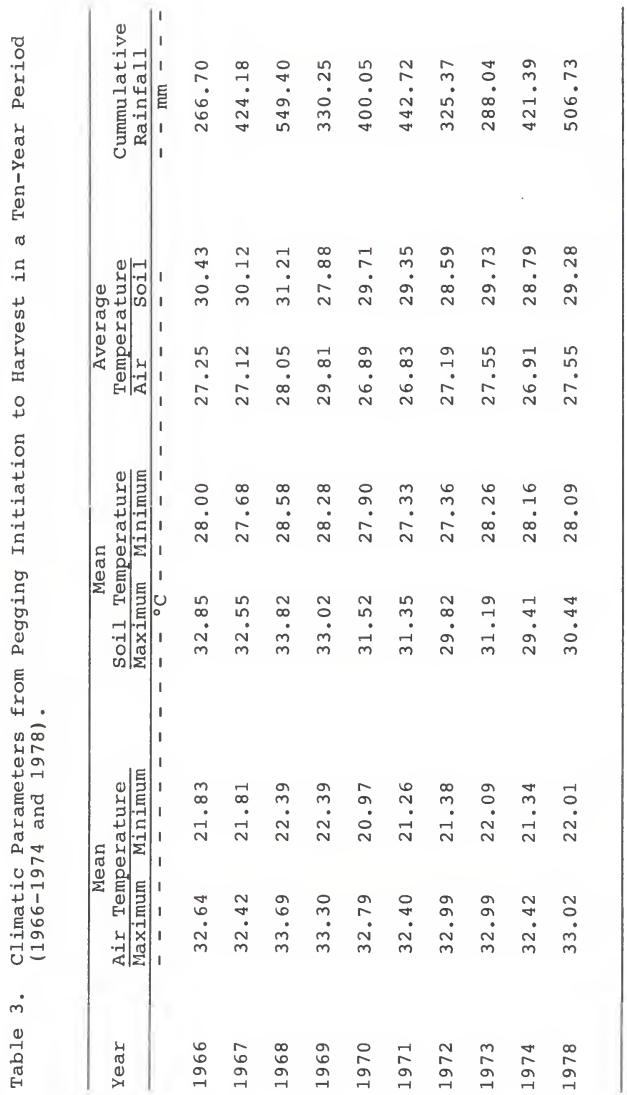


calculated involving climatic parameters with all other variables in order to study possible effects of temperature and water regime in the yearly variation of fatty acids, iodine number and oil percentage.

All statistical analyses were performed at the Northeast Regional Data Center of the State University System of Florida, Gainesville, Florida. The analyses were obtained using the procedures of the Statistical Analysis System (SAS) of the SAS Institute, Inc. The procedures are listed in Barr et al. (1979) and Helwig (1977).

of the 100 genotypes included in this study, only 40 appeared in more than one year, although genotypes that appeared only once might have had more than one replication. For the analysis of variance and subsequent test of means, only the genotypes that appeared at least in two years were considered. Due to missing values and unequal subclass numbers the data were analyzed by the method of least squares using the General Linear Model (GLM) procedure from SAS 79.5. Correlations were obtained using SAS's correlation procedure. A discussion of these analysis procedures can be found in references listed by Barr et al. (1979).

The whole experiment was considered a completely random design with a two-way classification model (years and genotypes) and no interaction. Genotypes whose fatty acid analyses were not made in a given year were handled as 
missing data. Unequal numbers of replications were also present.

The model used in the analysis of variance was

$$
\mathrm{Y}_{i j k}=\mu+\alpha_{i}+\beta_{j}+\varepsilon_{i j k}
$$

where $Y_{i j k}$ is the $k^{\text {th }}$ observation (replicate) of the $j^{\text {th }}$ genotype in the $i^{\text {th }}$ year,

$\mu$ is the overall mean for all the treatments, $\alpha_{i}$ is the effect of the $i^{\text {th }}$ year, $B_{j}$ is the effect of the $j^{\text {th }}$ genotype, and $\varepsilon_{i j k}$ is the component of random error associated with observation ijk.

An approximate test to select a group of one or more genotypes, so that the probability of including the genotype with the lowest (or the highest) mean is at least $(1-\alpha)$, would be a modification of the test proposed by Gupta in 1956.

In the original test if $\overline{\mathrm{Y}}_{\max }$ is the largest sample mean, then all treatments in the interval

$$
\bar{Y}_{\max }-V(\alpha ; t) \quad \sigma \bar{y}
$$

are retained and the probability that this interval includes the treatment with the largest mean is at least (1- $\alpha)$. One of the principal requirements to apply the original test developed by Gupta is that all populations have a 
common known variance $\sigma^{2}$. As the population variance is generally not known, the sample estimate for $\sigma^{2}$, i.e. error mean square, may be used provided the number of degrees of freedom is large, as it is in this study.

Another important requirement in the test is that each sample mean is based on the same number of observations. Due to unequal subclass numbers, the original test was modified by dividing the error mean square by the harmonic mean. For the same reason, least square means were utilized instead of the sample means. Thus, the critical highest mean would be

$$
\mathrm{LSM}_{\max }-\mathrm{V}(.05 ; t) \cdot\left[\frac{\mathrm{EMS}}{\mathrm{H}_{\mathrm{o}}}\right]^{\frac{1}{2}}
$$

where LSM $_{\max }$ is the maximum least square mean,

$V(.05 ; t)$ is the critical value for $\alpha=0.05$ and $t$ genotypes found in special tables (Gupta, 1956),

EMS is the error mean square provided by the analysis of variance, and

$\mathrm{H}_{\mathrm{O}}$ is the harmonic mean, obtained by the following formula:

$$
\frac{1}{\mathrm{H}_{0}}=\frac{1}{n_{0}}\left[\frac{1}{n_{1}}+\frac{1}{n_{2}}+\ldots+\frac{1}{n_{j}}\right]
$$

where $n_{j}$ is the number of observations for the $j^{\text {th }}$ genotype, and $n_{0}$ is the number of genotypes. 
As some values are desirable in either large or low amounts, depending on the standpoint considered (industrial or dietary), group separation was made taking into consideration that maximum or minimum values are desirable. Thus, the critical lowest mean would be

$$
\mathrm{LSM}_{\min }+\mathrm{V}(.05 ; t) \cdot\left[\frac{\mathrm{EMS}}{\mathrm{H}_{\mathrm{O}}}\right]^{\frac{1}{2}}
$$

where $\mathrm{LSM}_{\text {min }}$ is the minimum least square mean.

In order to use the Gupta test the least square means must be put first in increasing or decreasing order.

The data were analyzed combined (40 genotypes) and then later subdivided into three maturity groups (early, medium and late) and four commercial types (Virginia, Runner, Spanish and Valencia). Early maturing genotypes comprised those whose total cycle varied from 110 to 125 days. Medium maturity genotypes represented those maturing from 126 to 140 days, while later maturing genotypes had a total cycle ranging from 141 to 150 days. 


\section{RESULTS AND DISCUSSION}

The fatty acids, iodine value and oil content means of 100 genotypes over the ten years under study are presented in Table 4, as well as the number of observations on which the means are based.

The range in oil composition among the genotypes under investigation was rather large. Mean ranges in fatty acid composition were as follows: palmitic (hexadecanoic, c16:0) 6.90 to $17.50 \%$; stearic (octadecanoic, C18:0) 1.55 to $5.00 \%$; oleic (cis 9-octadecenoic, C18:1) 40.60 to 73.508 ; linoleic (cis 9, cis 12-octadecadienoic, C18:2) 8.60 to $39.15 \%$; arachidic (eicosanoic, C20:0) 0.10 to $2.00 \%$; eicosenoic (cis 11-eicosenoic, C20:1) 0.20 to 2.50\%; behenic (docosanoic, C22:0) 0.40 to $5.10 \%$; and lignoceric (tetracosanoic, C24:0) traces to $3.80 \%$. Iodine number varied from 75.00 to 105.00 , while oil percentage ranged from 46.20 to 53.40 \%

The data from this study indicate that there is quantitative diversity of fatty acids, iodine value and oil content in the genus Arachis, and that the magnitude of this diversity should be sufficient to permit the development of new varieties with improved chemical qualities.

Similar ranges in fatty acids were recorded by Worthington et al. (1972), when they studied 82 peanut 


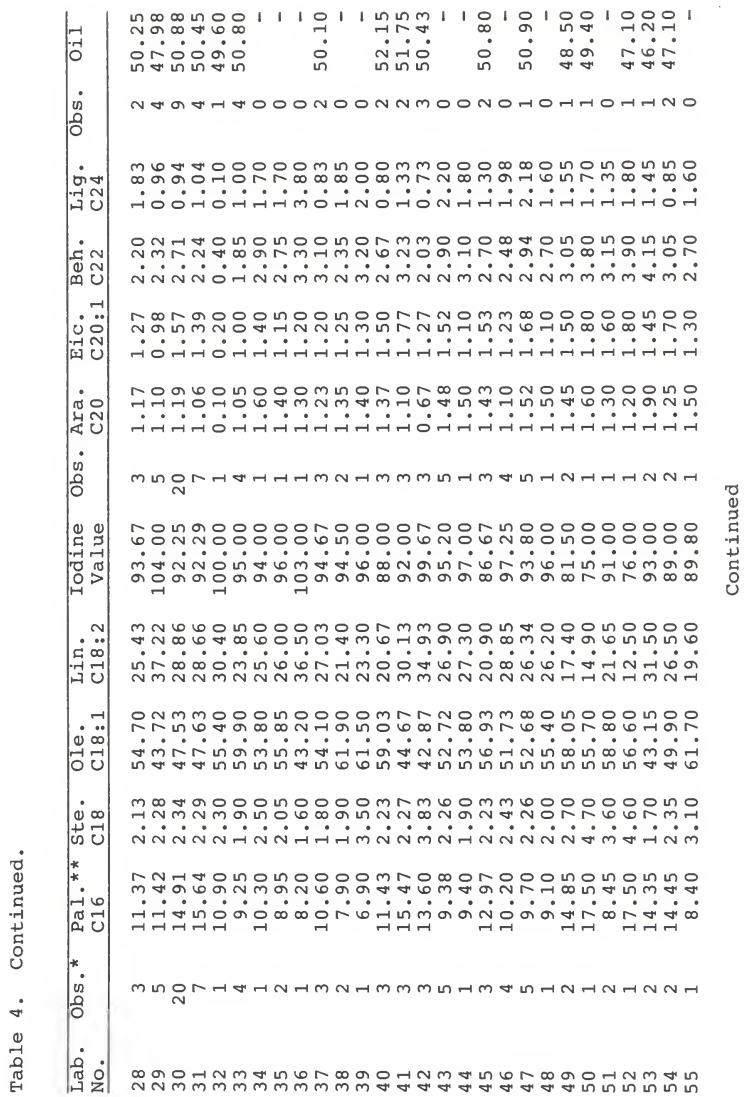




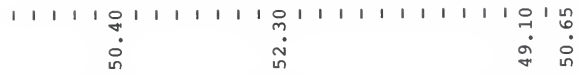

$000004000000040000000000040 n$

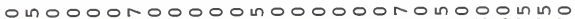
H

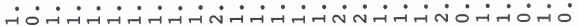

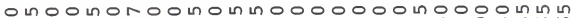

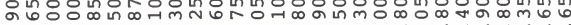

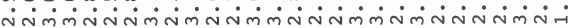

on 0 on

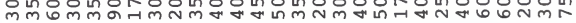

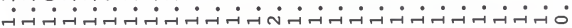

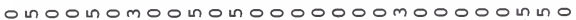

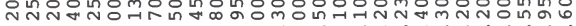

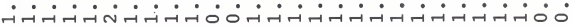

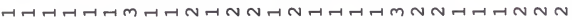

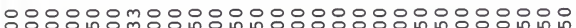
. . . . . . . . . . . . . . . . . . . -íं

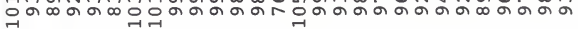

000000000 in 0000 in $0000 \mathrm{~m} 0$ in 0000 in 0 r I R A

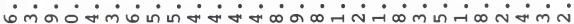
m N $N$ N

o in $0000 \mathrm{r} 000000000000 \mathrm{~m}$ in $\mathrm{n}^{\circ} 0000 \mathrm{in}$ ⿰丿⿱丄𠃍冂卄

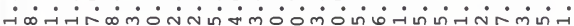
ه

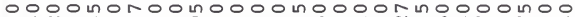

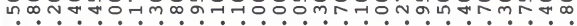

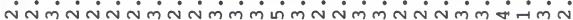

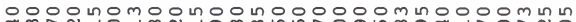
$\tan \mathrm{m}$.

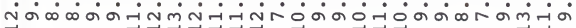

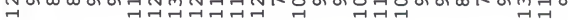

HNHANHM-HNHNNHNH-H

6r 


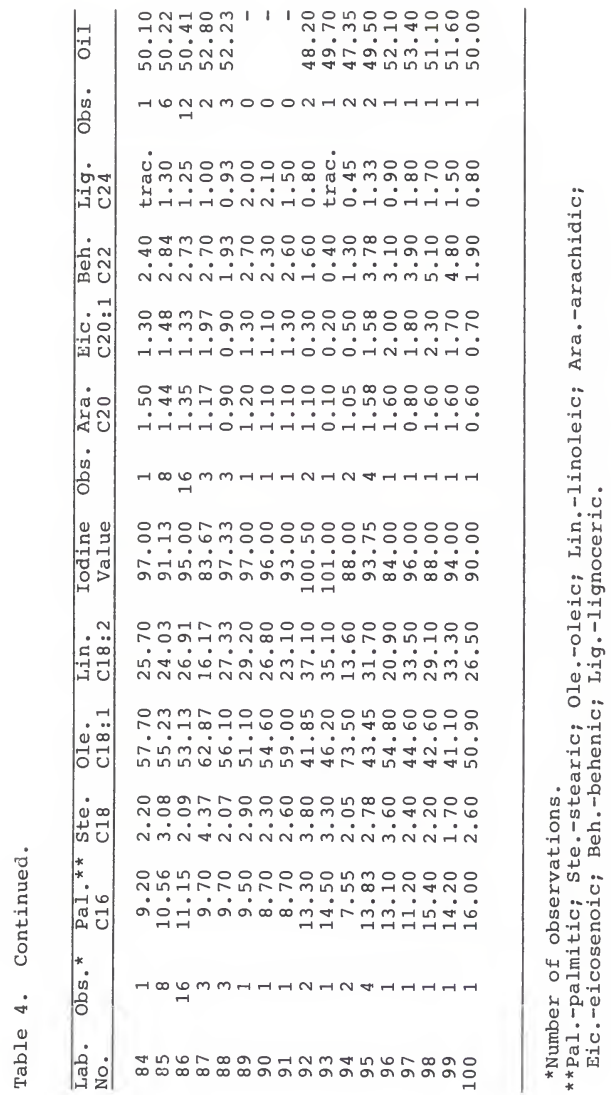


genotypes during a three-year period. Large differences in fatty acid composition of peanut samples were also reported by Holley and Hammons (1968). Differences of $20 \%$ in the high-low range for oil and 2178 for linoleic acid were noted in their study.

As shown in Table 4, oleic (C18:1) and linoleic (C18:2) acids are the major fatty acids, and together generally comprised about $80 \%$ of the total fatty acids present in the oil.

For the analysis of variance, and subsequent test of means, only the genotypes that appeared in at least two years were considered. Mean squares and significance levels of the combined data (40 genotypes) are shown in Table 5, as well as the variable means and coefficients of variation.

In the combined analysis of variance, genotypes and years were highly significant $(P<0.01)$ for iodine value, oil percentage and all fatty acids, except arachidic and behenic. For these two fatty acids, year effects were highly significant while the genotypic differences were not.

Yearly variation in fatty acid composition of peanut genotypes was also reported by other authors (Holley and Hammons, 1968; Worthington and Hammons, 1971; Worthington et al., 1972; and Tai, 1972). The source of variation is not well clarified, but appears to be related to climatic effects, such as temperature and moisture. The possible effects of temperature and rainfall on the chemical 
Table 5. Mean Squares from the Analysis of Variance,

Coefficients of Variation (C.V.) and Means of Fatty Acids, Iodine Value and Oil Percentage of 40 Peaunt Genotypes .

\begin{tabular}{lrrrrrr}
\hline Source & df & $\begin{array}{c}\text { Palmitic } \\
\text { C16 }\end{array}$ & $\begin{array}{c}\text { Stearic } \\
\text { C18 }\end{array}$ & $\begin{array}{c}\text { Oleic } \\
\text { C18:1 }\end{array}$ & $\begin{array}{c}\text { Linoleic } \\
\text { C18:1 }\end{array}$ & $\begin{array}{c}\text { Iodine } \\
\text { Value }\end{array}$ \\
\hline Model & 48 & $23.6119 * *$ & $2.2548 * * 295.1866^{* *} 216.9000 * * 176.1881 * *$ \\
Year & 9 & $9.9162 * *$ & $5.8223 * *$ & $38.1580^{* *}$ & $91.6908 * * 241.3358 * *$ \\
Genotype & 39 & $16.8954 * *$ & $1.3327 * * 318.3928 * * 221.9624 * * 116.6200 * *$ \\
Error & 166 & 1.2677 & 0.3780 & 8.2237 & 9.5769 & 11.8726 \\
& & & & & & \\
Mean & & 11.6730 & 2.4484 & 51.8372 & 27.6809 & 94.6651 \\
C.V. & 9.6454 & 25.1113 & 5.5321 & 11.1798 & 3.6399 \\
& & & & & \\
\hline
\end{tabular}

\begin{tabular}{lrcccc}
\hline Source & df & $\begin{array}{c}\text { Arachidic } \\
\text { C20 }\end{array}$ & $\begin{array}{c}\text { Eicosenoic } \\
\text { C20:1 }\end{array}$ & $\begin{array}{c}\text { Behenic } \\
\text { C22 }\end{array}$ & $\begin{array}{c}\text { Lignoceric } \\
\text { C24 }\end{array}$ \\
\hline Model & 48 & $0.5437 * *$ & $0.4578^{* *}$ & $1.4260^{* *}$ & $0.8507^{* *}$ \\
Year & 9 & $2.0979 * *$ & $0.9795^{* *}$ & $3.6380^{* *}$ & $2.7997^{* *}$ \\
Genotype & 39 & 0.1375 & $0.1372^{* *}$ & 0.5731 & $0.2105^{* *}$ \\
Error & 158 & 0.1158 & 0.0745 & 0.4884 & 0.1185 \\
& & & & & \\
Mean & & 1.2227 & 1.3304 & 2.6353 & 1.1005 \\
C.V. & 27.8369 & 20.5111 & 26.5186 & 31.2763 \\
& & & & & \\
\hline
\end{tabular}

\begin{tabular}{lrc}
\hline Source & df & Oil \\
\hline Model & 45 & $6.2587^{* *}$ \\
$\quad$ Year & 7 & $8.5014 * *$ \\
Genotype & 38 & $5.1883^{* *}$ \\
Error & 97 & 1.7206 \\
Mean & & 50.5832 \\
C.V. & & 2.5932 \\
\hline
\end{tabular}

**Significant at 0.01 level. 
composition of peanut genotypes in this study are discussed later.

The coefficients of variation for the combined data were low for oil, iodine value and oleic acid. Medium coefficients were found for palmitic and linoleic acids, while the coefficients of variation for stearic, eicosenoic, arachidic, behenic and lignoceric acids were very high. Iodine value, oil percentage and the major fatty acids seemed to be quantified in the chemical analyses with more relative precision, while the fatty acids that represent only small percentages of the total (C18, C20:1, C20, C22 and C24) were of difficult quantification. Higher coefficients of variation for the minor fatty acids in comparison with the major ones were also reported by Worthington and Holley (1967).

As is clearly seen in Table 5 , most of the variation in oleic (C18:1) and linoleic (C18:2) acids was due to genotype effects, while years appeared to have a greater influence on the iodine value and minor fatty acids $(\mathrm{C} 18, \mathrm{C} 20, \mathrm{C} 20: 1, \mathrm{C} 22$ and $\mathrm{C24}$ ). Very little seasonal variation in oleic and linoleic acid content of peanut oil was observed by Pickett and Holley (1956).

A modification of the test proposed by Gupta (1956) was utilized to obtain a set of least square genotype means which included either the highest or lowest yielding genotype. Use of least square means was necessary due to 
unequal subclass numbers. Procedures for the application of the test were described in the previous section.

Table 6 presents the least square means and standard errors of the forty genotypes, as well as least square mean group separation in relation to maximum and minimum values for all dependent variables. Genotype grouping was made taking into consideration that maximum or minimum values are desirable. There are some parameters, for example, linoleic acid, that are desirable in large amounts when considering human health, while for industrial quality of peanut products low amounts are sought.

Based on dietary qualities of the oil (low oleic, high linoleic, high iodine value) the best genotypes would include C10302A-4-3-B-1, genotypes derived from F 439 and F 529B, genotypes F 455-2-2, F 416-2, F 504A-2-1-1-1 and F 487A-7-10-2-B2. On the other hand, based on industrial qualities (high oleic, low linoleic, low iodine value), the best genotypes would include Storers Jumbo, genotypes derived from $F 393$ in general (including NC-FLA 14), F 520B-VAR-10-2-B, OT Early Bunch, F 420-100-2-4-1-1-4, genotypes derived from F 427B, Florigiant, F 435-2-3-1-B-B and F 490-2-1-1-2-1-1-2-B. Those are also, with the exception of Storers Jumbo, high oil genotypes.

Included in the best group of genotype means for all variables were genotypes from early, medium and late maturity groups, as well as Virginia, Runner, Spanish and Valencia commercial types. The data show that iodine 
Table 6. Least Square Means, Standard Errors and Genotype Grouping of Oil Components of 40 Peanut Genotypes.

\begin{tabular}{|c|c|c|c|}
\hline & & Palmitic AC & $(\mathrm{C} 16)$ \\
\hline & $\begin{array}{l}\text { ratory Number and } \\
\text { Genotype }\end{array}$ & $\begin{array}{c}\text { Least Square } \\
\text { Mean }\end{array}$ & $\begin{array}{c}\text { Standard } \\
\text { Error }\end{array}$ \\
\hline 31 & F $459 \mathrm{~B}-3-2-4-6-3-1-1-\mathrm{B}$ & $15.02 \star$ & $0.45^{-}$ \\
\hline 41 & F $501 \mathrm{~A}-12-1-1-1-3-1-8-\mathrm{b} 10$ & $14.43 *$ & 0.67 \\
\hline 42 & F $504 \mathrm{~A}-2-1-1-1$ & $14.22 *$ & 0.67 \\
\hline 30 & F $459 B-3-2-4-6-2-2$ & $14.05 *$ & 0.28 \\
\hline 92 & Pearl White Spanish & 13.82 * & 0.82 \\
\hline 19 & F $439-2-3-2-1$ & $13.79 *$ & 0.52 \\
\hline 49 & F 520B-VAR-10-2-B & $13.40 *$ & 0.82 \\
\hline 95 & Val Ga $803-1-1$ & $13.32 *$ & 0.57 \\
\hline 22 & F $439-16-6-3-2$ & $13.14 *$ & 0.26 \\
\hline 18 & F $435-2-3-1-B-B$ & $13.09 *$ & 0.43 \\
\hline 54 & F $531 \mathrm{~A}-7-4-\mathrm{B}$ & $13.00 *$ & 0.82 \\
\hline 53 & F $529 \mathrm{~B}-4-1-2$ & $12.90 *$ & 0.82 \\
\hline 81 & $\mathrm{C} 10302 \mathrm{~A}-4-3-\mathrm{B}-1$ & 12.30 & 0.82 \\
\hline 6 & F $416-2$ & 12.07 & 0.36 \\
\hline 29 & F $455-2-2$ & 12.00 & 0.52 \\
\hline 45 & F $519-3-1-2-1-B$ & 11.93 & 0.67 \\
\hline 28 & F $454-8-23-9-3-3-1-B 3$ & 11.86 & 0.66 \\
\hline 24 & F $439-17-2-1-1-3$ & 11.66 & 0.33 \\
\hline 23 & F $439-16-10-1-1$ & 11.59 & 0.81 \\
\hline 21 & F 439-16-4-9-1-B2 & 11.39 & 0.57 \\
\hline 20 & F 439-16-1-1-3-2-1 & 11.29 & 0.81 \\
\hline 86 & Florunner & 11.26 & 0.29 \\
\hline 85 & Florigiant & 10.58 & 0.40 \\
\hline 40 & F $490-2-1-1-2-1-1-2-B$ & 10.39 & 0.67 \\
\hline 88 & Pearl Early Runner & $10.25 * *$ & 0.67 \\
\hline 47 & F 519-4-1-1-1-3-2-B & $10.21 * \star$ & 0.62 \\
\hline 7 & F $420-100-2-4-1-1-4$ & $10.18 * *$ & 0.43 \\
\hline 17 & F $427 \mathrm{~B}-\mathrm{R}-3-1-1-\mathrm{B}-64$ & $10.15 * \star$ & 0.81 \\
\hline 15 & F $427 \mathrm{~B}-\mathrm{V}-5-\mathrm{B} 4$ & $9.83 * \star$ & 0.67 \\
\hline 83 & OT Early Bunch & $9.75^{* *}$ & 0.83 \\
\hline 33 & F $476-1-1-5-1$ & $9.61 * \star$ & 0.58 \\
\hline 37 & F $487 A-7-10-2-B 2$ & $9.56 * \star$ & 0.67 \\
\hline 16 & F $427 \mathrm{~B}-\mathrm{V}-11-\mathrm{B}$ & $9.20 * \star$ & 0.58 \\
\hline 14 & F $427 \mathrm{~B}-\mathrm{V}-4-73$ & $9.11 * \star$ & 0.83 \\
\hline 5 & F $393-9-5-4-2-1$ & $8.89 * \star$ & 0.47 \\
\hline 10 & F $427 B-3-1-7-4$ & $8.84 * \star$ & 0.58 \\
\hline 87 & NC-FLA 14 & $8.66 * \star$ & 0.70 \\
\hline 4 & F 393-7-1 & $8.18 * \star$ & 0.47 \\
\hline 94 & Storers Jumbo & $8.07 * \star$ & 0.82 \\
\hline 3 & F $393-6-3-2-2$ & $8.01 * *$ & 0.47 \\
\hline
\end{tabular}

*Best group of genotypes for desirable maximum values $(\mathrm{P}<.05)$ **Best group of genotypes for desirable minimum values $(\mathrm{P}<.05)$ 
Table 6. Continued.

\begin{tabular}{|c|c|c|c|}
\hline \multirow{2}{*}{\multicolumn{2}{|c|}{$\begin{array}{l}\text { Laboratory Number and } \\
\text { Genotype }\end{array}$}} & \multicolumn{2}{|c|}{ Stearic Acid (C18) } \\
\hline & & \multicolumn{2}{|c|}{$\begin{array}{cc}\text { Least Square } & \text { Standaro } \\
\text { Mean } & \text { Error }\end{array}$} \\
\hline 92 & Pearl White Spanish & 4.48 * & 0.45 \\
\hline 87 & NC-FLA 14 & $4.48 *$ & 0.37 \\
\hline 42 & F $504 \mathrm{~A}-2-1-1-1$ & 3.66 * & 0.37 \\
\hline 3 & F $393-6-3-2-2$ & $3.40 *$ & 0.26 \\
\hline 20 & F $439-16-1-1-3-2-1$ & $3.25 *$ & 0.44 \\
\hline 4 & F $393-7-1$ & 3.22 * & 0.26 \\
\hline 16 & F $427 \mathrm{~B}-\mathrm{V}-11-\mathrm{B}$ & 3.21 * & 0.32 \\
\hline 95 & Val Ga $803-1-1$ & $3.17 * \star$ & 0.31 \\
\hline 85 & Florigiant & $3.16 * *$ & 0.22 \\
\hline 7 & F $420-100-2-4-1-1-4$ & $2.98 * *$ & 0.24 \\
\hline 49 & F $520 \mathrm{~B}-\mathrm{VAR}-10-2-\mathrm{B}$ & $2.89 * *$ & 0.45 \\
\hline 18 & F $435-2-3-1-B-B$ & $2.78 * \star$ & 0.24 \\
\hline 94 & Storers Jumbo & $2.73 * *$ & 0.45 \\
\hline 5 & F $393-9-5-4-2-1$ & $2.65 * \star$ & 0.26 \\
\hline 15 & F $427 \mathrm{~B}-\mathrm{V}-5-\mathrm{B} 4$ & $2.58 * *$ & 0.37 \\
\hline 83 & OT Early Bunch & $2.58 * \star$ & 0.45 \\
\hline 54 & F $531 A-7-4-B$ & $2.54 * *$ & 0.45 \\
\hline 6 & F $416-2$ & $2.54 * *$ & 0.20 \\
\hline 88 & Pearl Early Runner & $2.47 * \star$ & 0.36 \\
\hline 28 & F $454-8-23-9-3-3-1-$ B 3 & $2.47 * *$ & 0.36 \\
\hline 30 & F $459 \mathrm{~B}-3-2-4-6-2-2$ & $2.47 \star \star$ & 0.15 \\
\hline 14 & F $\quad 427 B-V-4-73$ & $2.46 * \star$ & 0.45 \\
\hline 10 & F $427 \mathrm{~B}-3-1-7-4$ & $2.42 * \star$ & 0.32 \\
\hline 29 & F $455-2-2$ & $2.39 * \star$ & 0.28 \\
\hline 17 & F $427 B-R-3-1-1-B-64$ & $2.39 * *$ & 0.44 \\
\hline 41 & F $501 \mathrm{~A}-12-1-1-1-3-1-8-\mathrm{b} 10$ & $2.38 *$ * & 0.37 \\
\hline 45 & F $519-3-1-2-1-B$ & $2.34 * \star$ & 0.37 \\
\hline 40 & F $490-2-1-1-2-1-1-2-B$ & $2.35 * \star$ & 0.37 \\
\hline 31 & F $459 \mathrm{~B}-3-2-4-6-3-1-1-\mathrm{B}$ & $2.31 * \star$ & 0.24 \\
\hline 24 & F $439-17-2-1-1-3$ & $2.24 * *$ & 0.18 \\
\hline 86 & Florunner & 2.22 * & 0.16 \\
\hline 33 & F $476-1-1-5-1$ & $2.19 * \star$ & 0.31 \\
\hline 23 & F $439-16-10-1-1$ & $2.15 * \star$ & 0.44 \\
\hline 22 & F $439-16-6-3-2$ & $2.15 * \star$ & 0.14 \\
\hline 19 & F $439-2-3-2-1$ & $2.07 * *$ & 0.28 \\
\hline 47 & F 519-4-1-1-1-3-2-B & $2.00 \star \star$ & 0.34 \\
\hline 21 & F $439-16-4-9-1-B 2$ & $1.99 * \star$ & 0.31 \\
\hline 81 & $\mathrm{C} 10302 \mathrm{~A}-4-3-\mathrm{B}-1$ & $1.94 * \star$ & 0.45 \\
\hline 37 & F $487 A-7-10-2-B 2$ & $1.91 \star \star$ & 0.37 \\
\hline 53 & F $529 B-4-1-2$ & $1.89 * *$ & 0.45 \\
\hline
\end{tabular}

*Best group of genotypes for desirable maximum values $(\mathrm{P}<.05)$ **Best group of genotypes for desirable minimum values $(\mathrm{P}<.05)$ 
Table 6. Continued.

\begin{tabular}{|c|c|c|c|}
\hline \multicolumn{2}{|c|}{$\begin{array}{l}\text { Laboratory Number and } \\
\text { Genotype }\end{array}$} & $\begin{array}{c}\text { Oleic Acid } \\
\text { Least Square } \\
\text { Mean }\end{array}$ & 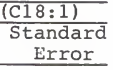 \\
\hline 94 & Storers Jumbo & $73.14 *$ & 2.08 \\
\hline 3 & F $393-6-3-2-2$ & $69.21 *$ & 1.20 \\
\hline 5 & F $393-9-5-4-2-1$ & 64.45 & 1.20 \\
\hline 4 & F $393-7-1$ & 64.20 & 1.20 \\
\hline 14 & F $427 B-V-4-73$ & 63.92 & 2.11 \\
\hline 10 & F $427 \mathrm{~B}-3-1-7-4$ & 62.61 & 1.49 \\
\hline 16 & F $427 \mathrm{~B}-\mathrm{V}-11-\mathrm{B}$ & 62.31 & 1.48 \\
\hline 87 & NC-FLA 14 & 62.26 & 1.71 \\
\hline 83 & OT Early Bunch & 62.00 & 2.11 \\
\hline 17 & F $427 \mathrm{~B}-\mathrm{R}-3-1-1-\mathrm{B}-64$ & 60.38 & 2.07 \\
\hline 33 & F $476-1-1-5-1$ & 60.25 & 1.47 \\
\hline 15 & F $\quad 427 B-V-5-B 4$ & 60.00 & 1.72 \\
\hline 7 & F $420-100-2-4-1-1-4$ & 59.68 & 1.10 \\
\hline 40 & F $490-2-1-1-2-1-1-2-B$ & 58.43 & 1.71 \\
\hline 45 & F $519-3-1-2-1-B$ & 56.33 & 1.71 \\
\hline 21 & F $439-16-4-9-1-B 2$ & 56.29 & 1.46 \\
\hline 49 & F $520 B-V A R-10-2-B$ & 56.15 & 2.09 \\
\hline 88 & Pearl Early Runner & 55.90 & 1.70 \\
\hline 20 & F $439-16-1-1-3-2-1$ & 55.41 & 2.07 \\
\hline 28 & F $454-8-23-9-3-3-1-B 3$ & 55.40 & 1.70 \\
\hline 85 & Florigiant & 55.20 & 1.02 \\
\hline 37 & F $487 \mathrm{~A}-7-10-2-\mathrm{B} 2$ & 53.49 & 1.71 \\
\hline 86 & Florunner & 53.41 & 0.73 \\
\hline 47 & F $519-4-1-1-1-3-2-B$ & 52.44 & 1.57 \\
\hline 23 & F $439-16-10-1-1$ & 51.91 & 2.07 \\
\hline 18 & F $435-2-3-1-B-B$ & 50.81 & 1.10 \\
\hline 24 & F $439-17-2-1-1-3$ & 48.91 & 0.85 \\
\hline 54 & F $531 \mathrm{~A}-7-4-\mathrm{B}$ & 48.00 & 2.09 \\
\hline 31 & F $459 B-3-2-4-6-3-1-1-B$ & 47.89 & 1.14 \\
\hline 30 & F $459 B-3-2-4-6-2-2$ & $46.59 * *$ & 0.72 \\
\hline 6 & F $416-2$ & $45.54 * *$ & 0.93 \\
\hline 29 & F $455-2-2$ & 44.24 ** & 1.32 \\
\hline 41 & F $501 \mathrm{~A}-12-1-1-1-3-1-8-\mathrm{b} 10$ & $44.06 * *$ & 1.71 \\
\hline 42 & F $504 \mathrm{~A}-2-1-1-1$ & $43.76 * *$ & 1.72 \\
\hline 95 & Val Ga 803-1-1 & $42.71 * *$ & 1.46 \\
\hline 19 & F $439-2-3-2-1$ & $41.98 * *$ & 1.32 \\
\hline 92 & Pearl White Spanish & 41.49 ** & 2.08 \\
\hline 22 & F $439-16-6-3-2$ & $41.48 * *$ & 0.66 \\
\hline 53 & F $529 B-4-1-2$ & $41.25 *$ * & 2.09 \\
\hline 81 & $\mathrm{C} 10302 \mathrm{~A}-4-3-\mathrm{B}-1$ & $41.10 * *$ & 2.09 \\
\hline
\end{tabular}

*Best group of genotypes for desirable maximum values $(\mathrm{P}<.05)$ **Best group of genotypes for desirable minimum values $(\mathrm{P}<.05)$ 
Table 6. Continued.

\begin{tabular}{|c|c|c|c|}
\hline \multicolumn{2}{|c|}{$\begin{array}{l}\text { Laboratory Number and } \\
\text { Genotype }\end{array}$} & $\begin{array}{c}\text { Linoleic Aci } \\
\text { Least Square } \\
\text { Mean }\end{array}$ & $\begin{array}{c}\text { (C18:2) } \\
\text { Standard } \\
\text { Error }\end{array}$ \\
\hline 81 & $\mathrm{C} 10302 \mathrm{~A}-4-3-\mathrm{B}-1$ & $38.01 *$ & 2.26 \\
\hline 22 & F $439-16-6-3-2$ & $36.96 *$ & 0.72 \\
\hline 19 & F $439-2-3-2-1$ & $36.01 *$ & 1.42 \\
\hline 29 & F $455-2-2$ & $35.58 *$ & 1.42 \\
\hline 53 & F $529 B-4-1-2$ & $35.21^{\star}$ & 2.26 \\
\hline 54 & F $531 \mathrm{~A}-7-4-\mathrm{B}$ & 34.97 * & 2.25 \\
\hline 6 & F $416-2$ & $33.65 *$ & 0.99 \\
\hline 42 & F $504 \mathrm{~A}-2-1-1-1$ & $33.58 *$ & 1.85 \\
\hline 95 & Val Ga $803-1-1$ & $33.12 *$ & 1.58 \\
\hline 41 & F $501 \mathrm{~A}-12-1-1-1-3-1-8-\mathrm{b} 10$ & $31.73 \star$ & 1.84 \\
\hline 30 & F $459 B-3-2-4-6-2-2$ & 30.89 & 0.78 \\
\hline 24 & F $439-17-2-1-1-3$ & 30.84 & 0.91 \\
\hline 92 & Pearl White Spanish & 30.21 & 2.26 \\
\hline 31 & F $459 \mathrm{~B}-3-2-4-6-3-1-1-\mathrm{B}$ & 28.77 & 1.23 \\
\hline 37 & F $\quad 487 \mathrm{~A}-7-10-2-\mathrm{B} 2$ & 28.63 & 1.84 \\
\hline 23 & F $439-16-10-1-1$ & 27.78 & 2.24 \\
\hline 47 & F $519-4-1-1-1-3-2-B$ & 27.70 & 1.70 \\
\hline 86 & Florunner & 26.51 & 0.79 \\
\hline 18 & F $435-2-3-1-B-B$ & 26.21 & 1.19 \\
\hline 88 & Pearl Early Runner & 25.75 & 1.83 \\
\hline 20 & F $439-16-1-1-3-2-1$ & 25.08 & 2.24 \\
\hline 21 & F $439-16-4-9-1-B 2$ & 24.86 & 1.58 \\
\hline 28 & F $454-8-23-9-3-3-1-B 3$ & 24.26 & 1.83 \\
\hline 85 & Florigiant & 23.89 & 1.11 \\
\hline 45 & F $519-3-1-2-1-B$ & 22.49 & 1.84 \\
\hline 40 & F $490-2-1-1-2-1-1-2-B$ & 22.26 & 1.84 \\
\hline 33 & F $476-1-1-5-1$ & 22.01 & 1.58 \\
\hline 15 & F $427 \mathrm{~B}-\mathrm{V}-5-\mathrm{B} 4$ & 21.64 & 1.85 \\
\hline 49 & F 520B-VAR-10-2-B & 21.11 & 2.26 \\
\hline 7 & F $420-100-2-4-1-1-4$ & 20.92 & 1.19 \\
\hline 17 & F $427 B-R-3-1-1-B-64$ & 20.89 & 2.23 \\
\hline 83 & OT Early Bunch & 20.35 & 2.27 \\
\hline 10 & F $427 \mathrm{~B}-3-1-7-4$ & 19.77 & 1.60 \\
\hline 14 & F $\quad 427 \mathrm{~B}-\mathrm{V}-4-73$ & 19.22 & 2.28 \\
\hline 16 & F $427 \mathrm{~B}-\mathrm{V}-11-\mathrm{B}$ & $18 \cdot 60$ & 1.60 \\
\hline 87 & NC-FLA 14 & $17.76 * \star$ & 1.84 \\
\hline 4 & F 393-7-1 & $17.07 * \star$ & 1.29 \\
\hline 5 & F $393-9-5-4-2-1$ & $16.89 * *$ & 1.29 \\
\hline & F $393-6-3-2-2$ & $13 \cdot 33 * \star$ & 1.29 \\
\hline 94 & Storers Jumbo & $11.47 * *$ & 2.25 \\
\hline
\end{tabular}

*Best group of genotypes for desirable maximum values $(\mathrm{P}<.05)$ **Best group of genotypes for desirable minimum values $(\mathrm{P}<.05)$ 
Table 6. Continued.

\begin{tabular}{|c|c|c|c|}
\hline & & Arachidic Ac & $(\mathrm{C20})$ \\
\hline Lab & ratory Number and & Least Square & Standard \\
\hline 53 & F $525 B-4-1-2$ & $1.88 *$ & 0.25 \\
\hline 4 & F $393-7-1$ & 1.54 * & 0.18 \\
\hline 81 & $\mathrm{C} 10302 \mathrm{~A}-4-3-\mathrm{B}-1$ & $1.53^{*}$ & 0.25 \\
\hline 45 & F $519-3-1-2-1-B$ & $1.50 *$ & 0.20 \\
\hline 47 & F 519-4-1-1-1-3-2-B & 1.48 * & 0.19 \\
\hline 5 & F $393-9-5-4-2-1$ & $1.47 * * *$ & 0.16 \\
\hline 10 & F $\quad 427 B-3-1-7-4$ & $1.46 * * *$ & 0.18 \\
\hline 95 & Val Ga $803-1-1$ & $1.46 * * *$ & 0.17 \\
\hline 85 & Florigiant & $1.45 * \star \star$ & 0.12 \\
\hline 40 & F $490-2-1-1-2-1-1-2-B$ & $1.43 * * *$ & 0.20 \\
\hline 49 & F 520B-VAR-10-2-B & $1.43 * * *$ & 0.25 \\
\hline 16 & F $427 \mathrm{~B}-\mathrm{V}-11-\mathrm{B}$ & $1.38 * * *$ & 0.18 \\
\hline 7 & F $420-100-2-4-1-1-4$ & $1.33 * * *$ & 0.13 \\
\hline 17 & F $427 \mathrm{~B}-\mathrm{R}-3-1-1-\mathrm{B}-64$ & $1.32 * \star \star *$ & 0.25 \\
\hline 86 & Florunner & $1.30 * \star *$ & 0.09 \\
\hline 3 & F $393-6-3-2-2$ & 1. $39 * * *$ & 0.14 \\
\hline 37 & F $487 \mathrm{~A}-7-10-2-\mathrm{B} 2$ & $1.30 * * *$ & 0.20 \\
\hline 14 & F $\quad 427 \mathrm{~B}-\mathrm{V}-4-73$ & $1.26 * * *$ & 0.25 \\
\hline 22 & F $439-16-6-3-2$ & $1.23 * \star *$ & 0.08 \\
\hline 87 & NC-FLA 14 & $1.23 * * *$ & 0.20 \\
\hline 54 & F $531 A-7-4-B$ & $1.23 * * *$ & 0.25 \\
\hline 92 & Pearl White Spanish & $1.22 * * *$ & 0.25 \\
\hline 21 & F $439-16-4-9-1-B 2$ & $1.21 * * *$ & 0.17 \\
\hline 31 & F $459 B-3-2-4-6-3-1-1-B$ & $1.19 * * *$ & 0.14 \\
\hline 18 & F $435-2-3-1-B-B$ & $1.19 * * *$ & 0.13 \\
\hline 30 & $F \quad 459 B-3-2-4-6-2-2$ & $1.18 * * *$ & 0.09 \\
\hline 33 & F $476-1-1-5-1$ & $1.18 * \star *$ & 0.17 \\
\hline 95 & Storers Jumbo & $1.17 * * *$ & 0.25 \\
\hline 41 & F $501 \mathrm{~A}-12-1-1-1-3-1-8-\mathrm{b} 10$ & $1.17 * \star *$ & 0.20 \\
\hline 24 & F $439-17-2-1-1-3$ & $1.16 * \star *$ & 0.10 \\
\hline 23 & F $439-16-10-1-1$ & $1.14 * \star$ & 0.25 \\
\hline 29 & F $455-2-2$ & $1.10 * *$ & 0.16 \\
\hline 19 & F $439-2-3-2-1$ & $1.08 * *$ & 0.16 \\
\hline 15 & F $\quad 427 B-V-5-B 4$ & $1.08 * *$ & 0.20 \\
\hline 6 & F $416-2$ & $1.08 * *$ & 0.12 \\
\hline 28 & F $454-8-23-3-3-1-B 3$ & $1.06 * *$ & 0.20 \\
\hline 88 & Pearl Early Runner & $0.99 * *$ & 0.20 \\
\hline 20 & F $439-16-1-1-3-2-1$ & $0.79 * *$ & 0.25 \\
\hline 42 & F $504 \mathrm{~A}-2-1-1-1$ & $0.76 * *$ & 0.20 \\
\hline 83 & OT Early Bunch & $0.75 * *$ & 0.25 \\
\hline
\end{tabular}

*Best group of genotypes for desirable maximum values $(\mathrm{P}<.05)$ **Best group of genotypes for desirable minimum values $(\mathrm{P}<.05)$ 
Table 6. Continued.

\begin{tabular}{|c|c|c|c|}
\hline \multicolumn{2}{|c|}{$\begin{array}{l}\text { Laboratory Number and } \\
\text { Genotype }\end{array}$} & \multicolumn{2}{|c|}{ 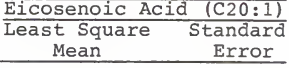 } \\
\hline 87 & NC-FLA 14 & 1.76 * & 0.16 \\
\hline 4 & F $393-7-1$ & $1.65 *$ & 0.14 \\
\hline 16 & F $\quad 427 \mathrm{~B}-\mathrm{V}-11-\mathrm{B}$ & $1.59 *$ & 0.14 \\
\hline 41 & F $501 \mathrm{~A}-12-1-1-1-3-1-8-\mathrm{b} 10$ & $1.56 *$ & 0.16 \\
\hline 10 & F $427 \mathrm{~B}-3-1-7-4$ & 1.54 * & 0.14 \\
\hline 5 & F $393-9-5-4-2-1$ & $1.51 *$ & 0.13 \\
\hline 47 & F $519-4-1-1-1-3-2-B$ & $1.49 *$ & 0.15 \\
\hline 85 & Florigiant & $1.47 *$ & 0.10 \\
\hline 23 & F $439-16-10-1-1$ & $1.44^{*}$ & 0.20 \\
\hline 95 & Val Ga 803-1-1 & 1.41 * & 0.14 \\
\hline 18 & F $435-2-3-1-B-B$ & $1.40 *$ & 0.10 \\
\hline 54 & F $531 A-7-4-B$ & $1.38 *$ & 0.20 \\
\hline 30 & F $459 B-3-2-4-6-2-2$ & 1.36 * & 0.07 \\
\hline 45 & F $519-3-1-2-1-B$ & 1.33 * & 0.16 \\
\hline 86 & Florunner & $1.33 *$ & 0.07 \\
\hline 3 & F $393-6-3-2-2$ & 1.30 * & 0.11 \\
\hline 17 & F $427 B-R-3-1-1-B-64$ & $1.30 *$ & 0.20 \\
\hline 40 & F $490-2-1-1-2-1-1-2-B$ & 1.30 * & 0.16 \\
\hline 24 & F $439-17-2-1-1-3$ & 1.27 * & 0.08 \\
\hline 31 & F $459 \mathrm{~B}-3-2-4-6-3-1-1-\mathrm{B}$ & 1.27 * & 0.11 \\
\hline 15 & F $427 \mathrm{~B}-\mathrm{V}-5-\mathrm{B} 4$ & 1.27 * & 0.16 \\
\hline 14 & F $427 \mathrm{~B}-\mathrm{V}-4-73$ & $1.26^{*}$ & 0.20 \\
\hline 22 & F $439-16-6-3-2$ & $1.26^{\star}$ & 0.07 \\
\hline 28 & F $454-8-23-9-3-3-1-B 3$ & $1.25 *$ & 0.16 \\
\hline 21 & F $439-16-4-9-1-B 2$ & $1.25 *$ & 0.14 \\
\hline 42 & F $504 \mathrm{~A}-2-1-1-1$ & $1.22 * \star \star *$ & 0.16 \\
\hline 7 & F $420-100-2-4-1-1-4$ & $1.21 * * *$ & 0.11 \\
\hline 20 & F $439-16-1-1-3-2-1$ & $1.19 * * *$ & 0.20 \\
\hline 49 & F 520B-VAR-10-2-B & $1.18 * *$ & 0.20 \\
\hline 33 & F $476-1-1-5-1$ & $1.17 * \star$ & 0.14 \\
\hline 6 & F $416-2$ & $1.14 * \star$ & 0.10 \\
\hline 53 & F $529 B-4-1-2$ & $1.13 * \star$ & 0.20 \\
\hline 88 & Pearl Early Runner & $1.11 * \star$ & 0.16 \\
\hline 29 & F $455-2-2$ & $1.11 * *$ & 0.13 \\
\hline 83 & OT Early Bunch & $1.11 * \star$ & 0.20 \\
\hline 19 & F $439-2-3-2-1$ & $1.10 * \star$ & 0.13 \\
\hline 37 & F $487 \mathrm{~A}-7-10-2-\mathrm{B} 2$ & $0.99 * *$ & 0.16 \\
\hline 81 & $\mathrm{C} 10302 \mathrm{~A}-4-3-\mathrm{B}-1$ & $0.88 * *$ & 0.20 \\
\hline 94 & Storers Jumbo & $0.86 * *$ & 0.20 \\
\hline 92 & Pearl White Spanish & $0.66 * *$ & 0.20 \\
\hline
\end{tabular}

*Best group of genotypes for desirable maximum values $(\mathrm{P}<.05)$ **Best group of genotypes for desirable minimum values $(\mathrm{P}<.05)$ 
Table 6. Continued.

\begin{tabular}{|c|c|c|c|}
\hline \multirow{2}{*}{\multicolumn{2}{|c|}{$\begin{array}{l}\text { Laboratory Number and } \\
\text { Genotype }\end{array}$}} & \multicolumn{2}{|c|}{ Behenic Acid (C22) } \\
\hline & & $\begin{array}{c}\text { Least Square } \\
\text { Mean }\end{array}$ & $\begin{array}{c}\text { Standard } \\
\text { Error }\end{array}$ \\
\hline 53 & F $529 B-4-1-2$ & $3.89 *$ & 0.51 \\
\hline 95 & Val Ga $803-1-1$ & $3.60 *$ & 0.36 \\
\hline 18 & F $435-2-3-1-B-B$ & $3.27 * * *$ & 0.27 \\
\hline 4 & F $393-7-1$ & $3.22 * * *$ & 0.36 \\
\hline 41 & F $501 \mathrm{~A}-12-1-1-1-3-1-8-\mathrm{b} 10$ & $3.17 * * *$ & 0.42 \\
\hline 5 & F $393-9-5-4-2-1$ & $3.10 * \star \star$ & 0.32 \\
\hline 81 & $\mathrm{C} 10302 \mathrm{~A}-4-3-\mathrm{B}-1$ & $3.09 * * *$ & 0.51 \\
\hline 37 & F $487 \mathrm{~A}-7-10-2-\mathrm{B} 2$ & $3.04 * \star *$ & 0.42 \\
\hline 85 & Florigiant & $2.87 * * *$ & 0.25 \\
\hline 19 & F $439-2-3-2-1$ & $2.82 \star \star \star$ & 0.32 \\
\hline 23 & F $439-16-10-1-1$ & $2.81 * \star *$ & 0.51 \\
\hline 54 & F $531 A-7-4-B$ & $2.79 \star \star \star$ & 0.51 \\
\hline 49 & F $520 \mathrm{~B}-\mathrm{VAR}-10-2-\mathrm{B}$ & $2.79 * * *$ & 0.51 \\
\hline 22 & F $439-16-6-3-2$ & $2.76 * \star \star$ & 0.17 \\
\hline 24 & F $439-17-2-1-1-3$ & $2.75 * \star \star$ & 0.21 \\
\hline 86 & Florunner & $2.73 * * *$ & 0.18 \\
\hline 45 & F $519-3-1-2-1-B$ & $2.64 \star \star \star$ & 0.42 \\
\hline 87 & NC-FLA 14 & 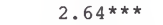 & 0.42 \\
\hline 40 & F $490-2-1-1-2-1-1-2-B$ & 2. $61 * * *$ & 0.42 \\
\hline 3 & F $393-6-3-2-2$ & $2.59 * \star \star$ & 0.29 \\
\hline 7 & F $420-100-2-4-1-1-4$ & $2.58 * * *$ & 0.27 \\
\hline 47 & F $519-4-1-1-1-3-2-B$ & $2.57 * \star \star$ & 0.38 \\
\hline 20 & F $439-16-1-1-3-2-1$ & $2.57 * \star \star$ & 0.51 \\
\hline 30 & F $459 B-3-2-4-6-2-2$ & $2.55 * * *$ & 0.18 \\
\hline 6 & F $416-2$ & $2.53 * * *$ & 0.25 \\
\hline 15 & F $427 \mathrm{~B}-\mathrm{V}-5-\mathrm{B} 4$ & $2.52 * \star *$ & 0.42 \\
\hline 10 & F $427 \mathrm{~B}-3-1-7-4$ & $2.51 * * *$ & 0.36 \\
\hline 29 & F $455-2-2$ & $2.49 * \star *$ & 0.32 \\
\hline 16 & F $427 \mathrm{~B}-\mathrm{V}-11-\mathrm{B}$ & $2.44 * \star *$ & 0.36 \\
\hline 17 & F $427 \mathrm{~B}-\mathrm{R}-3-1-1-\mathrm{B}-64$ & $2.35 * *$ & 0.51 \\
\hline 31 & F $459 \mathrm{~B}-3-2-4-6-3-1-1-\mathrm{B}$ & $2.31 * *$ & 0.28 \\
\hline 14 & F $427 \mathrm{~B}-\mathrm{V}-4-73$ & $2.30 * \star$ & 0.51 \\
\hline 88 & Pearl Early Runner & $2.30 * *$ & 0.41 \\
\hline 33 & F $476-1-1-5-1$ & $2.21 * \star$ & 0.36 \\
\hline 28 & F $454-8-23-9-3-3-1-B 3$ & $2.16 * *$ & 0.41 \\
\hline 92 & Pearl White Spanish & $2.12 * *$ & 0.51 \\
\hline 83 & OT Early Bunch & $2.12 * *$ & 0.52 \\
\hline 42 & F $504 \mathrm{~A}-2-1-1-1$ & $2.09 * *$ & 0.42 \\
\hline & F $439-16-4-9-1-B 2$ & $2.03 * \star$ & 0.36 \\
\hline 94 & Storers Jumbo & $1.82 * \star$ & 0.51 \\
\hline
\end{tabular}

*Best group of genotypes for desirable maximum values $(P<.05)$ **Best group of genotypes for desirable minimum values $(P<.05)$ 
Table 6. Continued.

\begin{tabular}{|c|c|c|c|}
\hline \multirow{2}{*}{\multicolumn{2}{|c|}{$\begin{array}{l}\text { Laboratory Number and } \\
\text { Genotype }\end{array}$}} & \multicolumn{2}{|c|}{ Lignoceric Acid (C24) } \\
\hline & & $\begin{array}{c}\text { Least Square } \\
\text { Mean }\end{array}$ & $\begin{array}{c}\text { Standard } \\
\text { Error }\end{array}$ \\
\hline 47 & F $519-4-1-1-1-3-2-B$ & $1.78 *$ & 0.19 \\
\hline 28 & F $454-8-23-9-3-3-1-$ B 3 & $1.66 *$ & 0.20 \\
\hline 49 & F $520 \mathrm{~B}-\mathrm{VAR}-10-2-\mathrm{B}$ & 1.59 * & 0.25 \\
\hline 53 & F $529 B-4-1-2$ & 1.49 * & 0.25 \\
\hline 41 & F $501 \mathrm{~A}-12-1-1-1-3-1-8-\mathrm{b} 10$ & $1.46 *$ & 0.20 \\
\hline 45 & F $519-3-1-2-1-B$ & 1.44 * & 0.20 \\
\hline 85 & Florigiant & 1.32 * & 0.12 \\
\hline 23 & F $439-16-10-1-1$ & $1.25 * * *$ & 0.25 \\
\hline 24 & F $439-17-2-1-1-3$ & $1.23 * * *$ & 0.10 \\
\hline 95 & Val Ga $803-1-1$ & $1.22 * \star \star$ & 0.18 \\
\hline 18 & F $435-2-3-1-B-B$ & $1.21 * * *$ & 0.13 \\
\hline 33 & F $476-1-1-5-1$ & $1.21 * * *$ & 0.18 \\
\hline 86 & Florunner & $1.19 * * *$ & 0.09 \\
\hline 17 & F $427 \mathrm{~B}-\mathrm{R}-3-1-1-\mathrm{B}-64$ & $1.18 * * *$ & 0.25 \\
\hline 19 & F $439-2-3-2-1$ & $1.17 * \star *$ & 0.16 \\
\hline 31 & F $459 \mathrm{~B}-3-2-4-6-3-1-1-\mathrm{B}$ & $1.16 * * *$ & 0.14 \\
\hline 92 & Pearl White Spanish & $1.16 * \star *$ & 0.25 \\
\hline 7 & F $420-100-2-4-1-1-4$ & $1.16 * \star *$ & 0.13 \\
\hline 15 & F $427 \mathrm{~B}-\mathrm{V}-5-\mathrm{B} 4$ & $1.14 * * *$ & 0.21 \\
\hline 87 & NC-FLA 14 & $1.12 * * *$ & 0.20 \\
\hline 83 & OT Early Bunch & $1.12 * \star *$ & 0.26 \\
\hline 88 & Pearl Early Runner & $1.11 * * *$ & 0.20 \\
\hline 22 & F $439-16-6-3-2$ & $1.11 * \star *$ & 0.08 \\
\hline 6 & F $416-2$ & $1.07 * * *$ & 0.13 \\
\hline 4 & F 393-7-1 & $1.06 * \star *$ & 0.18 \\
\hline 20 & F $439-16-1-1-3-2-1$ & $1.05 * * *$ & 0.25 \\
\hline 10 & F $427 \mathrm{~B}-3-1-7-4$ & $1.04 * *$ & 0.18 \\
\hline 21 & F $439-16-4-9-1-B 2$ & $1.04 * *$ & 0.18 \\
\hline 16 & F $427 \mathrm{~B}-\mathrm{V}-11-\mathrm{B}$ & $1.03 * \star$ & 0.18 \\
\hline 29 & F $455-2-2$ & $1.02 * *$ & 0.16 \\
\hline 30 & F $459 B-3-2-4-6-2-2$ & $0.94 * *$ & 0.09 \\
\hline 37 & F $487 \mathrm{~A}-7-10-2-\mathrm{B} 2$ & 0.96 ** & 0.20 \\
\hline 40 & F $490-2-1-1-2-1-1-2-B$ & 0.92 * & 0.20 \\
\hline 54 & F $531 A-7-4-B$ & $0.89 * \star$ & 0.25 \\
\hline 5 & F $393-9-5-4-2-1$ & 0.86 ** & 0.16 \\
\hline 94 & Ștorers Jumbo & $0.81 * \star$ & 0.25 \\
\hline 42 & F $504 \mathrm{~A}-2-1-1-1$ & $0.66 * *$ & 0.21 \\
\hline 81 & C1 $0302 A-4-3-B-1$ & $0.79 * *$ & 0.25 \\
\hline 14 & F $427 \mathrm{~B}-\mathrm{V}-4-73$ & $0.57 * \star$ & 0.25 \\
\hline
\end{tabular}

*Best group of genotypes for desirable maximum values $(\mathrm{P}<.05)$ **Best group of genotypes for desirable minimum values $(\mathrm{P}<.05)$ 
Table 6. Continued.

\begin{tabular}{|c|c|c|c|}
\hline & & Iodine V & ue \\
\hline Lab & $\begin{array}{l}\text { ratory Number and } \\
\text { Genotype }\end{array}$ & $\begin{array}{c}\text { Least Square } \\
\text { Mean }\end{array}$ & $\begin{array}{l}\text { Standard } \\
\text { Error }\end{array}$ \\
\hline 81 & $\mathrm{C} 10302 \mathrm{~A}-4-3-\mathrm{B}-1$ & $104.03 *$ & 2.52 \\
\hline 22 & F $439-16-6-3-2$ & $101.90 *$ & 0.80 \\
\hline 29 & F $455-2-2$ & $101.30 *$ & 1.58 \\
\hline 19 & F $439-2-3-2-1$ & $100.86 *$ & 1.59 \\
\hline 53 & F $529 B-4-1-2$ & $99.53 *$ & 2.52 \\
\hline 6 & F $416-2$ & $99.13^{*}$ & 1.11 \\
\hline 37 & F $487 A-7-10-2-B 2$ & $97.87 *$ & 2.05 \\
\hline 24 & F $439-17-2-1-1-3$ & $97.72 *$ & 1.02 \\
\hline 42 & F $504 \mathrm{~A}-2-1-1-1$ & 97.46 * & 2.06 \\
\hline 92 & Pearl White Spanish & 96.61 & 2.50 \\
\hline 95 & Val Ga $803-1-1$ & 96.21 & 1.76 \\
\hline 30 & F $459 B-3-2-4-6-2-2$ & 95.89 & 0.86 \\
\hline 47 & F 519-4-1-1-1-3-2-B & 95.58 & 1.89 \\
\hline 54 & F $531 \mathrm{~A}-7-4-\mathrm{B}$ & 95.53 & 2.52 \\
\hline 23 & F $439-16-10-1-1$ & 95.39 & 2.49 \\
\hline 41 & F $501 \mathrm{~A}-12-1-1-1-3-1-8-\mathrm{b} 10$ & 95.20 & 2.05 \\
\hline 86 & Florunner & 94.37 & 0.88 \\
\hline 88 & Pearl Early Runner & 94.35 & 2.04 \\
\hline 21 & F $439-16-4-9-1-B 2$ & 93.65 & 1.76 \\
\hline 31 & F $459 B-3-2-4-6-3-1-1-B$ & 93.12 & 1.37 \\
\hline 20 & F $439-16-1-1-3-2-1$ & 92.89 & 2.49 \\
\hline 33 & F $476-1-1-5-1$ & 91.90 & 1.76 \\
\hline 28 & F $454-8-23-9-3-3-1-B 3$ & 91.69 & 2.03 \\
\hline 18 & F $435-2-3-1-B-B$ & 91.28 * * & 1.33 \\
\hline 40 & F $490-2-1-1-2-1-1-2-B$ & $91.20 * *$ & 2.05 \\
\hline 85 & Florigiant & $91.03 * *$ & 1.23 \\
\hline 10 & F $427 B-3-1-7-4$ & $90.97 * *$ & 1.78 \\
\hline 15 & F $427 B-V-5-B 4$ & $90.71 * *$ & 2.06 \\
\hline 17 & F $427 B-R-3-1-1-B-64$ & $90.41 * *$ & 2.49 \\
\hline 14 & F $427 \mathrm{~B}-\mathrm{V}-4-73$ & $90.36 * *$ & 2.54 \\
\hline 45 & F 519-3-1-2-1-B & 89.87 * & 2.05 \\
\hline 7 & F $420-100-2-4-1-1-4$ & 89.85 * * & 1.33 \\
\hline 83 & OT Early Bunch & $89.71 * *$ & 2.53 \\
\hline 16 & F $427 B-V-11-B$ & 88.26 ** & 1.78 \\
\hline 49 & F 520B-VAR-10-2-B & $88.03 * *$ & 2.52 \\
\hline 5 & F $393-9-5-4-2-1$ & $87.17 * *$ & 1.44 \\
\hline 4 & F $393-7-1$ & $87.09 * *$ & 1.44 \\
\hline 87 & NC-FLA 14 & $86.87 * \star$ & 2.05 \\
\hline 3 & F $393-6-3-2-2$ & $84.87 * *$ & 1.44 \\
\hline 94 & Storers Jumbo & $84.11 * *$ & 2.50 \\
\hline
\end{tabular}

*Best group of genotypes for desirable maximum values $(P<.05)$ **Best group of genotypes for desirable minimum values $(\mathrm{P}<.05)$ 
Table 6. Continued.

\begin{tabular}{|c|c|c|c|}
\hline \multirow{2}{*}{\multicolumn{2}{|c|}{$\begin{array}{l}\text { Laboratory Number and } \\
\text { Genotype }\end{array}$}} & \multicolumn{2}{|c|}{ Oil Percentage } \\
\hline & & \multicolumn{2}{|c|}{$\begin{array}{cc}\begin{array}{c}\text { Least Square } \\
\text { Mean }\end{array} & \begin{array}{c}\text { Standard } \\
\text { Error }\end{array} \\
\end{array}$} \\
\hline 18 & F $435-2-3-1-B-B$ & $52.87 *$ & 0.67 \\
\hline 88 & Pearl Early Runner & $52.65^{*}$ & 0.83 \\
\hline 3 & F $393-6-3-2-2$ & $52.47 *$ & 0.67 \\
\hline 87 & NC-FLA 14 & $51.85 *$ & 1.00 \\
\hline 6 & F $416-2$ & $51.84 *$ & 0.54 \\
\hline 19 & F $439-2-3-2-1$ & $51.76 *$ & 0.83 \\
\hline 83 & OT Early Bunch & $51.36 *$ & 1.01 \\
\hline 20 & F $439-16-1-1-3-2-1$ & $51.34^{*}$ & 0.99 \\
\hline 40 & F $490-2-1-1-2-1-1-2-B$ & $51.20 *$ & 1.00 \\
\hline 7 & F $420-100-2-4-1-1-4$ & $51.07 *$ & 0.67 \\
\hline 23 & F $439-16-10-1-1$ & $50.99 *$ & 0.99 \\
\hline 5 & F $393-9-5-4-2-1$ & $50.91 *$ & 0.67 \\
\hline 41 & F $501 \mathrm{~A}-12-1-1-1-3-1-8-\mathrm{b} 10$ & $50.80 *$ & 1.00 \\
\hline 33 & F $476-1-1-5-1$ & $50.72 *$ & 0.73 \\
\hline 21 & F $439-16-4-9-1-B 2$ & $50.68 *$ & 0.83 \\
\hline 42 & F $504 \mathrm{~A}-2-1-1-1$ & $50.62 *$ & 1.20 \\
\hline 4 & F $393-7-1$ & $50.57 *$ & 0.63 \\
\hline 28 & F $454-8-23-9-3-3-1-B 3$ & 50.54 * & 0.99 \\
\hline 47 & F 519-4-1-1-1-3-2-B & $50.55^{*}$ & 1.39 \\
\hline 30 & F $459 B-3-2-4-6-2-2$ & $50.53^{\star}$ & 0.57 \\
\hline 10 & F $427 B-3-1-7-4$ & $50.49 *$ & 0.74 \\
\hline 15 & F $427 \mathrm{~B}-\mathrm{V}-5-\mathrm{B} 4$ & $50.40 *$ & 1.00 \\
\hline 86 & Florunner & $50.25 *$ & 0.49 \\
\hline 24 & F $439-17-2-1-1-3$ & 50.24 * & 0.60 \\
\hline 85 & Florigiant & $50.23 *$ & 0.62 \\
\hline 22 & F $439-16-6-3-2$ & $50.03^{*}$ & 0.54 \\
\hline 45 & F 519-3-1-2-1-B & $49.85 *$ & 1.00 \\
\hline 95 & Val Ga $803-1-1$ & $49.79 *$ & 0.99 \\
\hline 17 & F $427 B-R-3-1-1-B-64$ & $49.75^{*}$ & 1.38 \\
\hline 31 & F $459 B-3-2-4-6-3-1-1-B$ & $49.20 * *$ & 0.76 \\
\hline 37 & F $487 A-7-10-2-B 2$ & $49.15 *$ * & 1.00 \\
\hline 92 & Pearl White Spanish & 48.82 ** & 1.00 \\
\hline 81 & $\mathrm{C} 10302 \mathrm{~A}-4-3-\mathrm{B}-1$ & $48.75 * *$ & 1.39 \\
\hline 29 & F $455-2-2$ & 48.47 ** & 0.74 \\
\hline 49 & F $520 \mathrm{~B}-\mathrm{VAR}-10-2-\mathrm{B}$ & $48.15 * *$ & 1.39 \\
\hline 94 & Storers Jumbo & $47.97 *$ * & 1.00 \\
\hline 16 & F $427 \mathrm{~B}-\mathrm{V}-11-\mathrm{B}$ & $47.30 * *$ & 1.00 \\
\hline 54 & F $531 A-7-4-B$ & $46.75 *$ * & 1.22 \\
\hline 53 & F $529 B-4-1-2$ & $45.85 * *$ & 1.39 \\
\hline
\end{tabular}

*Best group of genotypes for desirable maximum values $(\mathrm{P}<.05)$ **Best group of genotypes for desirable minimum values $(\mathrm{P}<.05)$ 
value, oil percentage and fatty acid composition were not clearly separated among the three maturity groups of peanuts or among the four commercial types. It is difficult to determine specific group relationships among the genotypes involved in this study based only on the chemical characteristics observed. This is expected in view of the fact that most of the genotypes are crosses between different commercial types and also different maturity groups.

Norden and Block (1968) pointed out that peanut varieties derived from crosses between market types do not necessarily conform in chemical composition to the parental varieties. The authors commented that it is possible to obtain from a cross between Spanish and Virginia types, for example, a Virginia type variety that has oil with a chemical composition similar to that commonly found in Spanish peanuts, as evidenced with the F 416-1 genotype.

Even though the combined results of 40 genotypes showed random distribution of the studied variables, the genotypes were subdivided in maturity groups and commercial types, and analyzed separately to investigate possible trends of maturity group and market type means. Mean square values, levels of significance, and coefficients of variation are presented in Table 7 for the different maturity groups and in Table 8 for the different commercial types. The statistical analysis of the late maturity group was compromised due to the small number of degrees of freedom 
Table 7. Mean Squares from the Analysis of Variance, and Coefficients of Variation (C.V.) of Fatty Acids, Iodine Value and Oil Percentage for the Different Maturity Groups.

$\underline{\text { Early }}$

\begin{tabular}{|c|c|c|c|c|c|c|}
\hline Source & $\mathrm{df}$ & $\begin{array}{l}\text { Palmitic } \\
\text { C16 }\end{array}$ & $\begin{array}{c}\text { Stearic } \\
\text { C18 }\end{array}$ & $\begin{array}{l}\text { Oleic } \\
\text { c18:1 }\end{array}$ & $\begin{array}{c}\text { Linoleic } \\
\text { c18:1 }\end{array}$ & $\begin{array}{c}\text { Eicosenoic } \\
\text { C20:1 }\end{array}$ \\
\hline Model & 13 & $10.1416 * \star$ & $1.1813^{*}$ * & $65.0831 * \star$ & $\star 71.6441 *$ & * $0.6385 * *$ \\
\hline Year & 8 & $5.6573^{\star}$ & 1.3553 * * & 708 ** & * 80.8814 * & $* 0.5303 * *$ \\
\hline Genotype & 5 & 4.4297 & $1.3117 *$ & $89.7300 * *$ & * $67.7961 *$ & $* 0.0827$ \\
\hline Error & 29 & 2.3058 & 0.4150 & 7.3554 & 14.0079 & 0.05762 \\
\hline C.V. & & 10.6172 & 25.5538 & 5.6332 & 13.0292 & 16.8926 \\
\hline
\end{tabular}

\begin{tabular}{lrcccc}
\hline Source & df & $\begin{array}{c}\text { Arachidic } \\
\text { C20 }\end{array}$ & $\begin{array}{c}\text { Behenic } \\
\text { C22 }\end{array}$ & $\begin{array}{c}\text { Lignoceric } \\
\text { C24 }\end{array}$ & $\begin{array}{c}\text { Iodine } \\
\text { Value }\end{array}$ \\
\hline Model & 13 & $0.6227 * *$ & $2.2636^{*}$ & $0.3445^{*}$ & $110.8570 * *$ \\
$\quad$ Year & 8 & $0.8299 * *$ & $2.1740^{*}$ & $0.4517 *$ & $161.7193 * *$ \\
$\quad$ Genotype & 5 & 0.0653 & 1.9183 & 0.1604 & 45.2029 \\
Error & 29 & 0.0388 & 0.9146 & 0.1489 & 20.3151 \\
C.V. & & 16.9403 & 35.1486 & 38.9489 & 4.8672 \\
\hline
\end{tabular}

\begin{tabular}{lrl}
\hline Source & df & \multicolumn{1}{c}{ Oil } \\
\hline Model & 10 & 5.3404 \\
$\quad$ Year & 5 & 2.3741 \\
$\quad$ Genotype & 5 & 8.4310 ** \\
Error & 14 & 1.5924 \\
C.V. & & 2.4774 \\
\hline
\end{tabular}


Table 7. Continued

Medium

\begin{tabular}{|c|c|c|c|c|c|c|}
\hline Source & $\mathrm{df}$ & $\begin{array}{c}\text { Palmitic } \\
\text { C16 }\end{array}$ & $\begin{array}{c}\text { Stearic } \\
\text { C18 }\end{array}$ & $\begin{array}{l}\text { Oleic } \\
\text { C18:1 }\end{array}$ & $\begin{array}{c}\text { Linoleic } \\
\text { C18:2 }\end{array}$ & $\begin{array}{r}\text { Iodine } \\
\text { Value }\end{array}$ \\
\hline Model & 32 & $15.8124 * *$ & $2.5213 * \star$ & 303.1563 ** & 249.8823 * * & $196.4835 *$ * \\
\hline Year & 9 & $5.1718 * \star$ & $4.6093 * *$ & 663 & 910 & 5958 ** \\
\hline Genotype & 23 & $14.9440 * \star$ & 1. $3598 * *$ & 365.6451 ** & 280.9813 ** & 5777 ** \\
\hline Error & 112 & 1.0035 & 0.3099 & 184 & 7.6133 & 1633 \\
\hline C.V. & & 8.9244 & 23.1014 & 5.6531 & 9.7627 & 2.9863 \\
\hline
\end{tabular}

\begin{tabular}{lrcccc}
\hline Source & df & $\begin{array}{c}\text { Arachidic } \\
\text { C20 }\end{array}$ & $\begin{array}{c}\text { Eicosenoic } \\
\text { C20:1 }\end{array}$ & $\begin{array}{c}\text { Behenic } \\
\text { C22 }\end{array}$ & $\begin{array}{c}\text { Lignoceric } \\
\text { C24 }\end{array}$ \\
\hline Model & 32 & $0.4338 * *$ & $0.3406 * *$ & $0.9497 * *$ & $0.9617 * *$ \\
$\quad$ Year & 9 & $1.1950 * *$ & $0.5239 * *$ & $2.2196 * *$ & $2.0662 * *$ \\
$\quad$ Genotype & 23 & 0.1024 & $0.1460 *$ & 0.3194 & $0.2410 * *$ \\
Error & 104 & 0.1402 & 0.0801 & 0.3037 & 0.1078 \\
C.V. & 29.8747 & 21.5627 & 20.6292 & 28.4992 \\
\hline
\end{tabular}

\begin{tabular}{lrc}
\hline Source & df & \multicolumn{1}{c}{ Oil } \\
\hline Model & 29 & $6.0181 * *$ \\
Year & 6 & $8.4342 * *$ \\
Genotype & 23 & $4.1388 * *$ \\
Error & 68 & 1.9144 \\
C.V. & & 2.7319 \\
\hline
\end{tabular}


Table 7. Continued

Late

\begin{tabular}{lrccccc}
\hline Source & df & $\begin{array}{c}\text { Palmitic } \\
\text { C16 }\end{array}$ & $\begin{array}{c}\text { Stearic } \\
\text { C18 }\end{array}$ & $\begin{array}{c}\text { Oleic } \\
\text { C18:1 }\end{array}$ & $\begin{array}{c}\text { Linoleic } \\
\text { C18:1 }\end{array}$ & $\begin{array}{c}\text { Eicosenoic } \\
\text { C20:1 }\end{array}$ \\
\hline Model & 13 & $2.3236 * *$ & 0.6268 & 26.9579 & $17.4222 * *$ & 0.2768 \\
$\quad$ Year & 7 & $2.2147 *$ & 0.5101 & 4.7625 & 4.2476 & 0.1367 \\
$\quad$ Genotype & 6 & 0.6967 & 0.1736 & $38.7355 *$ & $20.0541 * *$ & 0.1606 \\
Error & 7 & 0.2855 & 0.8633 & 9.0029 & 2.2772 & 0.0803 \\
C.V. & & 5.8814 & 38.8140 & 4.8022 & 7.4688 & 21.7959 \\
\hline
\end{tabular}

\begin{tabular}{lrcccc}
\hline Source & df & $\begin{array}{c}\text { Arachidic } \\
\text { C20 }\end{array}$ & $\begin{array}{c}\text { Behenic } \\
\text { C22 }\end{array}$ & $\begin{array}{c}\text { Lignoceric } \\
\text { C24 }\end{array}$ & $\begin{array}{c}\text { Iodine } \\
\text { Value }\end{array}$ \\
\hline Model & 13 & 0.2118 & 0.4686 & 0.4090 & $26.7718^{*} *$ \\
$\quad$ Year & 7 & 0.3396 & 0.3764 & $0.6528 *$ & $15.6357^{*}$ \\
$\quad$ Genotype & 6 & 0.0522 & 0.1900 & 0.1246 & $15.0194 *$ \\
Error & 7 & 0.1406 & 1.1267 & 0.1328 & 3.7095 \\
C.V. & 31.4993 & 48.0401 & 37.7031 & 2.1165 \\
\hline
\end{tabular}

\begin{tabular}{lcc}
\hline Source & df & Oil \\
\hline Model & 9 & 3.8760 \\
$\quad$ Year & 4 & 1.6875 \\
Genotype & 5 & 5.1432 \\
Error & 5 & 1.0545 \\
C.V. & & 2.0562 \\
\hline
\end{tabular}

*Significant at 0.05 level.

**Significant at 0.01 level. 
Table 8. Mean Squares from the Analysis of Variance and Coefficients of Variation (C.V.) of Fatty Acids, Iodine Value and Oil Percentage for the Different Commercial Types.

Virginia

\begin{tabular}{|c|c|c|c|c|c|c|}
\hline Source & $\mathrm{df}$ & $\begin{array}{c}\text { Palmitic } \\
\text { C16 }\end{array}$ & $\begin{array}{c}\text { Stearic } \\
\text { C18 }\end{array}$ & $\begin{array}{l}\text { Oleic } \\
\text { c18: } 1\end{array}$ & $\begin{array}{c}\text { Linoleic } \\
\text { C18:2 }\end{array}$ & $\begin{array}{r}\text { Iodine } \\
\text { Value }\end{array}$ \\
\hline Model & 26 & $32.7609 * *$ & $\times 1.842$ & 296.23 & $194.4269 *$ * & $142.0117 *$ \\
\hline Year & 9 & 6.2540 ** & 2.589 & 32.90 & 67.821 & 152.2305 * \\
\hline Genotype & 17 & $24.8177 * \star$ & * $1.2318 * *$ & 404.4248 ** & 272.8478 ** & 127.5048 * \\
\hline Error & 73 & 1.3705 & 0.3850 & 8.5615 & 11.4390 & 14.9991 \\
\hline C.V. & & 10.2735 & 23.1912 & 5.3545 & 13.5292 & 4.1978 \\
\hline
\end{tabular}

\begin{tabular}{lrcccc}
\hline Source & df & $\begin{array}{c}\text { Arachidic } \\
\text { C20 }\end{array}$ & $\begin{array}{c}\text { Eicosenoic } \\
\text { C20:1 }\end{array}$ & $\begin{array}{c}\text { Behenic } \\
\text { C22 }\end{array}$ & $\begin{array}{c}\text { Lignoceric } \\
\text { C24 }\end{array}$ \\
\hline Model & 26 & $0.5809 * *$ & $0.4653 * *$ & 0.9374 & $0.6586 * *$ \\
$\quad$ Year & 9 & $1.4011^{*} *$ & $0.5112 * *$ & $1.4984 *$ & $1.3112 * *$ \\
$\quad$ Genotype & 17 & 0.1604 & $0.1612^{*}$ & 0.4789 & 0.2318 \\
Error & 66 & 0.1582 & 0.0839 & 0.6872 & 0.1598 \\
C.V. & 32.5298 & 20.8132 & 32.3124 & 40.1003 \\
\hline
\end{tabular}

\begin{tabular}{lrc}
\hline Source & df & \multicolumn{1}{c}{ Oil } \\
\hline Model & 21 & $7.0393 * \star$ \\
$\quad$ Year & 5 & $7.8737 * \star$ \\
Genotype & 16 & $6.6279 *$ \\
Error & 49 & 1.9059 \\
C.V. & & 2.7261 \\
\hline
\end{tabular}


Table 8. Continued.

Runner

\begin{tabular}{|c|c|c|c|c|c|c|}
\hline Source & $d f$ & $\begin{array}{c}\text { Palmitic } \\
\text { C16 }\end{array}$ & $\begin{array}{c}\text { Stearic } \\
\text { C18 }\end{array}$ & $\begin{array}{l}\text { Oleic } \\
\text { C18:1 } \\
\end{array}$ & $\begin{array}{c}\text { Linoleic } \\
\text { C18:2 }\end{array}$ & $\begin{array}{c}\text { Iodine } \\
\text { Value }\end{array}$ \\
\hline Mode1 & 24 & $9.6687 * *$ & 1.2812 * & 187.5219 & $155.0354 * * 1$ & 106.8266 ** \\
\hline Year & 9 & $5.3361 * *$ & $2.6830 *$ & 13.4144 & 25.2334 ** & 73.5654 ** \\
\hline Genotype & 15 & $9.0719 * *$ & 0.4165 & 235.4717 * & $\star 172.5665$ ** & 97.2179 * * \\
\hline Error & 71 & 0.9907 & 0.3337 & 8.4285 & 7.1857 & 7.5197 \\
\hline C.V. & & 8.5352 & 26.8933 & 5.8190 & 8.9619 & 2.8237 \\
\hline
\end{tabular}

\begin{tabular}{lrlccc}
\hline $\begin{array}{l}\text { Source } \\
\text { df }\end{array}$ & $\begin{array}{c}\text { Arachidic } \\
\text { C20 }\end{array}$ & $\begin{array}{c}\text { Eicosenoic } \\
\text { C20:1 }\end{array}$ & $\begin{array}{c}\text { Behenic } \\
\text { C22 }\end{array}$ & $\begin{array}{c}\text { Lignoceric } \\
\text { C24 }\end{array}$ \\
Model & 24 & $0.2704 * *$ & $0.2488^{* *}$ & $0.8994^{* *}$ & $0.8530 * *$ \\
Year & 9 & $0.4840^{* *}$ & $0.3452^{* *}$ & $1.3064 * *$ & $1.4419 * *$ \\
$\quad$ Genotype & 15 & 0.0354 & 0.0616 & 0.2973 & $0.1873^{* *}$ \\
Error & 70 & 0.0530 & 0.0638 & 0.2671 & 0.0736 \\
C.v. & & 18.7185 & 19.6548 & 19.5930 & 22.7132 \\
\hline
\end{tabular}

\begin{tabular}{lrl}
\hline Source & df & \multicolumn{1}{c}{ Oil } \\
\hline Model & 21 & $5.0389 * *$ \\
Year & 6 & $9.0703 * \star$ \\
Genotype & 15 & $2.8734 * *$ \\
Error & 36 & 0.9709 \\
C.V. & & 1.9506 \\
\hline
\end{tabular}

Continued 
Table 8. Continued.

Spanish

\begin{tabular}{|c|c|c|c|c|c|c|}
\hline Source & $d f$ & $\begin{array}{c}\text { Palmitic } \\
\text { C16 }\end{array}$ & $\begin{array}{c}\text { Stearic } \\
\text { C18 }\end{array}$ & $\begin{array}{l}\text { Oleic } \\
\text { C18: } 1\end{array}$ & $\begin{array}{c}\text { Linoleic } \\
\text { C18: } 2\end{array}$ & $\begin{array}{l}\text { Iodine } \\
\text { Value }\end{array}$ \\
\hline Model & 7 & 0.9596 & 1.1875 & 21.6171 * & 32.6922 & $40.8889 * *$ \\
\hline Year & 6 & 1.1177 & 1.0031 & 3.6495 & 8.7745 & $27.0357 *$ * \\
\hline Genotype & 1 & 0.2025 & 3.6100 & 115.5625 ** & $* 79.2100 *$ & $25.0000 * *$ \\
\hline Error & 1 & 0.4225 & 0.4900 & 0.0225 & 0.4900 & 0.0001 \\
\hline C.V. & & 4.9118 & 24.5136 & 0.3065 & 2.4287 & 0.0000 \\
\hline
\end{tabular}

\begin{tabular}{lccccc}
\hline Source & df & $\begin{array}{c}\text { Arachidic } \\
\text { C20 }\end{array}$ & $\begin{array}{c}\text { Eicosenoic } \\
\text { C20:1 }\end{array}$ & $\begin{array}{c}\text { Behenic } \\
\text { C22 }\end{array}$ & $\begin{array}{c}\text { Lignoceric } \\
\text { C24 }\end{array}$ \\
\hline Model & 7 & 0.4539 & 0.5917 & 2.2413 & $0.3679 * *$ \\
$\quad$ Year & 6 & 0.5196 & 0.3767 & 2.0090 & 0.4081 * \\
$\quad$ Genotype & 1 & 0.0225 & 0.1600 & 0.0900 & 0.0001 \\
Error & 1 & 0.0625 & 0.0400 & 0.1600 & 0.0001 \\
C.V. & & 22.7273 & 17.3077 & 14.3426 & 0.0000 \\
\hline
\end{tabular}

\begin{tabular}{lcc}
\hline Source & df & Oil \\
\hline Model & 7 & $7.5144^{*}$ \\
Year & 6 & $0.9315^{*}$ \\
Genotype & 1 & $14.0625^{\star} \star$ \\
Error & 1 & 0.0025 \\
C.V. & & 0.0968 \\
\hline
\end{tabular}

*Significant at 0.05 level. $\star \star$ Significant at 0.01 level. 
for the error term. The same is true for the Spanish commercial type. No statistical analysis could be done in the Valencia type since only one genotype was tested.

Significant differences among genotypes were observed in the early maturity groups for stearic $(P<0.05)$, oleic and linoleic acids and for oil content $(P<0.01)$. Yearly differences were statistically significant for all variables except oil percentage. Coefficients of variation were low for oil, iodine value and oleic acid, and high for stearic, behenic and lignoceric acids. Coefficients of variation were medium for palmitic, linoleic, eicosenoic and arachidic acids.

Medium maturity group genotype effects were significant for all variables, except arachidic and behenic acids. Year effects were significant for all variables analyzed. The same trends among coefficients of variation found in the earlier types were found in this group, although lower values were observed for all responses.

Significant differences were found among the genotypes of the late maturity group for the variables oleic and linoleic acids and iodine value. Significant year effects were detected only for palmitic and lignoceric acids and iodine value. Coefficients of variation were smaller than those for the early and medium groups for palmitic, oleic and linoleic acids, as well as iodine value and oil percentage. Very high coefficients of variation were found for stearic, arachidic, behenic and lignoceric fatty acids. 
Table 9 presents the means of all the variables for maturity groups and commercial types. Although not statistically analyzed, early maturity genotypes seem to have larger percentages of palmitic, stearic, eicosenoic and behenic acids and oil contents in comparison with the medium and late maturity groups. The amount of palmitic acid, for example, was $27.42 \%$ larger than for the medium maturity group, and $57.42 \%$ higher than the late maturity group. The increase in oil content was only $0.57 \%$ in relation to the medium group, and $1.99 \%$ larger than the late genotypes.

Late maturing genotypes had a larger amount of oleic acid and less linoleic acid than the early and medium maturity groups. Oleic acid was $29.78 \%$ larger than the early maturing genotypes, and 21.028 larger than the medium maturity genotypes. On the other hand, linoleic acid, in the same group, was $29.66 \%$ less than the early maturity group, and $28.51 \%$ less than the medium maturing genotypes. Due to this inverse relationship, the iodine value of the late maturing genotypes was considerably lower than that found for the two other maturity groups: $1.73 \%$ less than the earlier genotypes, and $4.89 \%$ less than the medium maturing genotypes. These findings are in agreement with the results reported by Worthington and coworkers (1972). They pointed out that the late maturing large seeded varieties, most of them from the Virginia type, were higher in oleic and lower in linoleic than the earlier maturing types. 
Table 9. Mean Oil Composition of Peanut Genotypes for the Different Maturity Groups and Commercial Types.

\begin{tabular}{lrrr}
\hline \multirow{2}{*}{ Variables } & \multicolumn{3}{c}{ Maturity Group } \\
\cline { 2 - 4 } Palmitic & 14.30 & Medium & Late \\
Stearic & 2.52 & 11.22 & 9.09 \\
Oleic & 48.14 & 2.41 & 2.46 \\
Linoleic & 28.73 & 51.63 & 62.48 \\
Arachidic & 1.16 & 28.26 & 20.20 \\
Eicosenoic & 1.42 & 1.25 & 1.19 \\
Behenic & 2.72 & 1.31 & 1.30 \\
Lignoceric & 0.99 & 2.67 & 2.21 \\
Iodine Value & 92.60 & 1.15 & 0.97 \\
Oil Content & 50.94 & 95.68 & 91.00 \\
& & 50.65 & 49.94 \\
\hline
\end{tabular}

\begin{tabular}{lrrrr}
\hline \multirow{2}{*}{ Variables } & \multicolumn{4}{c}{ Commercial } \\
\cline { 2 - 5 } Virginia & Runner & Spanish & Valencia \\
\hline Palmitic & 11.40 & 11.66 & 13.23 & 13.83 \\
Stearic & 2.66 & 2.15 & 2.86 & 2.76 \\
Oleic & 54.65 & 49.89 & 48.94 & 43.45 \\
Linoleic & 25.00 & 29.91 & 28.82 & 31.70 \\
Arachidic & 1.22 & 1.23 & 1.10 & 1.58 \\
Eicosenoic & 1.39 & 1.29 & 1.16 & 1.58 \\
Behenic & 2.57 & 2.64 & 2.79 & 3.78 \\
Lignoceric & 1.00 & 1.19 & 1.02 & 1.33 \\
Iodine Value & 92.26 & 97.11 & 93.56 & 93.75 \\
Oil Content & 50.64 & 50.51 & 51.63 & 49.50
\end{tabular}


Analysis of variance of commercial types showed large genotype effects, especially for oleic and linoleic acids, while year effects were more pronounced in the minor fatty acids (C18, C20, C20:1, C22 and C24). Year effects on oil percentage were highly evident on Runner and Virginia type peanuts, but very small year effects were found in the Spanish genotypes.

As evidenced in Table 9, although not statistically analyzed, the Spanish and Valencia commercial types appear to have higher amounts of palmitic, stearic and behenic acids in relation to the others. Linoleic acid contents were larger in Valencia type peanuts in comparison to the other types (5.98 to $26.81 \%$ higher). On the other hand, oleic acid was comparatively lower (11.23 to $20.49 \%$ lower). Worthington and Holley (1967) reported similar variation among the commercial types.

Oil percentage showed small variation among the different market types as well as among the different maturity groups.

Iodine values were especially high for the Runner genotypes in comparison with all others. These results contradict findings by Pickett and Holley (1951) and Fore et al. (1953). Those authors pointed out that oils from Runner genotypes contained less linoleic acid and had higher stabilities than oils from Spanish or Virginia market types. The major reason for the difference in results seems to be the different genetic background of the genotypes used by 
those authors in comparison with the ones investigated in this study. Another possible explanation for the results found could be related to maturity of the peanut seeds. Young et al. (1972b) and Sanders (1980b) reported that oleic acid content increased with maturity, while linoleic acid decreased in mature peanut seeds. Although early genotypes were harvested 7 to 12 days in advance to the other genotypes, all harvesting was complete after 125 to 130 days (Table 2). Thus, Runner genotypes, generally of medium late (131 to 140 days) to late maturing (141 to 150 days) cycles, appear to be harvested in this study before complete maturation, which could be responsible for the high iodine value found.

Virginia genotypes had larger amounts of oleic acid (9.54 to $25.78 \%$ more) and lower amounts of linoleic acid (13.25 to $21.14 \%$ less) in comparison to the other market types. Similar results were found in an earlier paper (Jamieson et al., 1921) and were confirmed by others (Pickett and Holley, 1951; Fore et al., 1953; Freeman et al., 1954).

Although the subdivision of the data in maturity groups or commercial types does not fit for all genotypes, general trends, like the ones pointed out, are still visible within groups. As the time passes, distinction of maturity groups and market types based on chemical characteristics of the seeds will be less evident due to the complete intercross 
compatibility of the four market types and the three maturity groups. Evidences that this is already occurring can be found in a recent bulletin (Mozingo et al., 1982), where no trends in oil composition among market types or maturity groups could be detected, especially anong the newer genotypes.

The previously described modified Gupta's test was used for variables that were statistically significant by the $F$ test. Table 10 shows the least square means, standard errors and genotype grouping for the different maturity groups. The same information is presented in Table 11 for the three commercial types. No test was applied for Valencia type, since there was only one genotype.

Based on the approximate statistical test, the best genotype from the industrial standpoint in the early maturity group is OT Early Bunch. A late maturing genotype with good industrial quality is Storers Jumbo. Medium maturity genotypes with a higher level of saturation include lines derived from F 393 (including NC-FLA 14) and F $420-100-2-4-1-1-4$.

The best genotypes from the nutritional standpoint are Pearl White Spanish, Val Ga 803-1-1 and genotypes derived from $F$ 459B, for the early maturity group. Best late maturing genotypes include genotypes derived from F 427B and F 476-1-1-5-1. Genotypes F 439-2-3-2-1, F439-16-6-3-2, C10302A-1-2-4-5-B, F 416-2 and F 455-2-2 in the medium 

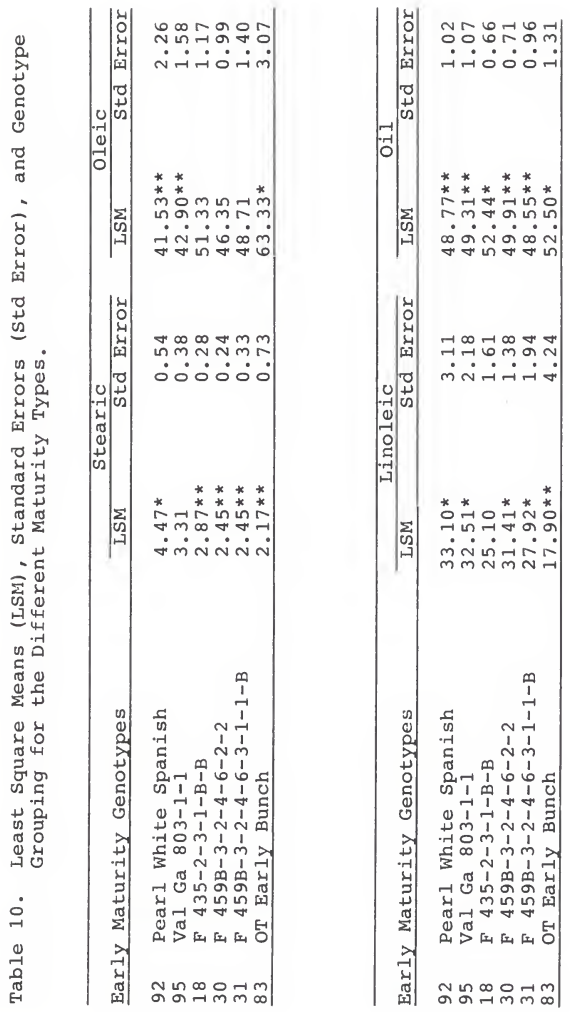
" m N

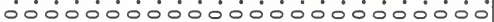

* * * * * * * * * * * * * * * * * * * * * $* * * *$

******************* ************* $*^{*} *^{*}$

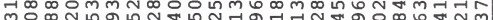
. . . . . . . . . . . .

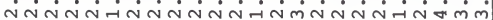

Hก L G

- $\dot{0} \dot{0} \dot{0} \dot{0} \dot{0} \dot{0} \dot{0} \dot{0} \dot{0} \dot{0} \dot{0} \dot{0} \dot{0} \dot{0} 0$

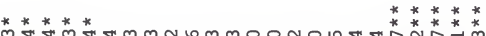

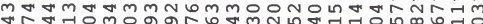
. . . . . . . . . . . . ? *mmm N

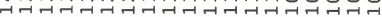


NaNNNNHN

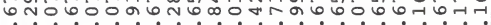

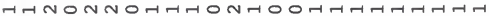

$* * * *$

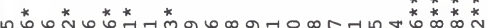
ט m N - . . . . . . . . . . . . . . . H. $m M N M N M N N N$ N $N$ N N N N N N

$\infty \omega \sigma \pi$ \%

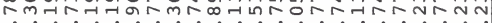

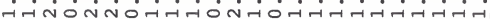

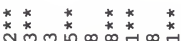

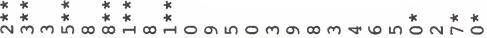

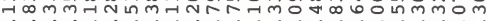

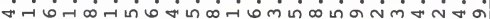
垱

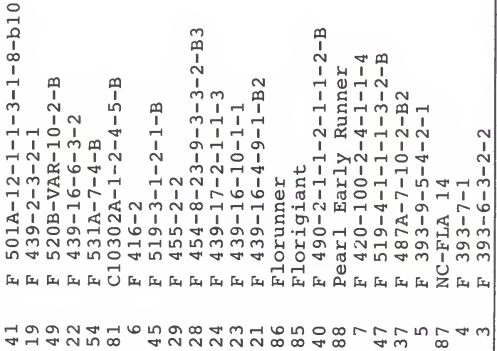




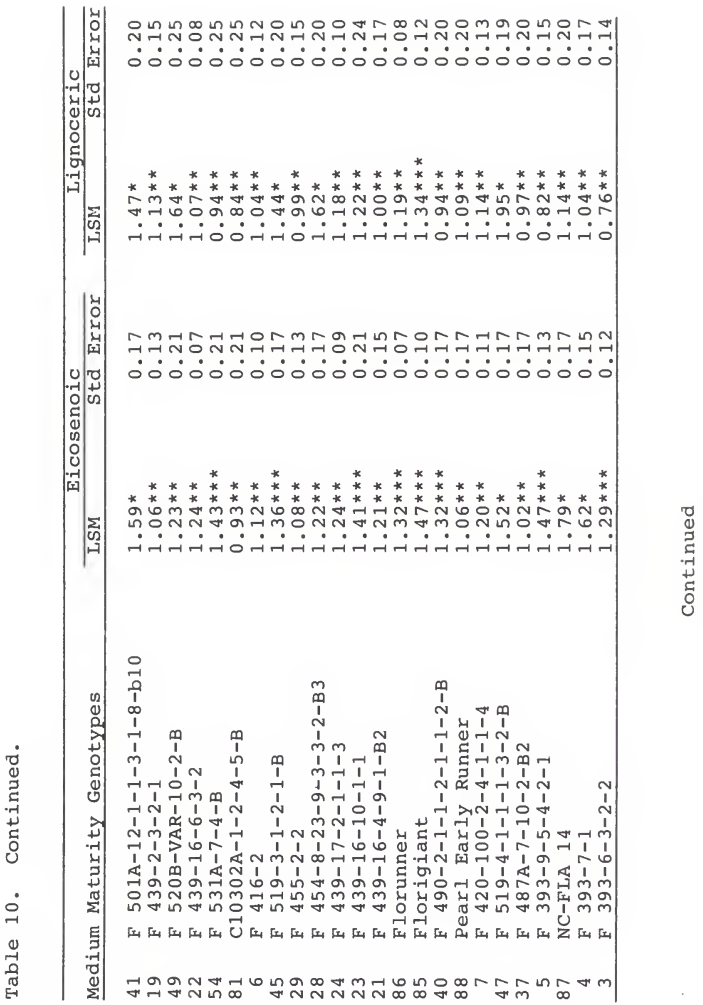




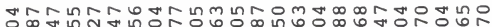

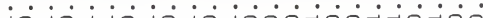
rono-70

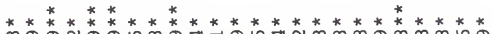

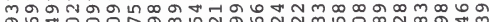
?. . ? ? ? ? ? ? ? ? ?

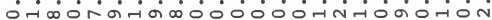

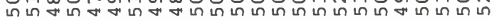

$m m \forall G \forall \forall \forall m m-n N N m N m-1-1 m-1 m-0$ mm-

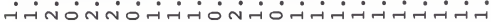

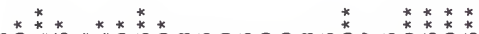

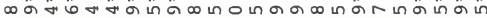

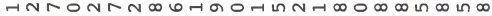

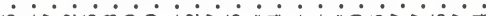

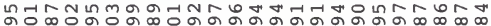
क임

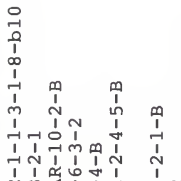

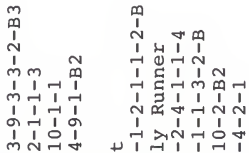

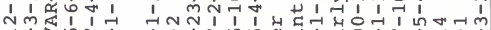
$\rightarrow 1>6 \pi 1$ I 1 I 尔尚

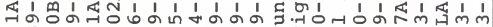

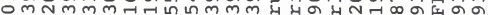

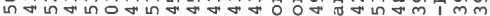

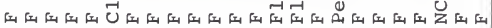
귬ำ 

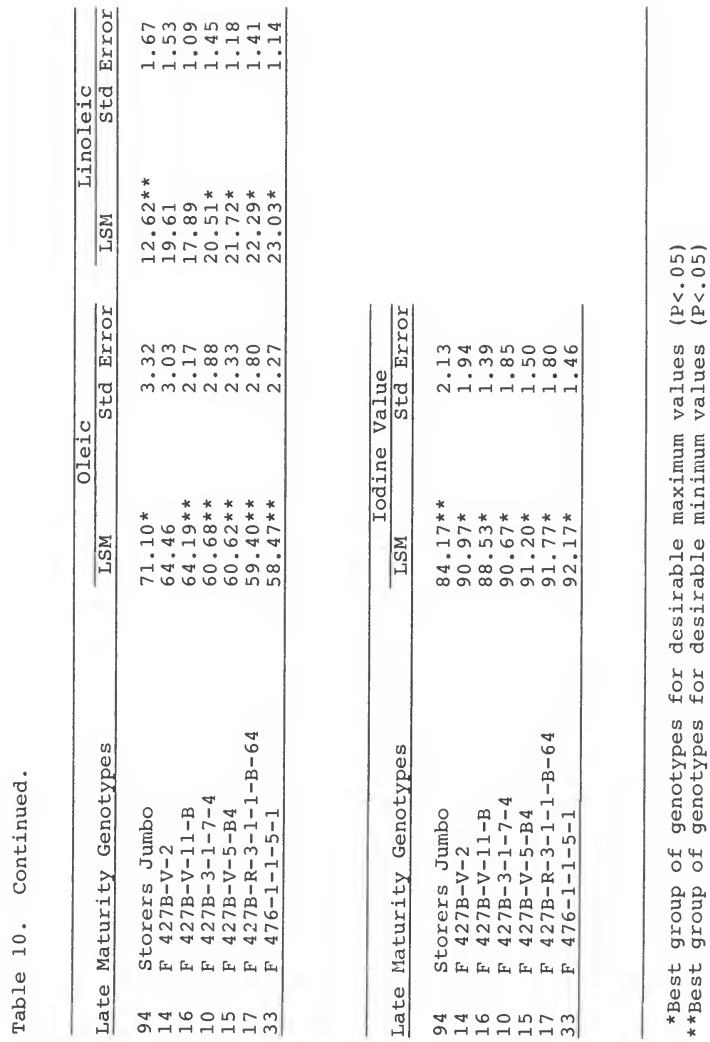


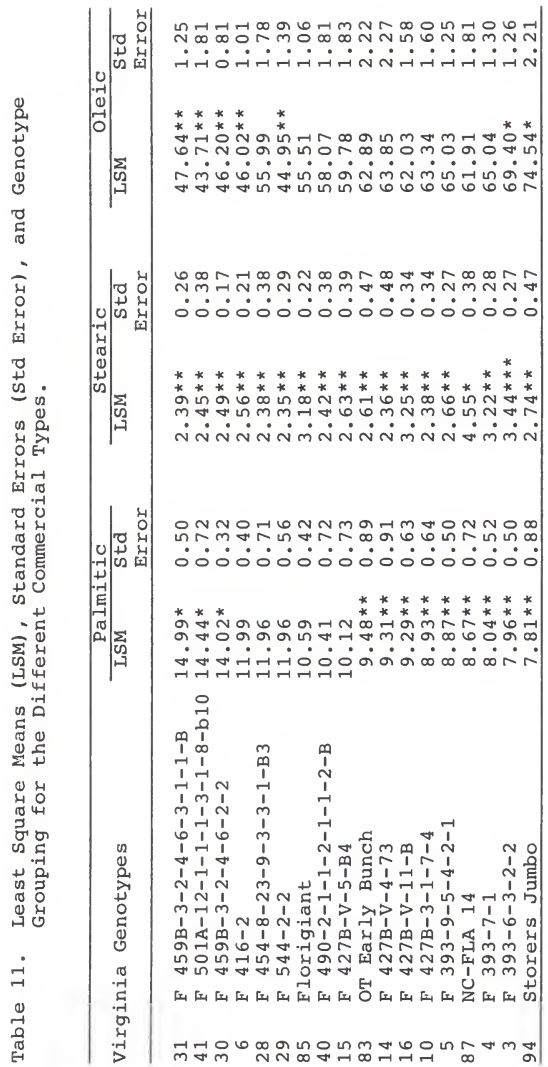




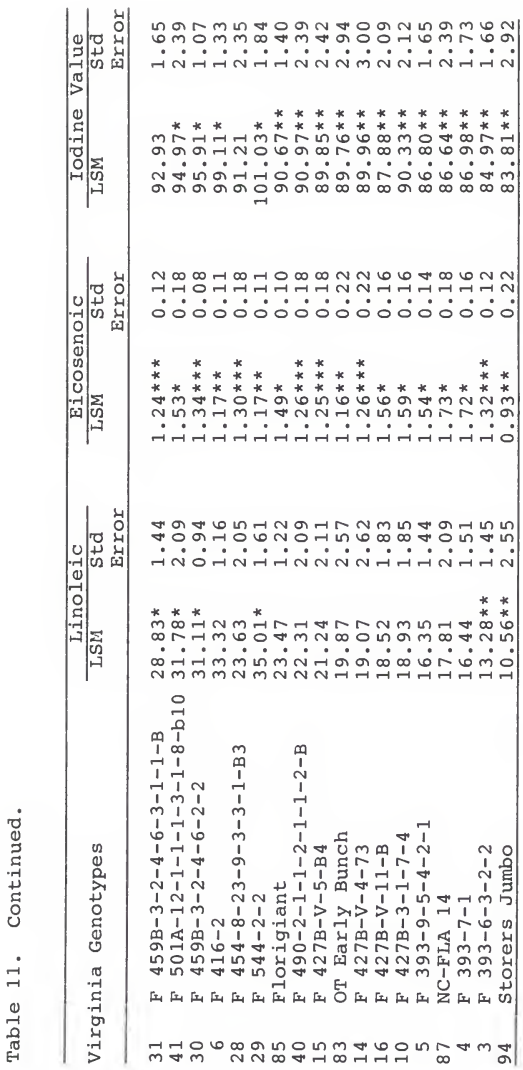




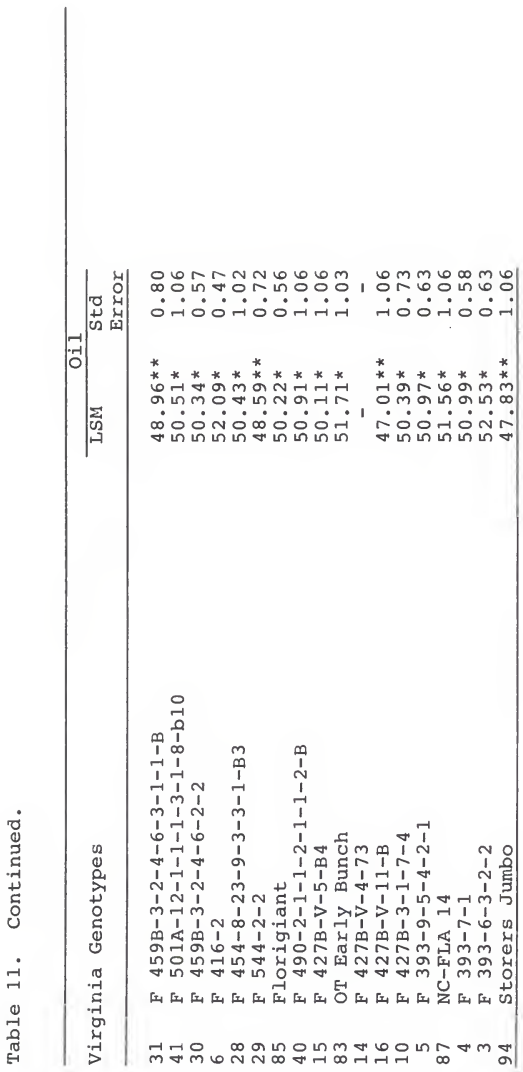




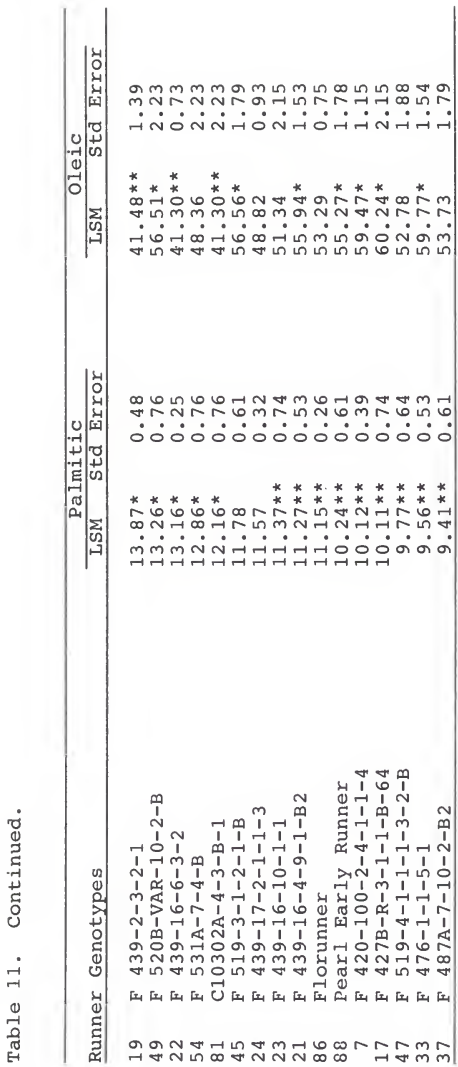




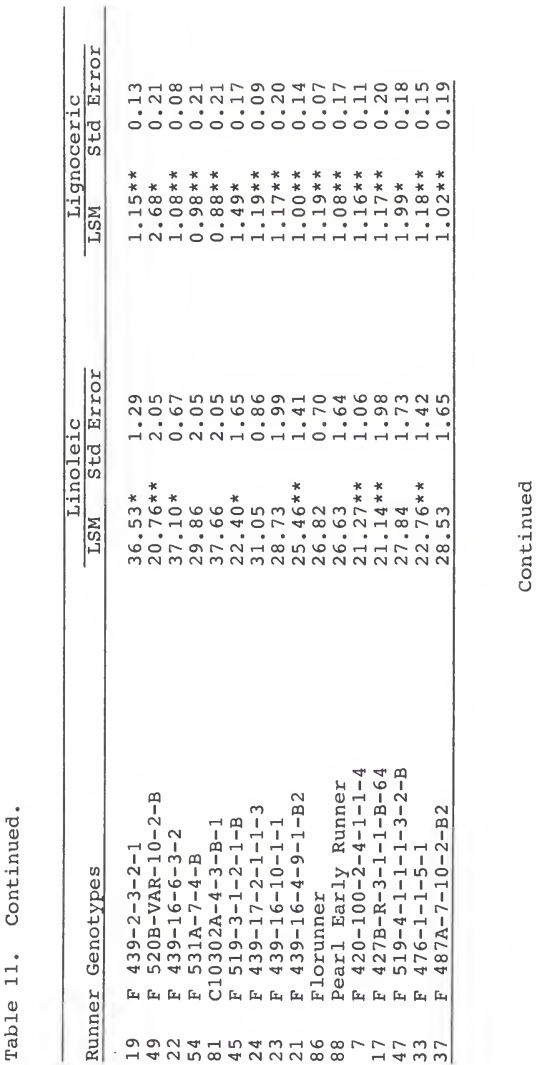




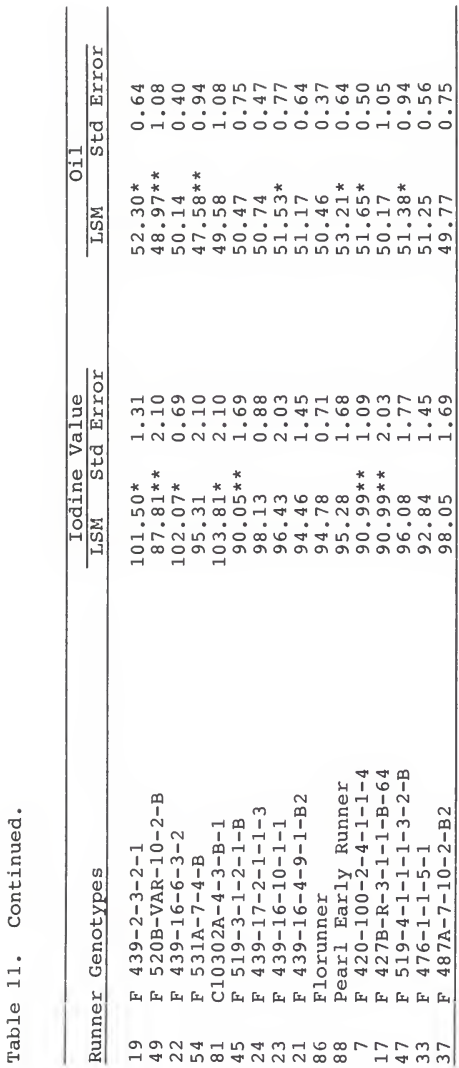




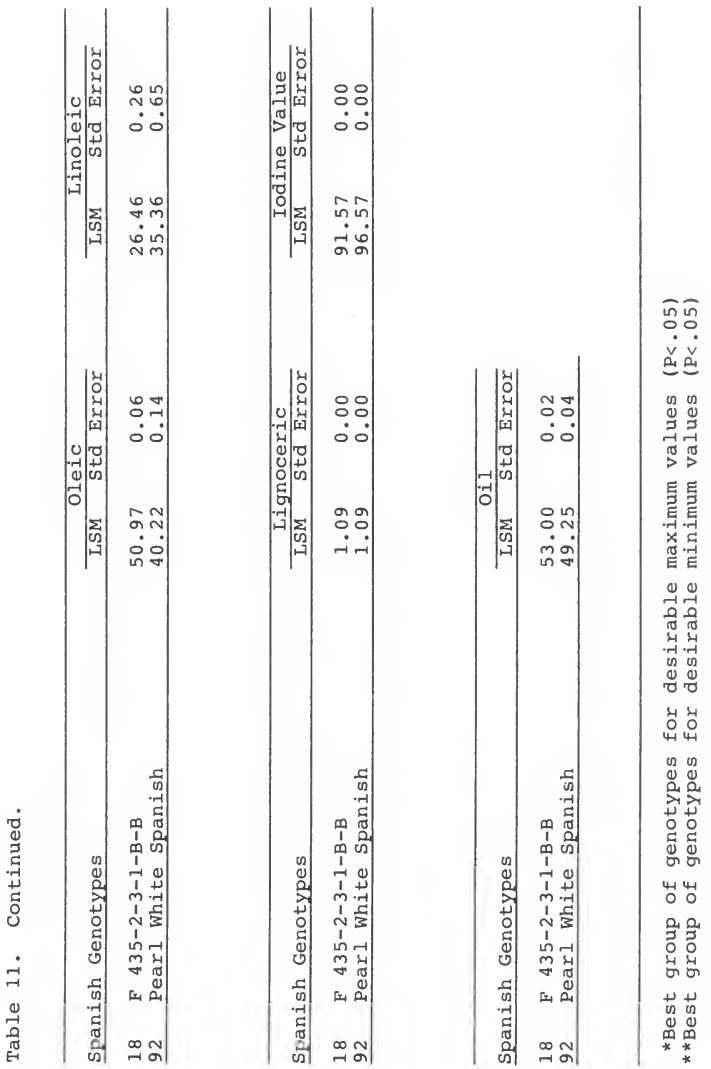


maturity group can be considered superior in nutritional oil qualities.

Within the commercial types, the best genotypes in relation to industrial quality are Florigiant, F 490-2-1-1-2-1-1-2-B, genotypes derived from F 427B, OT Early Bunch, genotypes derived from F 393 (including NC-FLA 14) and Storers Jumbo (Virginia types). In the Runner types the best group of genotypes include F 520B-VAR-10-2-B, F 519-3-1-2-1-B, F 420-100-2-4-1-1-4 and F $427 \mathrm{~B}-\mathrm{R}-3-1-1-\mathrm{B}-64$.

The best genotypes from the dietary standpoint are F 544-2-2, F 459B-3-2-4-6-2-2 and F 416-2 in the Virginia group. Runner genotypes considered nutritionally best include F 439-2-3-2-1, F 439-16-6-3-2 and F 519-3-1-2-1-B.

F 435-2-3-1-B-B, a Spanish genotype, is better for industrial quality than Pearl White Spanish. This last one is consequently better than the former from a dietary standpoint.

The results presented here indicated that in each of the three principal commercial types (Virginia, Runner and Spanish) there is high variability in relation to fatty acid composition, iodine value and oil percentage. It should be possible to select from each group, genotypes that best suit industrial or dietary qualities. Breeding programs need not be restricted to just one type, since every commercial type presented enough variability to select for desirable chemical characteristics. The same is true when comparing 
the best genotypes in the different maturity groups. Khan and coworkers (1974) found a similar pattern of variation among commercial types when studying fatty acid composition of segregating populations derived from infraspecific peanut crosses.

Subdivided and combined data, in general, showed highly significant year effects. Seasonal variation has been extensively reported (Eheart et al., 1955; Holley and Hammons, 1968; Worthington et al., 1972; Tai, 1972) and has been related, at least in part, to temperature and moisture conditions. Attempts to find significant relationships between these parameters have generally failed, mainly due to the indeterminate growth habit of the species and the underground fruit formation and development.

In order to investigate possible associations of temperature, rainfall and the yearly variation of fatty acid composition, iodine value and oil content, correlation coefficients were calculated involving these variables and climatic parameters during the period of pegging formation until harvest.

Correlation coefficients were calculated for the combined data, and later among different maturity groups and commercial types. Results and levels of significance are presented in Tables 12, 13 and 14. The true numbers of observations are less than the ones reported, in view of the fact that the year-temperature-rainfall axis has the same value for all genotypes. Thus, correlation coefficients are biased downward. 


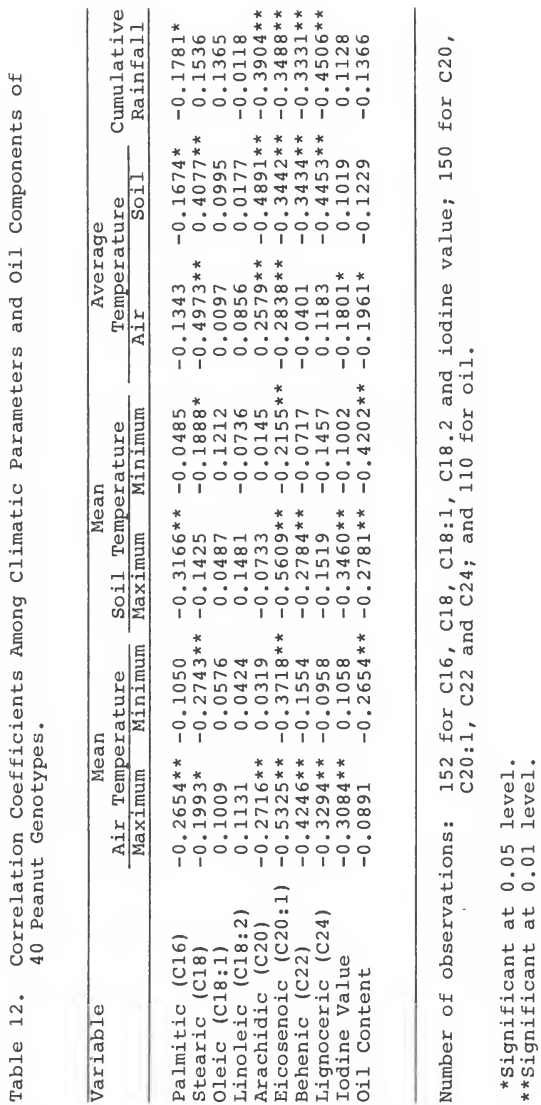




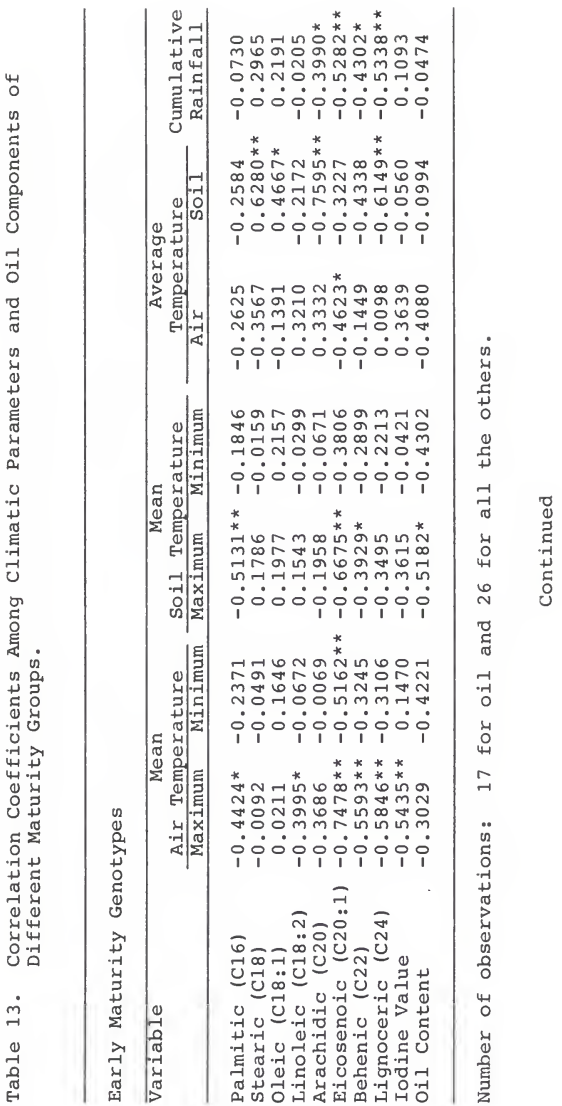




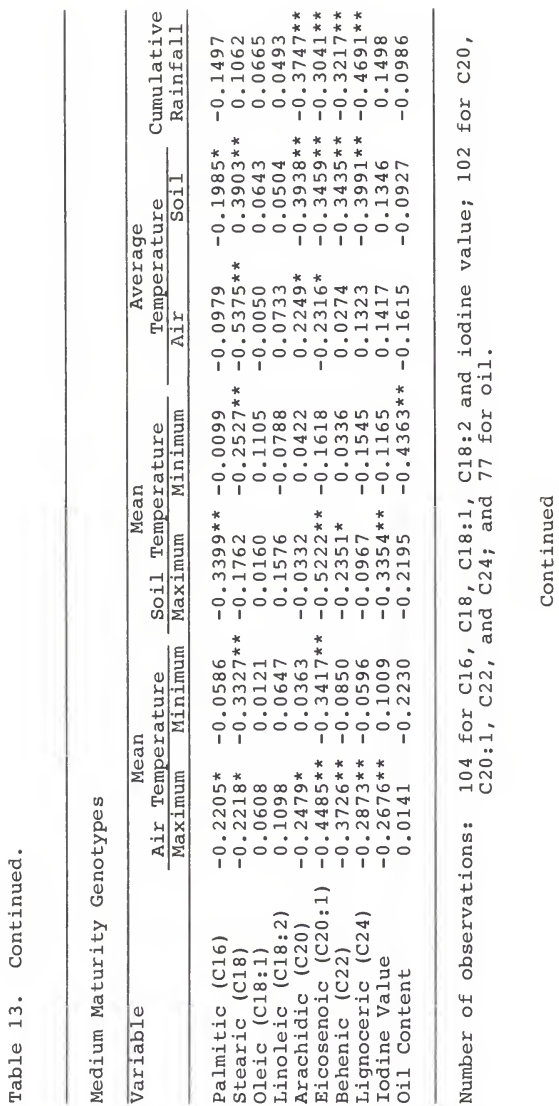




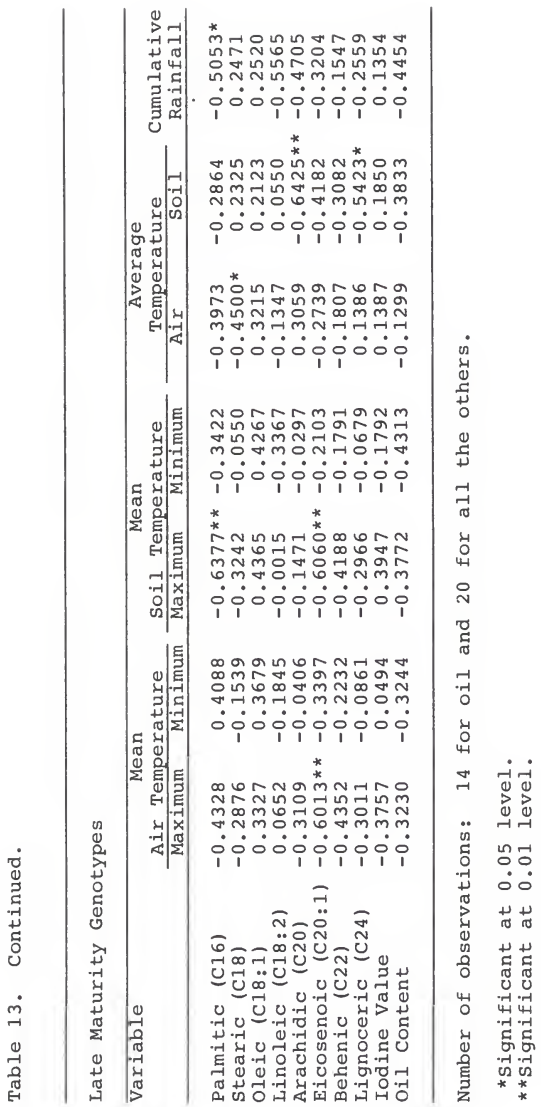




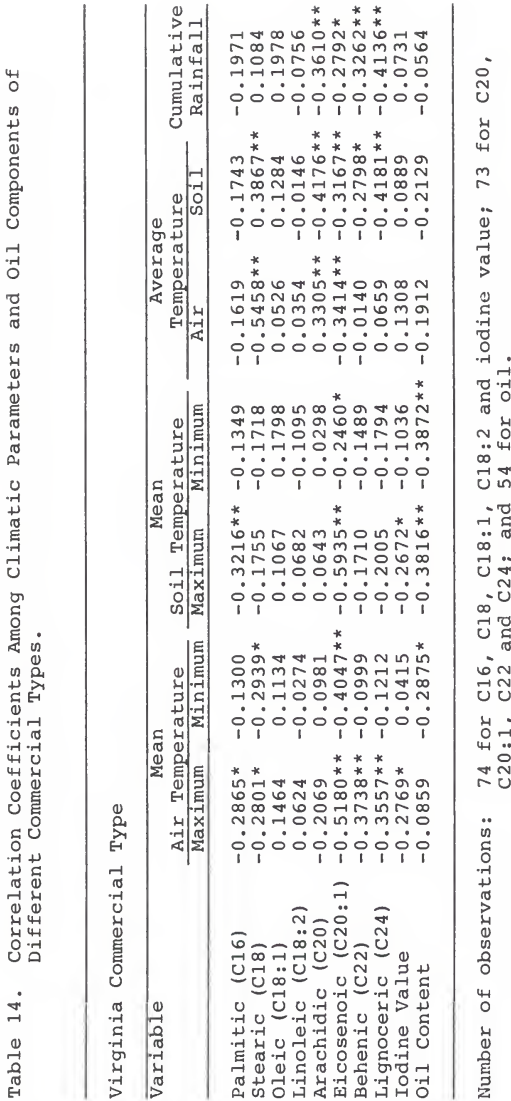




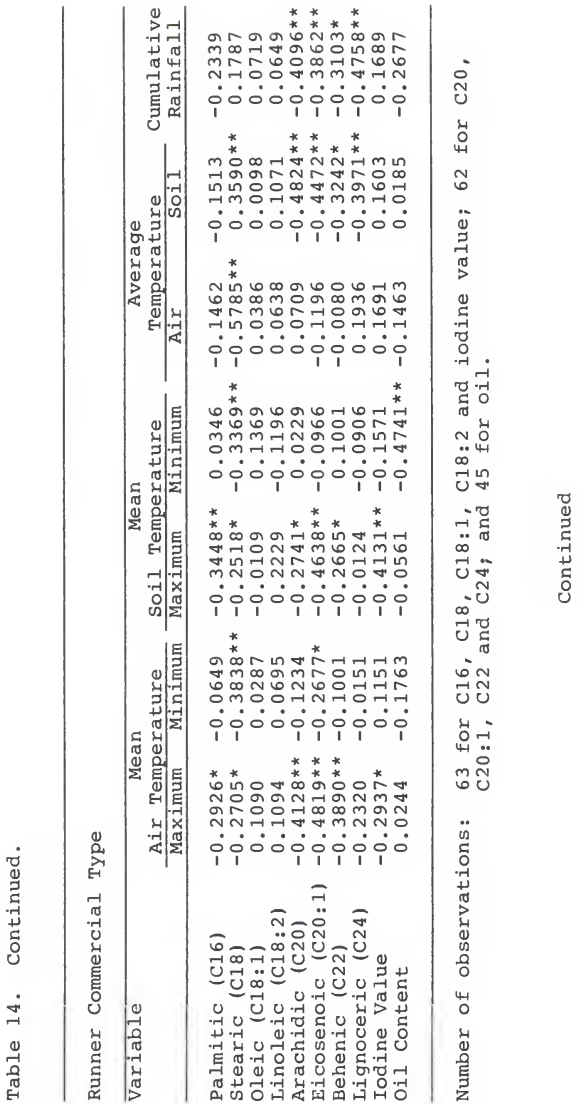




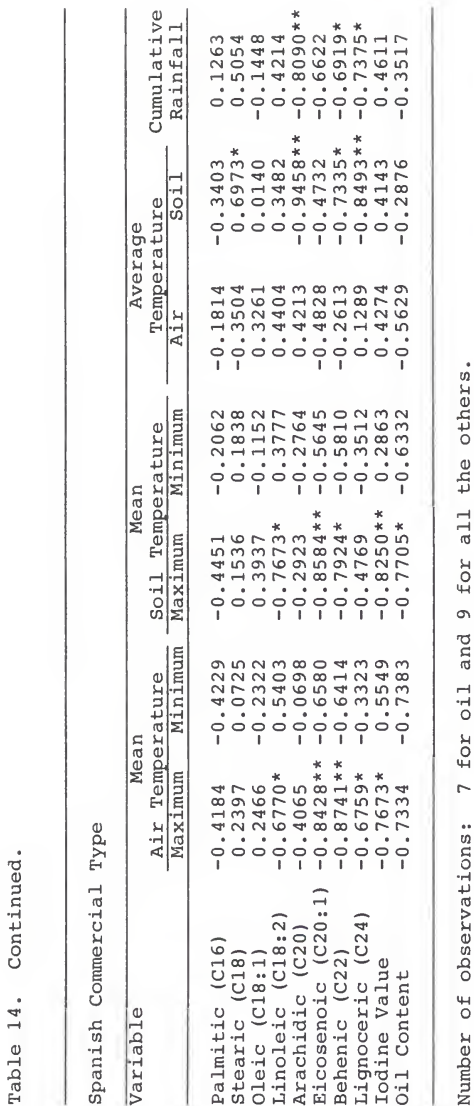

ปี 


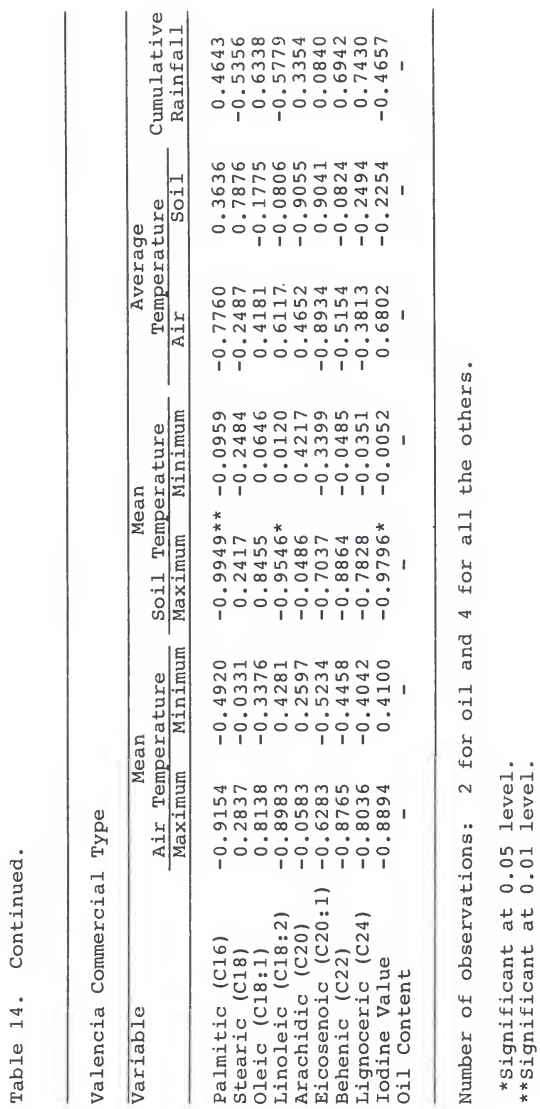


Iodine value showed negative correlation coefficients with maximum air and soil temperatures, and also with average air temperature for the combined data. Maximum air and soil temperatures also presented good associations with iodine value for the different maturity groups and commercial types. Late genotypes showed no significant correlation coefficients involving climatic parameters and iodine value. Early maturing genotypes presented a statistically significant association of iodine value only with maximum air temperature.

The negative correlation coefficients found for iodine value and temperature parameters seem to indicate that as the air and soil temperatures increased the iodine values of the genotypes decreased. Thus, peanut varieties grown in cooler regions might be expected to have higher iodine values than when grown in warmer climates. Indications that this in fact occurs are provided in a recent bulletin by Mozingo et al. (1982). The authors reported higher iodine values for Florigiant and UF 75102 (F 519) genotypes, grown in Virginia and North Carolina in comparison with the results reported here. Moreover, in data involving two locations, a higher iodine value is reported for all genotypes in the cooler location (Virginia) than in the warmer region (North Carolina). Two-year data also show significant differences for all genotypes in oil composition. The 1981 crop had always higher iodine values than the 1980 crop. The only climatic parameter given was 
rainfall, thus no comparisons of the results based on temperature differences were possible.

Oil percentage showed negative correlations with minimum air temperature, maximum and minimum soil temperatures and average air temperature for the combined data. Subdivision of the genotypes indicates negative correlations between oil and some of the mentioned parameters. No correlation involving oil content was significant for the late maturing genotypes.

The negative correlation coefficients found for oil percentage appear to indicate that higher temperatures from pegging until harvest (especially maximum and minimum soil temperatures) should result in genotypes with less oil content than the ones under cooler temperatures during the same period. These findings are in agreement with Mozingo et al. (1982), who reported that Florigiant, Keel 29 and NC 17941 genotypes grown in North Carolina had less oil than when grown in Virginia.

Oleic and linoleic acids, in general, did not show any significant correlation with climatic parameters, except in the early maturity genotypes, where oleic was positively correlated with average soil temperature, while linoleic showed a negative correlation with maximum air temperature. Cumulative rainfall showed significant negative associations with the minor fatty acids, C18, C20, C20:1, C22 and C24. No significant correlations of rainfall with iodine value and oil percentage were found. 
The subdivision of the data by commercial type showed a similar pattern of association among climatic parameters and oil composition components.

Stearic acid (C18) had a consistent, statistically significant, positive correlation with average soil temperature, although for all other temperature parameters significant negative values were found. No explanation could be found for this phenomenon in the literature (Kirschenbauer, 1960; Hilditch and Williams, 1964; Applequist, 1975; and Robinson, 1980).

All other statistically significant correlation coefficients presented in Tables 12,13 and 14 are negative, appearing to indicate that increases in temperature are associated with decreases in fatty acids, oil content and iodine value. Eicosenoic acid (C20:1) seemed to be particularly associated with temperature and rainfall parameters. From the results presented here it might be inferred that altering planting dates within a region could alter the chemical composition of peanut genotypes.

Correlations among fatty acids were also calculated to measure the degree of association among oil components. Values and levels of significance are presented in Table 15. A highly significant $(P<.01)$ negative association between oleic and linoleic acid was found. Several authors have reported the same association (Holley and Hammons, 1968; Worthington and Hammons, 1971; Khan et al., 1974; Sekhon et al. , 1980). 


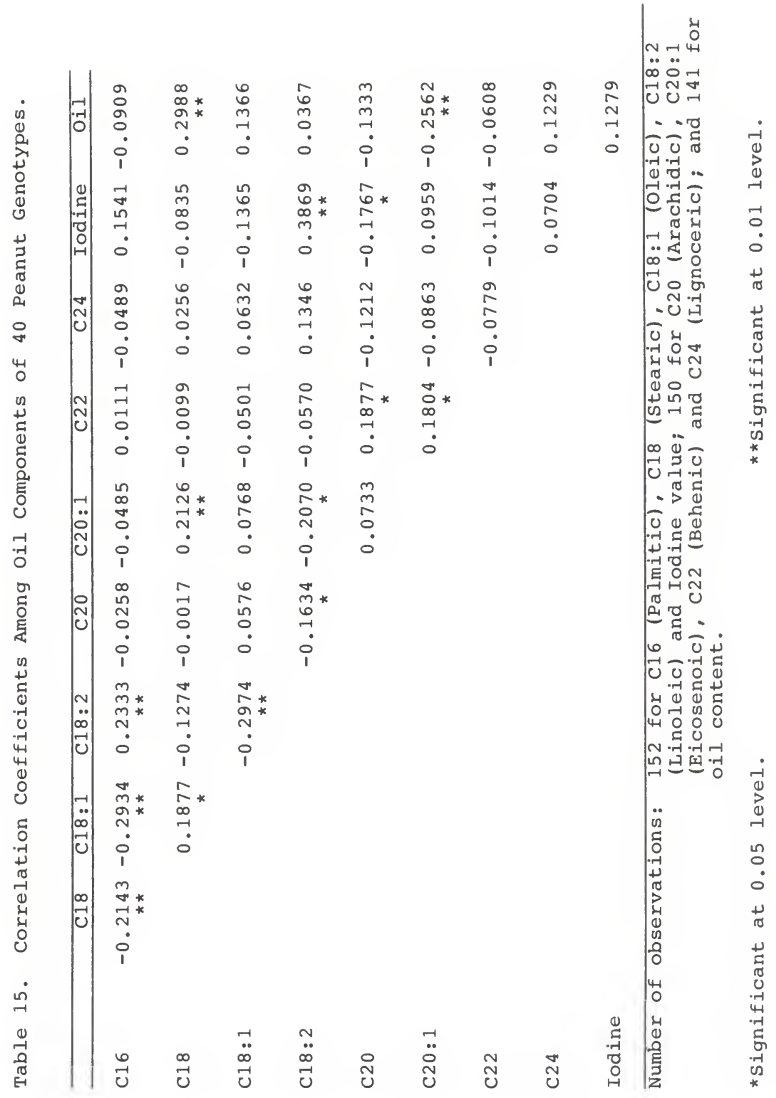


Considering the other fatty acids, results showed that there was a significant positive correlation involving palmitic and linoleic acids, while linoleic had significant negative correlations with arachidic and eicosenoic acids. Behenic was positively associated with arachidic and eicosenoic, while lignoceric acid did not show any meaningful association with the other oil components. Iodine value presented a strong positive correlation with linoleic acid, and a negative $(\mathrm{P}<.05)$ association with arachidic acid.

Oil percentage was positively associated with stearic and negatively associated with eicosenoic acid.

Selection for lower levels of linoleic acid, to increase the stability and shelf-life of peanut products, might be expected to result in a lower level of palmitic acid and a higher level of oleic acid. An increase in the amounts of arachidic and eicosenoic acid might also occur due to the negative association involving these parameters. Selection of low linoleic genotypes could result in genotypes with lower iodine values due to the strong positive association between these variables.

Selection of genotypes with higher levels of unsaturation could result in an increase in the amounts of palmitic acid and in a decrease in the arachidic and eicosenoic acids contents. 
SUMMARY AND CONCLUSIONS

A hundred genotypes from the Peanut Breeding Project of the University of Florida were chemically analyzed for oil content, fatty acid composition and iodine value during a ten-year period. Genotypes involved in this study included early, medium and late maturing lines, as well as Virginia, Runner, Spanish and Valencia market types.

The results show that peanut oil is comprised primarily of oleic, linoleic and palmitic acids, with the first two accounting for about 808 of the total.

Means of the hundred genotypes over the years under study show an impressive variation in fatty acid composition, iodine value and oil percentage. Oil composition among the genotypes varied as follows: palmitic 6.90 to 17.508 ; stearic 1.55 to 5.008 ; oleic 40.60 to 73.508 ; linoleic 8.60 to $39.15 \%$; arachidic 0.10 to 2.008 ; eicosenoic 0.20 to 2.508 ; behenic 0.40 to 5.108 ; and lignoceric traces to 3.808 . Iodine value varied from 75 to 105, while oil percentage ranged from 46.2 to $53.4 \%$. The magnitude of this diversity should permit, through selection and hybridization, the development of new varieties with improved chemical qualities. 
Based on dietary and industrial qualities, the best group of genotype means, relative to oil composition, included members of all the three maturity groups (early, medium and late), as well as of the four market types (Virginia, Runner, Spanish and Valencia).

The subdivision of the data by maturity and market type showed that, as a group, early maturity genotypes had larger percentages of palmitic, stearic, eicosenoic an behenic acids and oil content compared with genotypes in the medium and late maturity groups; whereas late maturing genotypes had larger percentages of oleic acid and less linoleic acid than the two other groups. However, relatively high levels of genetic variability for oil composition could be found within each group. The same is true when comparing the different market types. Although Spanish and Valencia types presented higher amounts of palmitic, stearic and behenic acids compared with Virginia and Runner types, a rather large range of these components was found in each group. It is difficult to assign specific group relationships among the genotypes involved in this study based only on the chemical characteristics observed. The large variation in oil composition found within each group indicates that it should be possible to select varieties that best suit industrial or dietary qualities in each maturity group and/or market type. 
Subdivided and combined data generally showed a significant year effect. Eicosenoic, a minor fatty acid, seems to be particularly affected by climatic variations.

The negative correlation coefficients found for iodine value and temperature appear to indicate that as air and soil temperatures increased the iodine number of the genotypes showed lower values. Oil percentage also showed negative correlations with air and soil temperatures. The negative associations found between oil percentage and temperature suggest that higher temperatures during pod and seed formation would lower the oil content.

As a rule, no significant correlations among oleic acid, linoleic acid and climatic parameters were found. Minor fatty acids seem to be affected by moisture conditions. Significant negative associations were found involving minor fatty acids and cumulative rainfall. No significant correlations were found between iodine value or oil percentage and cumulative rainfall.

The significant iodine value association with maximum air and soil temperatures is of considerable importance, and might help explain the poorer industrial quality of oils from cooler locations. Based on this association it might be inferred that earlier or delayed plantings could be used to alter the chemical composition of peanut genotypes within a given location.

Correlation coefficients among oil components suggest that selection for lower levels of linoleic acid, to improve 
peanut shelf-life, could result in a decrease in the amount of palmitic acid and an increase in the oleic acid percentage. A corresponding increase in arachidic and eicosenoic acid might also occur due to the negative association between linoleic acid and these variables. 
Agronomy Department. 1966-1978. Climatological data for Gainesville, Florida and B.R.U. University of Florida. IFAS. Gainesville, F1.

Ahuja, K.L., K.S. Sekhon and I.S. Bhatia. 1971. Regional differences in fatty acid composition of peanut. Oleagineux 26:693-694.

Appelquist, L.A. 1975. Recent Advance in the Chemistry and Biochemistry of Plant Lipids. T. Gailliard and E.I. Mercer, eds. Academic Press, New York. 263 pages.

A.O.A.C. 1970. Official methods of analysis of the Association of official Analytical Chemists. 11th ed., W. Howitz, ed. Assoc. Off. Anal. Chem., Washington, D.C. Cd. $1-25$.

Bailey, W.K., and J.E. Bear. 1973. Components of earliness of maturity in peanuts, Arachis hypogaea L. J. Am. Peanut Res. and Educ. Assoc. 5:32-39.

Barker, C., and T.P. Hilditch. 1950. The influence of environment upon the composition of sunflower seed oils. I. Individual varieties grown in different parts of Africa. J. Sci. Food Agr. 1:118-121.

Barr, A.J., J.H. Goodnight, J.P. Sall, W.H. Blair, and D.M. Chilko. 1979. SAS User's Guide, SAS Institute Inc., Cary, NC 27511. pp. 237-263.

Bernsohn, J., and L.M. Stephanides. 1967. Aetiology of multiple sclerosis. Nature 215:821-823.

Beuchat, L.R., D.H. Smith, and C.T. Young. 1974. Effect of foliar fungicides on aflotoxin, oil and protein content and maturing rate of peanut kernels. J. Sci. Food Agr. $25: 477-482$.

Brown, D.F., C.M. Cater, and K.F. Mattil. 1974. Effects of extraction solvents, cold pressing, and period of storage upon oven stability of peanut oil. J. Am. Oil Chem. Soc. 51:502-506. 
Burr, G.O., and M.M. Burr. 1929. A new deficiency disease produced by rigid exclusion of fat from the diet. $\mathrm{J}$. Biol. Chem. 82:345-367.

Cecil, S.R. 1975. Storage stability of peanut butter from ten peanut genotypes. Proc. Am. Peanut Res. and Educ. Assoc. $7: 36-43$.

Cherry, J.P. 1977. Potential sources of peanut seed protein and oil in the genus Arachis. J. Agr. Food Chem. 25:186-193.

Chopra, A.K., and J.S. Kanwar. 1966. Effects of sulphur fertilization on the chemical composition and nutrient uptake by legumes. J. Indian Soc. Soil Sci. 14:69-76.

Cobb, W.Y., and B.R. Johnson. 1973. Physicochemical properties of peanuts. Chap. 6, 209-257. In:

Peanuts--Culture and Uses. Am. Peanut Res. and Educ. Assoc. Inc., Stillwater, Okla.

Craig, B.M., and N.L. Murty. 1959. Quantitative fatty acid analyses of vegetable oils by gas liquid

chromatography. J. Am. Oil Chem. Soc. 36:549-552.

Crawford, R.V., and T.P. Hilditch. 1950. The component fatty acid and glycerides of groundnut oils. J. Sci. Food Agr. 1:372-379.

Eheart, J.F., R.W. Young, and A.H. Allison. 1955. Variety, type, year and location effects on the chemical composition of peanuts. Food Res. 20:497-505.

Exler, J., R.M. Avena, and J.L. Weihrauch. 1977. XI. Leguminous seeds. Comprehensive evaluation of fatty acids in foods. J. Am. Dietet. Assoc. 69:412-415.

Fedeli, E., G. Favini, F. Camurati, and G. Jacinis. 1968. Regional differences of lipid composition in morphologically distinct fatty tissues. III. Peanut seeds. J. Am. Oil Chem. Soc. 45:676-679.

Fisher, G.S., W.G. Bickford, and F.G. Dollear. 1947. Correlation of stability with fatty acid composition of hydrogenated vegetable oil. J. Am. Oil Chem. Soc. $24: 379-382$.

Fore, S.P., N.J. Morris, C.H. Mack, A.F. Freeman, and W.G. Bickford. 1953. Factors affecting the stability of crude oils of 16 varieties of peanuts. J. Am. Oil Chem. Soc. 30:298-301.

Freeman, A.F., N.J. Morris, and R.K. Willich. 1954. Peanut butter. U.S. Dept. Agr. AIC-370. 22 pages. 
French, R.B. 1962. Analysis of peacan, peanut and other oils by gas liquid chromatography and ultra violet spectroscopy. J. Am. Oil Chem. Soc. 39:176-178.

Fristom, G.A., B.C. Steward, J.L. Weihrauch, and L.P. Posati. 1975. Comprehensive evaluation of fatty acids in foods. IV. Nuts, peanuts, and soups. J. Am. Dietet. Assoc. 67:351-355.

Grande, F., J.T. Anderson, and A. Keys. 1970. Comparison of effect of palmitic and stearic acids in the diet on serum cholesterol in man. Am. J. Clin. Nut. 23 : $1184-1193$.

Gupta, S.S. 1956. On a decision rule for a problem in ranking means. Institute of Statistics, Mimeograph series no. 150, University of North Carolina, Chapel Hill. 104 pages.

Harris, P., and A.T. James. 1969. The effect of low temperature on fatty acid biosynthesis in plants. Biochem. J. 112:325-330.

Hartzook, A. 1969. The effect of maturity upon fatty acid composition in the oil of groundnut (Arachis hypogaea L.) seeds. Curr. Sci. 38:176.

Helwig, J.T. (ed.) 1977. SAS supplemental library user's guide. SAS Institute, Inc., Raleigh, N.C. 171 pages.

Higgins, H.B., K.T. Holley, T.A. Pickett, and C.D. Wheeler. 1941. I. Peanut breeding and characteristics of some new strains. Ga. Agr. Exp. Sta. Bull no. 213. 3 pages.

Hilditch, T.P. 1956. The Chemical Constitution of Natural Fats. 3rd ed. rev. Wiley, New York. 664 pages.

Hilditch, T.P., and P.N. Williams. 1964. Chemical Composition of Natural Fats. 4 th ed. Chapman and Hall, Ltd., London. 207 pages.

Hokes, J.C. 1977. Factors affecting the oxidative stability of oils from various peanut cultivars. M.s. Thesis, University of Georgia, Athens, Ga. 127 pages.

Holaday, C.E., and J.L. Pearson. 1974. Effects of genotype and production area on the fatty acid composition, total oil and total protein in peanuts. J. Food Sci. 39: 1206-1209.

Holley, K.T., and R.O. Hammons. 1968. Strain and seasonal effects on peanut characteristics. Univ. Ga. Col. Agr. Exp. Sta., Res. Bul. 32. 27 pages. 
Holman, R.T. 1968. Essential fatty acid defficiency. $p$. 279-348. In: R.T. Holman (ed.) Progress in the Chemistry of Fats and Other Lipids. Vol. IX., part 2. Pergamon Press, New York.

Hovis, A.R., C.T. Young, and C.W. Kuhn. 1979. Effect of two strains of peanut mottle virus on fatty acids, aminoacids and protein of six peanut lines. Peanut Sci. 6:88-92.

Informacoes Agricolas. 1981. Instituto de Economia Agricola, Vol. 9, Sao Paulo, Brasil. 87 pages.

Iverson, J.L., D. Firestone, and W. Horwitz. 1963. Fatty acid composition of oil from roasted and unroasted peanuts by gas liquid chromatography. J. Ass. Off. Agric. Chem. 46:718-725.

Jamieson, G.S., W.S. Baughman, and D.H. Brauns. 1921. The chemical composition of peanut oil. J. Am. Chem. Soc. $43: 1272-1381$.

Khan, A., D.A. Emery, and J.A. Singleton. 1974. Refractive index as a basis for assessing fatty acid composition in segregating populations derived from infraspecific crosses of cultivated peanuts. Crop Sci. 14:464-468.

Khan, R.Y.A., T. Laksminarayana, G. Azeemoddin, D.A. Ramayya, and S.D.T. Rao. 1979. Shelf-life of sunflower oil and groundnut oil. J. Food Sci. and Tech. 16:90-92.

Kirschenbauer, H.G. 1960. Fats and Oils. An Outline of their Chemistry and Technology. 2nd ed. Chapman and Hall, Ltd., London. 240 pages.

Koman, V., and J. Kotuc. 1976. Computer determination of chemical and physical values of fats and oils from GLC fatty acid composition, acid value, and titer. J. Am. Oil Chem. Soc. 52:563-566.

Kritchevsky, D., S.A. Tepper, D. Vesselinovitch, and R.W. Wissler. 1970. Influence of peanut oil on experimental atherosclerosis: further studies. Circulation 42: Suppl. III. 18 pages.

Laurence, R.C.N., R.W. Gibbons, and C.T. Young. 1976. Changes in yield, protein, oil and maturity of groundnut cultivars with the application of sulphur fertilizers and fungicides. J. Agric. Sci., Camb. 86 : 245-250. 
Mason, M.E., J.A. Newell, B.R. Johnson, P.E. Koehler, and G.R. Waller. 1969. Nonvolatile flavor components of peanuts. J. Agr. Food Chem. 17:728-732.

Mozingo, R.W., R.D. Ashburn and C.T. Young. 1982. Peanut variety and quality evaluation results. 1981. II. Quality data. Tidewater Res. and Contin. Educ. Center. Inform. Series no. 71. 52 pages.

National Diet Heart Study. 1967. Circulation 37(3), Suppl. no. 1. Am. Heart Assoc., New York. 428 pages.

Newell, J.A., M.E. Mason, and R.S. Matlock. 1967. Precursors of typical and atypical roasted peanut flavor. J. Agr. Food Chem. 15:767-772.

Norden, A.J. and D.H. Block. 1968. Variety blends: consideration in peanut oil improvement and production. Oleagineux 23:583-585.

Packard Operation Manual. 1967. Theoretical discussion of gas chromatography, Section VI, p. 1-2., no. $2022 / 1$. Packard Instrument Company, Inc., Chicago.

Pancholy, S.K., A.S. Deshpande, and S. Krall. 1978. Aminoacids, oil and protein content of some selected peanut cultivars. Am. Peanut Res. and Educ. Assoc. Proc. 10:30-37.

Pancholy, S.K., R. Sepulvedo, and S.M.M. Basha. 1980. Oil, total protein, and amino acid composition of 77 peanut lines and cultivars. Am. Peanut Res. and Educ. Assoc. Proc. 12:13-22.

Pattee, H.E., and A.E. Purcell. 1967. Carotenoid pigments of peanut oil. J. Am. Oil Chem. Soc. 44:328-330.

Pattee, H.E., and S.L. Sessoms. 1967. Relationship between Aspergillus flavus growth, fat acidity and aflotoxin content in peanuts. J. Am. Oil Chem. Soc. 44:61-63.

Pattee, H.E., E.G. Johns, J.A. Singleton, and T.H. Sanders. 1974. Composition changes in peanut fruit parts during maturation. Peanut Sci. 1:57-62.

Pattee, H.E., A.E. Purcell, and E.B. Johns. 1969. Changes in carotenoid and oil content during maturation of peanut seeds. J. Am. Oil Chem. Soc. 46:629-631.

Pickett, T.A., and K.T. Holley. 1951. Susceptibility of types of peanuts to rancidity development. J. Am. Oil Chem. Soc. 28:478-479. 
Pickett, T.A., and K.T. Holley. 1956. Seasonal variation in the character of lipids in pure lines of spanish peanuts. J. Am. Oil Chem. Soc. 33:650-652.

Ratner, E.I., R. Lobel, H. Feldhay, and A. Hartzook. 1979. Some characteristics of symbiotic nitrogen fixation, yield, protein and oil accumulation in irrigated peanuts (Arachis hypogaea L.). Plant and Soil $51: 373-38 \overline{6}$.

Robinson, T. 1980. The Organic Constituents of Higher Plants. 4th ed. Cordus Press, North Amherst, Mass. 352 pages.

Sanders, T.H. 1980a. Effects of variety and maturity on lipid class composition of peanut oil. J. Am. Oil Chem. Soc. 57:8-11.

Sanders, T.H. 1980b. Fatty acid composition of lipid classes in oils from peanuts differing in variety and maturity. J. Am. Oil Chem. Soc. 57:12-15.

Sekhon, K.S., S.K. Gupta, K.L. Ahuja, and S.V. Jaswal. 1980. Variability in fatty acid composition in semispreading peanut types. Oleagineux 35:409-411.

St. Angelo, A.J., and R.L. Ory. 1973. Investigations of causes and prevention of fatty acid peroxidation in peanut butter. J. Am. Peanut Res. and Educ. Assoc. $5: 128-133$.

St. Angelo, A. J., and R.L. Ory. 1974. Development of lipid peroxidation during long-term storage of raw and roasted peanuts. Am. Peanut Res. and Educ. Assoc. Proc. 6:56-57.

Stumpf, P.K., and C. Bradbeer. 1959. Fat metabolism in higher plants. Ann. Rev. Plant Physiol. 10:197-222.

Sturkie, D.G., and G.A. Buchanan. 1973. Cultural practices. Chap. 9, pp. 299-313. In: Peanuts-Culture and Uses. Am. Peanut Res. and Educ. Assoc., Inc., Stillwater, Okla.

Tai, Yai-Po. 1972. Inheritance of oleic to linoleic fatty acid ratio in peanuts (Arachis hypogaea L.). Ph.D. dissertation. Okla. State Univ. Univ. Microfilms. Ann Arbor, Mich. (Diss. Abstr. 33:5698-BO.)

U. S. Dept. of Agric. Agricultural Statistics. 1979. Washington, D.C. 83 pages.

Vergroesen, A.J. 1977. Physiological effects of dietary linoleic acid. Nutrition Reviews 35:1-5. 
Ward, H.S., Jr., and U.L. Diener. 1961. Biochemical changes in shelled peanut caused by storage fungi. I. Effects of Aspergillus tamarii, four species of A. glaucus, and Penicillium citrinum. Phytopathology $\overline{5} 1: 2 \frac{1}{44-250}$.

Woodroof, J.G. 1973. Peanuts: Production, Processing, Products. 2nd. ed. AVI Publishing Co., Westport, Conn. 330 pages.

Worthington, R.E. 1968. Developmental changes in peanut lipid fatty acids. Proc. Fifth Nat. Peanut Res. Conf. p. 87-98.

Worthington, R.E. 1977. The linolenic acid content of peanut oil. J. Am. Oil Chem. Soc. 54:167-169.

Worthington, R.E., and R.O. Hammons. 1971. Genotypic variation in fatty acid composition and stability of Arachis hypogaea L. oil. Oleagineux 26:695-700.

Worthington, R.E., and R.O. Hammons. 1977. Variability in fatty acid composition among Arachis genotypes: a potential source of product improvement. J. Am. Oil. Chem. Soc. 54:105-108.

Worthington, R.E., R.O. Hammons, and J.R. Allison. 1972. Varietal differences and seasonal effects on fatty acid composition and stability of oil from 82 peanut genotypes. J. Agr. Food Chem. 20:727-730.

Worthington, R.E., and K.T. Holley. 1967. Linolenic acid content of peanut oil. J. Am. Oil Chem. Soc. $44: 515-516$.

Worthington, R.E., and D.H. Smith. 1973. Effects of several foliar fungicides on the fatty acid composition and stability of peanut oil. J. Agr. Food Chem. 21 : $619-621$.

Worthington, R.E., and D.H. Smith. 1974. Modification of peanut oil fatty acid composition by foliar applications of $2^{\prime}, 2^{\prime}$-dimethyl succinohydrazide (Kylar). J. Agr. Food Chem. 22:507-508.

Young, C.T., S.R. Cecil, and D.H. Smith. 1972a. Effect of leafspot control on the arginine maturity index of peanuts. J. Am. Peanut Res. Educ. Assoc. 4:52-57.

Young, C.T., and K.T. Holley. 1965. Comparison of peanut varieties in storage and roasting. Univ. Ga. Col. Agr. Exp. Sta. Tech. Bul. N.S. 41 . 30 pages. 
Young, C.T., M.E. Mason, R.S. Matlock, and G.R. Waller. 1972b. Effect of maturity on the fatty acid composition and stability of eight varieties of peanut grown at Perkins, Oklahoma in 1968. J. Am. Oil Chem. Soc. 49:314-317.

Young, C.T., R.E. Worthington, R.O. Hammons, R.S. Matlock, G.R. Waller, and R.D. Morrison. 1974. Fatty acid composition of Spanish peanut oils as influenced by planting location, soil moisture conditions, variety and season. J. Am. Oil Chem. Soc. 51:312-315. 


\section{BIOGRAPHICAL SKETCH}

Marilene L.A. Bovi was born to Miguel and Olivia Leao on May 22, 1948. In her precollege years, she lived in sao Paulo (SP), Brasil.

In 1968, she enrolled in the Escola Superior de Agricultura "Luiz de Queiroz" (Piracicaba, SP, Brasil), from which she received her B.S. degree as Engenheiro Agronomo in 1972 .

After graduation, Mrs. Bovi joined the Instituto Agronomico de Campinas (SP, Brasil) to work as a plant breeder on perennial tropical plants research. In the fall of 1978, she enrolled in the Graduate School of the University of Florida, in the Agronomy Department, and received her Master of Science degree in August of 1980. Since then she has been working toward her Doctor of Philosophy degree. 
I certify that I have read this study and that in my opinion it conforms to acceptable standards of scholarly presentation and is fully adequate, in scope and quality, as a dissertation for the degree of Doctor of Philosophy.

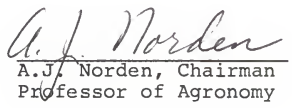

I certify that I have read this study and that in my opinion it conforms to acceptable standards of scholarly presentation and is fully adequate, in scope and quality, as a dissertation for the degree of Doctor of Philosophy.

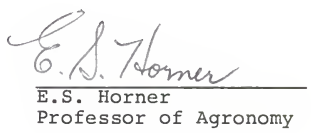

I certify that I have read this study and that in my opinion it conforms to acceptable standards of scholarly presentation and is fully adequate, in scope and quality, as a dissertation for the degree of Doctor of Philosophy.

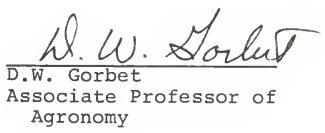


I certify that I have read this study and that in my opinion it conforms to acceptable standards of scholarly presentation and is fully adequate, in scope and quality, as a dissertation for the degree of Doctor of Philosophy.

$$
\begin{aligned}
& \text { fly. Martin } \\
& \text { F.G. Martin } \\
& \text { Associate Professor of } \\
& \text { Statistics }
\end{aligned}
$$

I certify that I have read this study and that in my opinion it conforms to acceptable standards of scholarly presentation and is fully adequate, in scope and quality, as a dissertation for the degree of Doctor of Philosophy.

$$
\begin{aligned}
& \frac{\text { fm gylene }}{\text { P.M. Lyrene }} \\
& \text { Associate professor of } \\
& \text { Horticultural Science }
\end{aligned}
$$

This dissertation was submitted to the Graduate Faculty of the College of Agriculture and to the Graduate Council, and was accepted as partial fulfillment of the requirements for the degree of Doctor of Philosophy.

December 1982

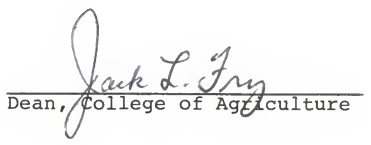

$\overline{\text { Dean for Graduate Studies and }}$ Research 